\title{
Sea ice and large-scale atmospheric variability around East Antarctica
}

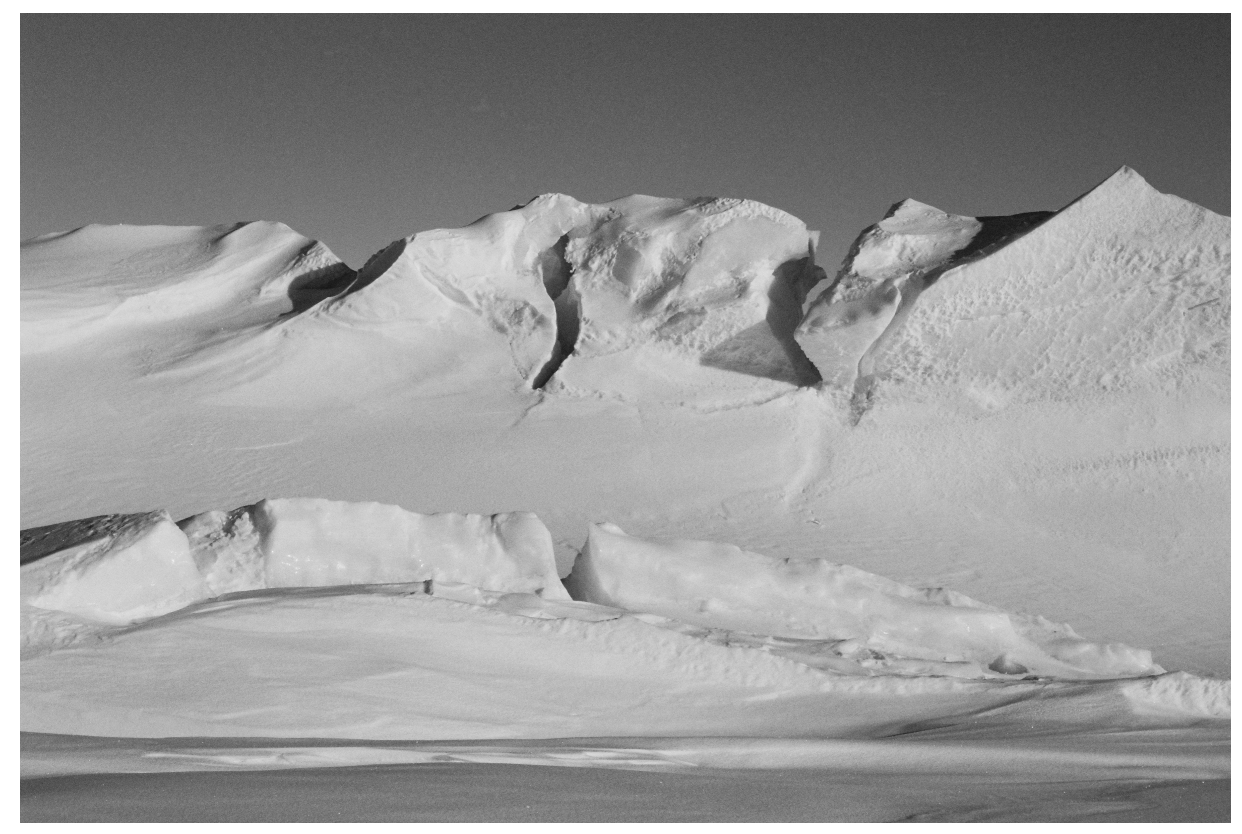

\section{Florence Isaacs}

School of Geography, Environment, and Earth Science

Victoria University of Wellington

This dissertation is submitted for the degree of

Doctor of Philosophy 

For my Grandpa, David Cargill Isaacs 



\section{Acknowledgements}

This thesis would not have been possible without the endless support and encouragement of my supervisors - James Renwick, Ruzica Dadic, and Andrew Mackintosh. I feel very privileged to have had such generous and genuinely invested supervisors guiding me every step of the way.

This research was made possible by funding from Victoria University of Wellington and Antarctica New Zealand, for which I am extremely grateful. Support was also provided by the Antarctic Research Centre Endowed Development Fund, which funded my attendance at the Karthaus Summer School on Ice and Climate, Italy, and enabled me to present my research at the CLIVASH2K workshop in Cambridge, UK, and at the AGU Fall Meeting in San Francisco, USA. I would also like to thank Antarctica New Zealand for the incomparable experience of a field trip to Antarctica, the memories of which kept me going through many late nights writing this thesis. Thank you to the K066 field team (Natalie, Greg, Gemma, Brett, Pete and Walter) for making me feel so welcome and at home on the ice.

Thank you to Marjo, Matt and Hannah for being the best office buddies and friends to do this alongside of. Thanks to all my lovely friends and family for putting up with the mania that has been this past three and a half years. Special thanks to my fellow Helios-dwellers for your constant support, for being the best lockdown companions, and for making the prospect of writing a thesis during a global pandemic a lot more bearable. Mum and Dad-thanks for being my biggest cheerleaders, for giving me my love of science, and for shaping me into the adult and scientist that I am.

Thank you most of all to Jelly, for keeping me grounded, fed, and sane while I wrote this thesis, and for being the motivation to move back across the world and do this $\mathrm{PhD}$ in the first place. LBs bb, none of this would have been possible without you.

Finally, I would like to acknowledge all the women and queer scientists who came before me, for making it possible for me to be myself while doing what I love. I hope that the science community continues to expand and embrace those who don't fit the status quo. 



\begin{abstract}
Antarctica's sea ice cover is an important component in the global climate system. The variability and recent trends of sea ice concentration are, however, not accurately reproduced by models. Evaluating model performance is hampered because the processes that determine sea ice distribution are not yet well understood, particularly in the East Antarctic region. Here I explore the relationships between recent climate variability and sea ice around East Antarctica, the spatial variability in these relationships, and the impacts that these may have on other aspects of the climate and cryosphere. To achieve this, I analysed satellite-derived HadlSST sea ice concentration (SIC) alongside ERA5 atmospheric reanalysis data for the period between 1979-2018.

I found that variability in sea ice coverage around East Antarctica was affected by El Niño Southern Oscillation (ENSO), the Indian Ocean Dipole (IOD), the Southern Annular Mode (SAM), and Zonal Wave 3 (ZW3). Additionally, I found that the influence of each of these modes varied spatially and temporally, and that sea ice variability affected how regional scale climate responded to changes in large-scale circulation. Summer and autumn SIC around Dronning Maud Land between $10^{\circ} \mathrm{E}$ and $70^{\circ} \mathrm{E}$ exhibited a statistically significant negative correlation with the Niño 3.4 index. Analysis of ERA5 data suggests that a southwardpropagating atmospheric wave train triggered by SST anomalies in the tropical Pacific extends into Dronning Maud Land and alters sea ice concentration by encouraging meridional airflow. Shifts in meridional flow in Dronning Maud Land affected sea ice thermodynamically, by altering local heat transport and in turn altering sea ice formation and melt.

Sea ice around the Western Pacific sector (WPS) of East Antarctica showed a significant association with variability in the IOD and the SAM. The IOD was correlated with SIC in all seasons but summer. The IOD-SIC relationship is likely driven by an IOD-associated atmospheric wave-train which propagates polewards from the tropical Indian Ocean to Wilkes Land, altering regional circulation and in turn affecting SIC through changes to local climate and sea ice transport. The correlation between WPS SIC and the SAM shifts from positive in
\end{abstract}


summer and autumn to negative in winter and spring, and is likely due to the influence of the SAM on katabatic winds and coastal polynyas, which in turn affect SIC.

A significant correlation was observed between SIC variability around East Antarctica and precipitation variability across the continent and the near-coastal Southern Ocean. Further analysis showed that SIC affected how continental precipitation responded to large-scale atmospheric circulation, including modes such as ZW3 and the SAM. Specifically, increased southward moisture flux was only associated with increased precipitation in the inland coastal regions of the continent when SIC was anomalously low. These findings suggest that any future decrease in sea ice may result in greater coupling of climate variability with continental precipitation. 


\section{Table of contents}

List of figures $\quad$ xiii

$\begin{array}{ll}\text { List of Abbreviations } & \text { xv }\end{array}$

1 Introduction 1

1.1 Antarctic sea ice ...................... 2

1.1.1 East Antarctic sea ice environment . . . . . . . . . . . 2

1.1.2 Sea ice impact on climate .............. 4

1.1.3 Climatic drivers of sea ice distribution . . . . . . . . . . . 4

1.2 Recent sea ice trends and variability . . . . . . . . . . . 5

1.3 Large-scale drivers of recent sea ice variability . . . . . . . . . . . . 6

1.3.1 Southern Annular Mode . . . . . . . . . . . . . 7

1.3.2 El Niño-Southern Oscillation . . . . . . . . . . . . 8

1.3.3 Zonal Wave $3 \ldots \ldots \ldots . \ldots \ldots 11$

1.3.4 Indian Ocean Dipole . . . . . . . . . . . . . . . 11

1.4 Links between Antarctic sea ice, climate, and ice sheets . . . . . . . . . . . 12

1.5 Aims and organisation of thesis . . . . . . . . . . . . . . . 14

2 Data and Methods 17

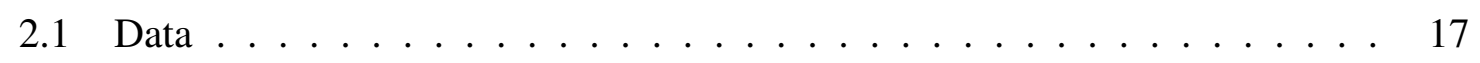

2.1 .1 Sea ice concentration . . . . . . . . . . . . 17 
2.1 .2 Sea ice motion . . . . . . . . . . . . . . 18

2.1.3 Atmospheric reanalysis data . . . . . . . . . . . . . 19

2.1.4 Climate mode indices . . . . . . . . . . . . . . . . . . . 19

2.2 Analysis techniques . . . . . . . . . . . . . . . . 20

2.2.1 Linear correlation . . . . . . . . . . . . . . . . . 20

2.2.2 Composite analysis . . . . . . . . . . . . . . 21

3 SAM and IOD influence sea ice variability around Western Pacific sector of $\begin{array}{ll}\text { East Antarctica } & 23\end{array}$

3.1 Introduction . . . . . . . . . . . . . . . . . . . 24

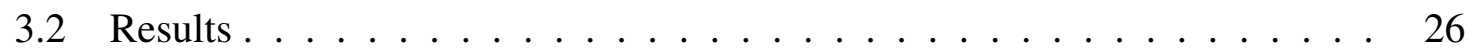

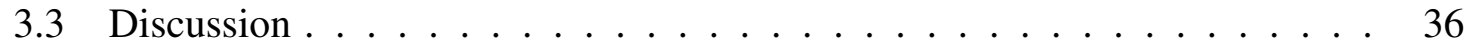

3.3.1 IOD influence on SIC . . . . . . . . . . . . . . . . 37

3.3 .2 SAM influence on SIC . . . . . . . . . . . . . . . 38

3.3.3 SAM/IOD interaction . . . . . . . . . . . . . . . 41

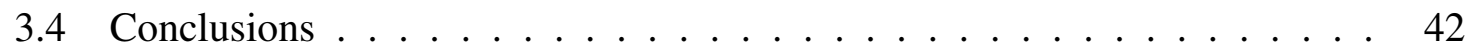

4 ENSO modulates summer and autumn sea ice variability around Dronning Maud Land $\quad 45$

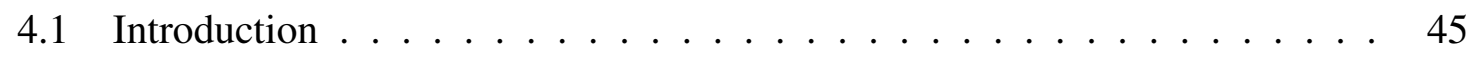

4.2 Results . . . . . . . . . . . . . . . . . 47

4.2.1 Sea ice correlation with Niño 3.4 index . . . . . . . . . . . 47

4.2.2 Sea ice correlation and composites with atmospheric reanalysis . . 48

4.2.3 Niño 3.4 correlation with atmospheric reanalysis $\ldots . . . . . .56$

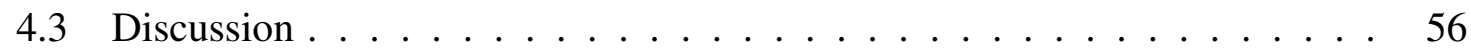

4.4 Conclusions . . . . . . . . . . . . . . . . . . . . . 64

5 Sea ice modulates precipitation response to large-scale climate variability across East Antarctica 


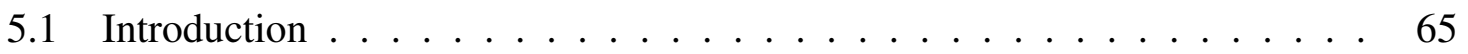

5.2 Results . . . . . . . . . . . . . . . . . . . 68

$5.2 .1 \quad$ Localised correlations . . . . . . . . . . . . . . . 68

5.2.2 Larger scale correlation . . . . . . . . . . . . . . . . 72

5.2 .3 Composite analysis . . . . . . . . . . . . . . 73

5.3 Discussion . . . . . . . . . . . . . . . . 75

5.4 Conclusions . . . . . . . . . . . . . . . . . 78

6 Synthesis and conclusions $\quad 81$

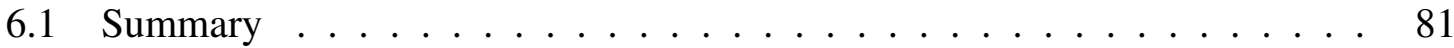

6.1.1 SAM and IOD influence sea ice variability around Western Pacific sector of East Antarctica . . . . . . . . . . . . . . . . . . . 81

6.1.2 ENSO modulates summer and autumn SIC around Dronning Maud Land . . . . . . . . . . . . . . . . . . 83

6.1.3 SIC modulates precipitation response to climate variability . . . . 83

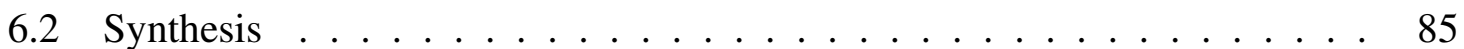

6.3 Contributions and Future Directions . . . . . . . . . . . . . . 86

$\begin{array}{lr}\text { References } & 89\end{array}$ 



\section{List of figures}

1.1 Average seasonal sea ice concentration between 1979 and $2018 \ldots \ldots$

1.2 Sea ice concentration trends and variability around Antarctica for 1979-2018 6

1.3 Schematic of the Southern Annular Mode . . . . . . . . . . . . . . 8

1.4 Schematic of El Niño-Southern Oscillation _ . . . . . . . . . . . . 10

1.5 Schematic of Zonal Wave $3 \ldots \ldots$. . . . . . . . . . . . . 12

1.6 Schematic of the Indian Ocean Dipole . . . . . . . . . . . . . . . . 13

1.7 Line plot of correlation between SIC around East Antarctica and SAM, IOD, ENSO, and ZW3 . . . . . . . . . . . . . . . . . . . . . . . . . 15

2.1 Map of East Antarctic study area . . . . . . . . . . . . . . . . . . 22

3.1 Map of Western Pacific sector and associated place names _ . . . . . . . 24

3.2 Line plot of correlation between SIC around East Antarctica with SAM, IOD, ENSO, and ZW3 . . . . . . . . . . . . . . . . . . . . . . . . . . . . . . 27

3.3 Average seasonal SIC around the Western Pacific sector . . . . . . . . . . . 28

3.4 Map of correlation between IOD and SIC around Antarctica . . . . . . . 29

3.5 Map of correlation between SIC in IOD-correlated sectors, and atmospheric reanalysis . . . . . . . . . . . . . . . . . 31

3.6 Map of correlation between IOD, atmospheric reanalysis and sea ice motion 32

3.7 Map of correlation between the SAM and SIC around Antarctica . . . . . . 33

3.8 Map of correlation between the SAM, atmospheric reanalysis and sea ice motion . . . . . . . . . . . . . . . . . . . . . 34 
3.9 Scatterplots of the IOD index against the SAM index $\ldots \ldots \ldots$. . . . . . 35

3.10 Composite sea ice anomalies during different IOD and SAM phase combina-

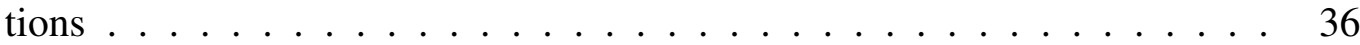

4.1 Map of the Dronning Maud Land study area . . . . . . . . . . . . . . . . . 47

4.2 Line plot of correlation between SIC and ENSO . . . . . . . . . . . . 48

4.3 Dronning Maud Land SIC time series and seasonal averages _ . . . . . . 50

4.4 Map of correlation between Dronning Maud Land SIC, air temperature, and geopotential height . . . . . . . . . . . . . . . . . . 51

4.5 Map of correlation between Dronning Maud Land SIC and SST _ . . . . 52

4.6 Composites of SST and geopotential height for Dronning Maud Land SIC . 53

4.7 Composites of air temperature and geopotential height for Dronning Maud Land SIC . . . . . . . . . . . . . . . . . . . . . . . . . 54

4.8 Composites of northward heat flux around Dronning Maud Land . . . . . . 55

4.9 Composites of sea ice motion around Dronning Maud Land . . . . . . . . . 57

4.10 Correlation between ENSO, air temperature, and sea ice motion around Dronning Maud Land . . . . . . . . . . . . . . . . . . . . 58

4.11 Correlation between ENSO, SST, and geopotential height around Dronning Maud Land . . . . . . . . . . . . . . . . . . . . . . . . . . . . . 59

4.12 Correlation between ENSO, wind, and northward heat flux around Dronning Maud Land . . . . . . . . . . . . . . . . . . . . . . . . . . . 60

5.1 Map of correlation between SIC and precipitation around Antarctica . . . . 69

5.2 Map of correlation between SIC and northward moisture flux around Antarctica 70

5.3 Map of correlation between SIC and evaporation around Antarctica . . . . . 71

5.4 Map of correlation between SIC and geopotential height around Antarctica 72

5.5 Precipitation anomalies for southward moisture flux over the sea ice zone . 74 


\title{
List of Abbreviations
}

\section{Roman Symbols}

\author{
ASL Amundsen Sea Low \\ CDW Circumpolar Deep Water \\ DJF December-January-February \\ DMI Dipole Mode Index \\ DML Dronning Maud Land \\ EAIS East Antarctic Ice Sheet \\ ECMWF European Centre for Medium-Range Weather Forecasts \\ ENSO El Niño Southern Oscillation \\ H500 500hPa geopotential height \\ IOD Indian Ocean Dipole \\ JAS July-August-September \\ JJA June-July-August \\ MAM March-April-May \\ NOAA National Oceanic and Atmospheric Administration \\ NthHF vertically integrated northward heat flux \\ NthMF vertically integrated northward water vapor flux \\ PSA Pacific South American Pattern
}


xvi | List of Abbreviations

SAM Southern Annular Mode

SIA sea ice area

SIC sea ice concentration

SIE sea ice extent

SON September-October-November

SST sea surface temperature

T2M 2m air temperature

WAIS West Antarctic Ice Sheet

WPS Western Pacific sector

ZW1 Zonal Wave-1

ZW3 Zonal Wave-3 


\section{Chapter 1}

\section{Introduction}

The polar regions are disproportionately affected by global climate change, and some areas of Antarctica are among the most rapidly warming regions on the planet (e.g. Bromwich et al., 2013; Clem et al., 2020; Steig et al., 2009). However, Antarctica is also one of the least well-studied regions on the globe, its remote nature and harsh climate resulting in sparse and relatively short observational records. This has resulted in large uncertainties in modelled climate projections, and in projections of cryospheric change (IPCC, 2019).

Antarctic sea ice in particular is currently not well constrained in models, and contributes substantial uncertainty to global climate models (IPCC, 2019). This is in part because the processes and mechanisms governing Antarctic sea ice variability are not yet well understood (National Academies of Sciences, Engineering and Medicine and others, 2017). Antarctic sea ice is an important component in the global climate system, modulating atmospheric and oceanic circulation at scales ranging from regional through hemispheric (e.g. Bader et al., 2013; England et al., 2020; Kidston et al., 2011; Marzocchi and Jansen, 2017; Nadeau et al., 2019). Through its control on surface albedo, heat, and moisture fluxes, changes in Antarctic sea ice have far-reaching implications for local climate (e.g. Krinner et al., 2007; Wang et al., 2020), ecosystems (e.g. Michel et al., 2019; Reiss et al., 2017; Trathan et al., 2020), and human access to Antarctica. At a larger scale, changes in Antarctic sea ice have implications for extra-polar climates (e.g. England et al., 2020), and the sensitivity of global climate to atmospheric warming (Caldeira and Cvijanovic, 2014).

Sea ice around East Antarctica has recently been linked to aspects of the surface mass balance of the East Antarctic Ice Sheet (Miles et al., 2016, 2017), an ice sheet with a volume equivalent to $53 \mathrm{~m}$ potential sea level rise (Fretwell et al., 2013). It is therefore crucial that 
we increase our understanding of the drivers of sea ice change, to better inform models, and reduce uncertainty in projected future change.

\subsection{Antarctic sea ice}

Antarctica is at least partially surrounded by sea ice throughout the entire year (Figure 1.1). Between March and September, cold air and sea surface temperatures drive sea ice growth around the continent, reaching an average maximum extent of approximately 19 million $\mathrm{km}^{2}$ in September (Dieckmann and Hellmer, 2010; Parkinson and Cavalieri, 2012), an area larger than the continent itself. In the austral spring (Figure 1.1c), warm temperatures then drive much of the sea ice to melt again, retreating to a minimum extent of approximately 4 million $\mathrm{km}^{2}$ by February (Parkinson and Cavalieri, 2012). At this point, sea ice is restricted to a narrow band around much of the Antarctic coastline, with the exception of more significant extents in the Weddell Sea and Ross Sea regions (Figure 1.1).

\subsubsection{East Antarctic sea ice environment}

The sea ice zone around much of the East Antarctic coastline is relatively narrow at its maximum extent in comparison to other sea ice sectors (Figure 1.1). As with the rest of the Southern Ocean, sea ice here reaches is maximum in September, and its minimum by late February. At its minimum extent in austral summer, the distribution of sea ice around East Antarctica is essentially confined to small hotspots over the continental shelf (Massom et al., 2013). The sector is characterised by strong seasonality, as well as regional variability, making it a highly complex environment (Massom et al., 2013).

In terms of the broader environment, the East Antarctic coastline is situated at lower latitudes to much of the rest of the continental coast, ranging from $66^{\circ} \mathrm{S}$ off Cape Ann, to $70^{\circ} \mathrm{S}$ around Prydz Bay. The coastal zone is made up of steep terrain, which rapidly rises from sea level to the heights of the Antarctic Plateau (4000m) and the East Antarctic Ice Sheet (EAIS), and contains very few ice-free areas. The region is characterised by strong katabatic winds, and the passage of cyclones which bring frequent precipitation as well as changeable air temperature and wind direction (Jones and Simmonds, 1993; Worby et al., 1996). 

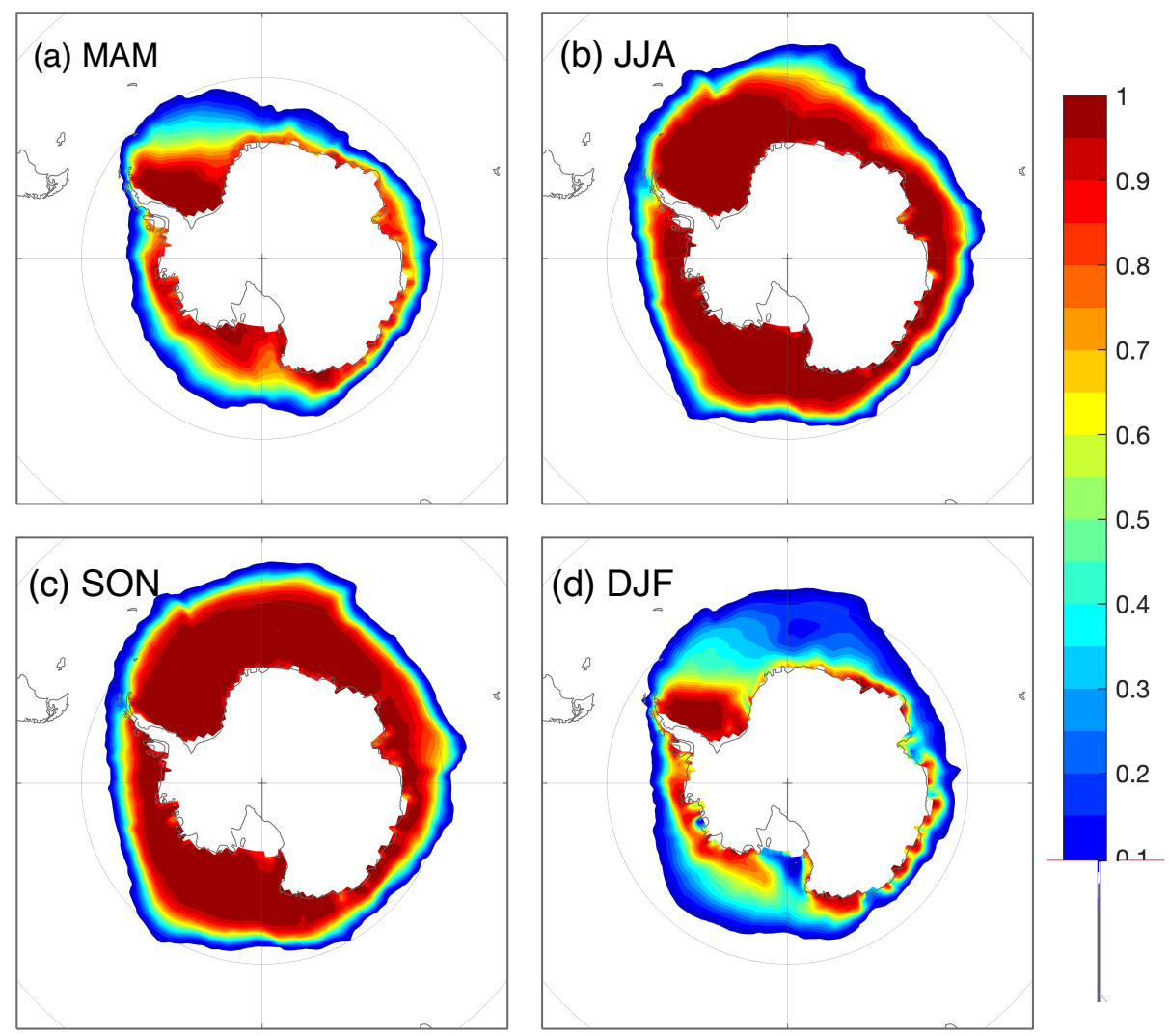

Fig. 1.1 Average seasonal HadISST sea ice concentration around Antarctica over the period between 1979-2018 in March-April-May (MAM) (a), June-July-August (JJA) (b), September-OctoberNovember (SON) (c), and December-January-February (DJF) (d). 


\subsubsection{Sea ice impact on climate}

The annual cycle of change in sea ice coverage around Antarctica has a profound impact on both global climate and global oceans. Sea ice effectively acts as a barrier between the ocean and atmosphere, controlling atmosphere-ocean transfers of heat and moisture (e.g. Maykut, 1986; Rind et al., 1995) and changing surface albedo, thus altering the local radiation budget (e.g. Brandt et al., 2005; Curry et al., 1995). Changes in sea ice distribution can therefore drive changes in air temperature (e.g. Kumar et al., 2010; Screen and Simmonds, 2010; Serreze et al., 2009), atmospheric moisture content (Lenaerts et al., 2016; Noone and Simmonds, 2004), surface winds (Raphael et al., 2011), and atmospheric stability, which in turn drive changes in global circulation (e.g. Bader et al., 2013; England et al., 2020; Kidston et al., 2011; Wang et al., 2020). There is also evidence to suggest that sea ice plays an important role in global oceanic circulation, with the expulsion of brine that occurs with sea ice formation crucial to the formation of Antarctic deep bottom water (Marzocchi and Jansen, 2017; Nadeau et al., 2019).

\subsubsection{Climatic drivers of sea ice distribution}

Sea ice distribution in the Southern Ocean at any given point or time is determined by the processes of sea ice formation, melt, and transport, which are in turn driven by a complex range of dynamic and thermodynamic processes. At a fundamental level, changes in sea ice formation, melt, and transport are induced by changes in SST, air temperature, surface winds and precipitation. SST and air temperature determine the melting and freezing regimes of sea ice, while surface winds drive horizontal sea ice transport and redistribution around the Southern Ocean (Holland and Kwok, 2012; Purich et al., 2016; Wang et al., 2019). Meridional surface winds also control changes in SST and air temperature, as they alter atmospheric and oceanic heat fluxes to and from the sea ice zone, either advecting cold, dry air from the continent, or warm, moist air from the lower latitudes (Holland and Kwok, 2012; Stammerjohn et al., 2008). Precipitation over sea ice alters sea ice albedo, which affects air temperatures through changes to surface radiation and heat fluxes (Eicken et al., 1995; Massom et al., 2001). The addition of new snow on the sea ice can also alter the thermal conductivity at the surface, as well as driving sea ice thickening by depressing the existing sea ice below sea level, enabling surface flooding and refreezing (Lytle and Ackley, 2001; Powell et al., 2005; Sturm and Massom, 2009). 


\subsection{Recent sea ice trends and variability}

The difficult access to Antarctica and the Southern Ocean has resulted in minimal direct observational records of Antarctic sea ice in comparison to its Northern Hemisphere counterpart (Newman et al., 2019). Coupled with the large size of the Antarctic sea ice zone, this lack of data means that large-scale changes in sea ice have only really been able to be studied since the onset of satellite monitoring in 1979. Currently spanning more than 40 years, the satellite-derived sea ice record is becoming increasingly viable in terms of examining interannual and interdecadal scale variability and trends (Parkinson and Cavalieri, 2012).

One of the key findings from the satellite sea ice record is that total sea ice coverage around the Antarctic continent has over the past four decades exhibited a small but significant positive trend (e.g. Comiso and Nishio, 2008; Parkinson, 2019; Parkinson and Cavalieri, 2012, Figure 1.2b), despite modelled projections consistently predicting a negative trend (e.g. Mahlstein et al., 2013; Polvani and Smith, 2013; Turner et al., 2013a). This trend is in direct contrast to the Arctic, where sea ice has experienced a substantial decline over the satellite era (Meier et al., 2014), and is expected to be ice-free in summer by mid-century unless greenhouse gas emissions are drastically reduced (Notz and Stroeve, 2018). In the Arctic, these trends have been attributed to anthropogenic climate change driving increases in air temperature and SST. In the Antarctic, however, the drivers of the small positive trend in sea ice coverage since the late 1970s are less clear, with studies variously suggesting possible influence from decreases in stratospheric ozone (Turner et al., 2009), changes in surface winds (Holland and Kwok, 2012) internal atmospheric variability (e.g. Ludescher et al., 2019), freshening of surface waters due to increased glacial melt (Bintanja et al., 2013), and trends in modes of climate variability such as the Southern Annular Mode (e.g. Goosse et al., 2009; Thompson and Solomon, 2002) and El Niño Southern Oscillation (e.g. Liu et al., 2002; Turner, 2004; Yuan, 2004).

The overall positive trend (shown in Figure 1.2) also masks substantial temporal and spatial variability. Record maximum sea ice concentration was reached in 2014, only to be followed by a record minimum in 2016 (Stuecker et al., 2017; Turner et al., 2017b), and sea ice concentration is simultaneously increasing in the Ross Sea region, while rapidly decreasing in the areas of the Bellingshausen sea and the Antarctic Peninsula (Figure 1.2a). Interannual variability is particularly strong around East Antarctica (Raphael and Hobbs, 2014), a region where sea ice trends are particularly unclear. 

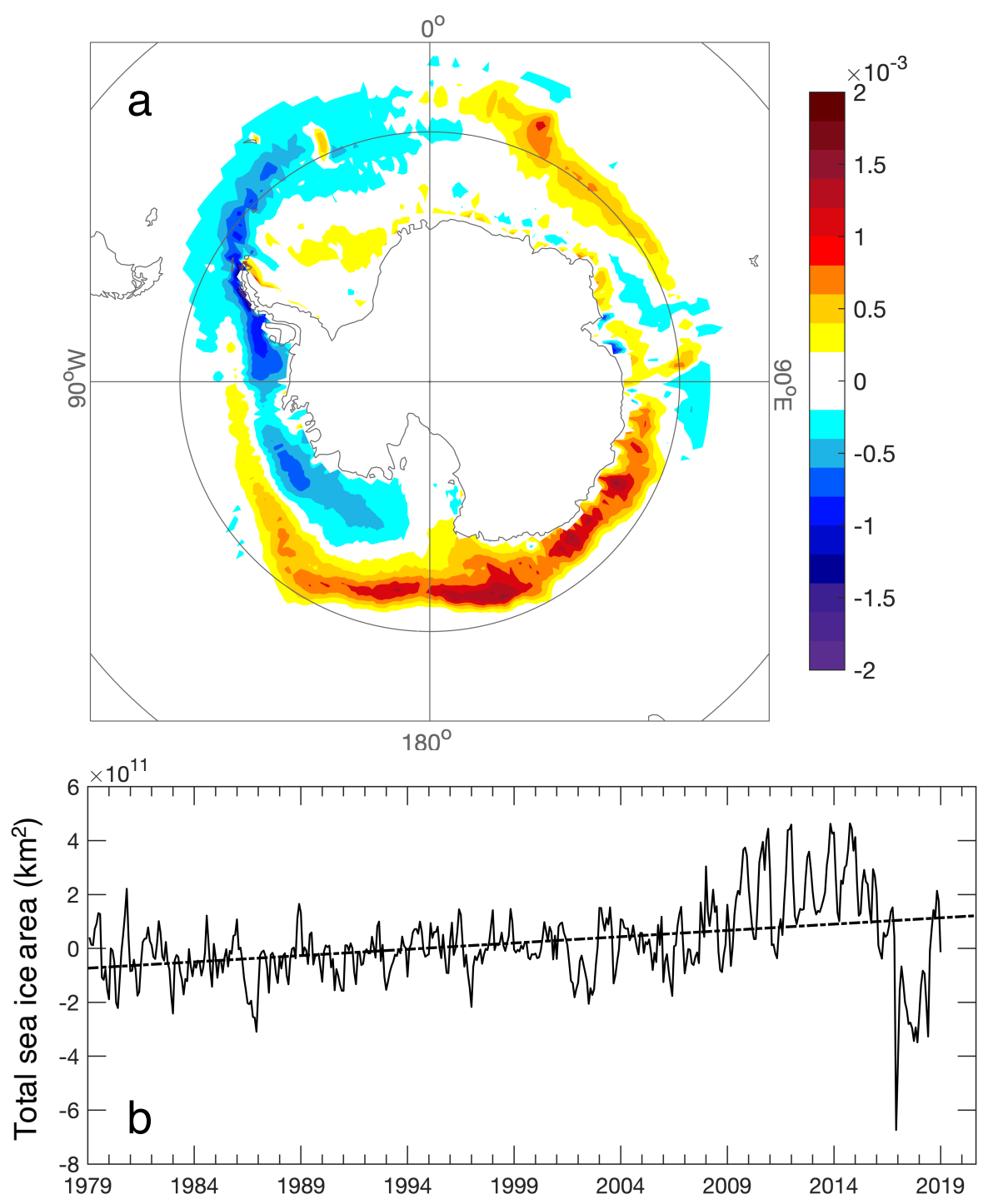

Fig. 1.2 (a) Map of linear trend in HadISST sea ice concentration over the 40-year period 1979-2018. (b) Timeseries of monthly HadISST sea ice concentration anomaly (solid line) for the same period, calculated using a 1981-2010 climatological base period. Dash-dot line shows linear trend.

\subsection{Large-scale drivers of recent sea ice variability}

Understanding the drivers behind the changes in Antarctica's sea ice is a rapidly growing and active area of research. Sea ice variability has been linked to atmospheric and oceanic forcing by a number of studies, thought to contribute to some degree to the puzzling positive trend in sea ice coverage around Antarctica (e.g. Hobbs et al., 2016; Jones et al., 2016; National Academies of Sciences, Engineering and Medicine and others, 2017; Renwick et al., 2012; Turner et al., 2016; Zhang, 2007). 
One factor thought to particularly influence interannual variability in Antarctic sea ice is large-scale atmospheric variability. Antarctica is influenced by a range of well-known patterns of climate variability, such as the Southern Annular Mode (SAM), the El Niño Southern Oscillation (ENSO), the Pacific Decadal Oscillation (PDO), and Zonal Waves 1 and 3 (ZW1 and ZW3 respectively). Each of these modes of climate variability are associated with changes to Southern Hemisphere circulation, and consequently to the Antarctic climate, cryosphere, and ocean systems.

\subsubsection{Southern Annular Mode}

The SAM, an oscillation in the strength and position of the belt of westerly winds encircling Antarctica, is a particularly dominant mode of climate variability throughout the whole Antarctic and Southern Ocean region (Rogers and Loon, 1982; Thompson and Wallace, 2000). The state of the SAM is defined by the difference in zonal mean sea level pressure between $40^{\circ} \mathrm{S}$ and $65^{\circ} \mathrm{S}$. As depicted in Figure ??, the positive phase of the SAM is associated with a strengthened and more poleward circumpolar westerly wind belt, along with anomalous low pressure and temperatures over the Antarctic continent (Fyfe, 2003; Gillett et al., 2006; Marshall, 2007; Thompson and Solomon, 2002; Thompson and Wallace, 2000). A negative phase represents a weakening of the westerly winds and a northward shift in their latitude, and anomalously high pressure and temperatures over the continent. The SAM can switch between positive and negative states within a matter of days, and in Antarctica the contraction and expansion of westerly winds is known to influence air temperatures (e.g. Marshall, 2007; Marshall and Thompson, 2016; Nicolas and Bromwich, 2014), regional circulation features (Clem et al., 2017, 2016), cyclonic activity (Grieger et al., 2018; Yin, 2005) and precipitation (Marshall et al., 2017; Medley and Thomas, 2019; Turner et al., 2019; Van Den Broeke and Van Lipzig, 2004).

Some studies have also linked sea ice variability specifically to the SAM (Doddridge and Marshall, 2017; Hall and Visbeck, 2002; Hobbs et al., 2016; Holland and Kwok, 2012; Lefebvre et al., 2004; Pezza et al., 2008; Stammerjohn et al., 2008). The influence of the SAM on sea ice variability is highly complex, with a strong component of regional and seasonal variability. The SAM broadly affects Antarctic sea ice by altering surface winds, which in turn alter meridional heat fluxes, ocean heat fluxes, and sea ice transport (Hall and Visbeck, 2002). A positive SAM phase can drive increases in sea ice, due to the associated strengthening of zonal winds and enhanced Ekman transport (Hall and Visbeck, 2002; Lefebvre et al., 2004; Watterson, 2000). Strengthened southerly winds bring colder air to the sea ice zone, lowering air temperatures and providing conditions favourable for increased 

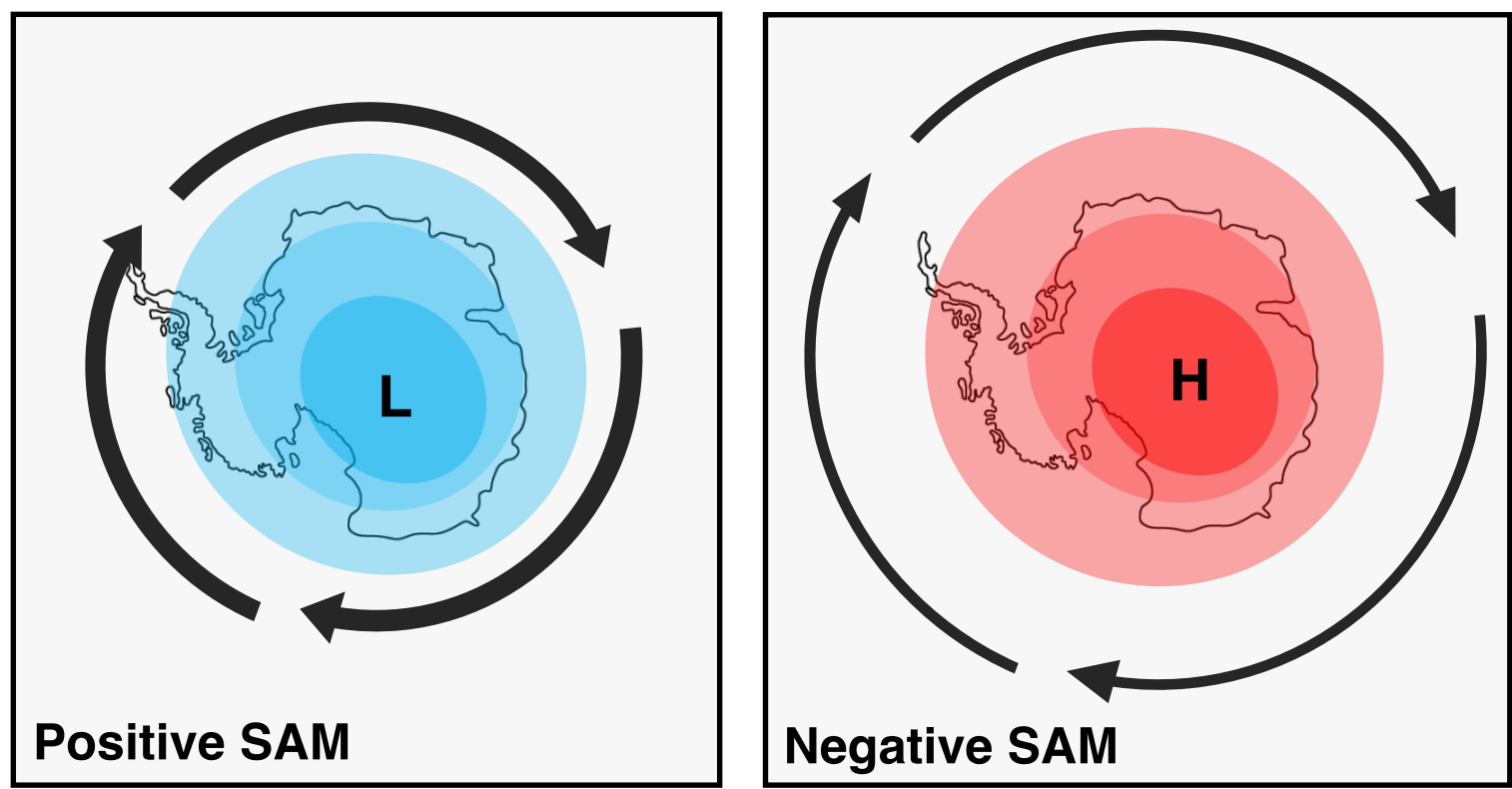

Fig. 1.3 Schematic showing the positive and negative phases of the Southern Annular Mode (SAM) around Antarctica

sea ice coverage. Enhanced Ekman transport, in which water in the ocean is transported at an angle to the wind direction (Price et al., 1987), occurs due to the strengthened westerlies associated with a positive phase of the SAM, and acts to increase northward transport of sea ice between $45^{\circ} \mathrm{S}$ and the Antarctic coastline (Hall and Visbeck, 2002; Kostov et al., 2017; Lefebvre et al., 2004).

The SAM can also affect sea ice coverage via its interactions with quasi-stationary atmospheric circulation features such as the Amundsen Sea Low (ASL). The ASL has been shown to contribute to a dipole trend in sea ice coverage between the Ross Sea and the Amundsen-Bellingshausen Sea regions, where sea ice concentration is increasing in the former, and decreasing in the latter (Fogt et al., 2012b; Hosking et al., 2013a; Turner et al., 2013b). A positive SAM phase can enhance the ASL, and in turn drive anomalously high SIC in the Ross Sea and anomalously low SIC in the Amundsen-Bellingshausen Sea regions (Coggins and McDonald, 2015; Hobbs and Raphael, 2010; Holland and Kwok, 2012; Hosking et al., 2013b).

\subsubsection{EI Niño-Southern Oscillation}

The El Niño-Southern Oscillation (ENSO) teleconnection is known to link Antarctica with tropical Pacific climate and sea surface temperatures (SST). ENSO is a phenomenon com- 
prised of the El Niño/ La Niña pattern, a periodic fluctuation in a dipole of sea surface temperature across the equatorial Pacific Ocean, and the Southern Oscillation, a bimodal variation in sea level pressure measured between Darwin and Tahiti (Wang et al., 2017). El Niño phases, as depicted in Figure 1.4, are characterised by warm SST anomalies in the eastern equatorial Pacific, off the coast of South America, and a weakening of the easterly trade winds (Trenberth, 1997). La Niña phases are associated with cold SST anomalies in the eastern equatorial Pacific, and a strengthening of the easterly trade winds. The state of ENSO can be quantified using a number of different indices, such as the Southern Oscillation Index, the standardised difference in sea level pressure between Tahiti and Darwin, and the Niño SST Indices, the difference in SST across the equatorial Pacific Ocean.

ENSO has been linked to variability in various components of the earth system around the globe, extending into the mid- and high-latitudes (e.g. Domeisen et al., 2019; Lin and Qian, 2019; Yeh et al., 2018). The deep atmospheric convection generated by equatorial anomalies triggers the poleward propagation of atmospheric Rossby waves to the high latitudes, altering storm tracks and affecting regional circulation over the Southern Ocean and Antarctica (Karoly, 1989; Mo and Higgins, 1998; Yuan, 2004). This teleconnection with the tropical Pacific is thought to contribute to variability in Antarctic air temperatures (e.g. Clem et al., 2018; Ding et al., 2011; Kwok and Comiso, 2002; Rahaman et al., 2019), SST (Ferster et al., 2018), precipitation (e.g. Bromwich et al., 2000; Cullather et al., 1996; Genthon and Cosme, 2003), and circulatory features such as the Amundsen Sea Low (e.g. Clem et al., 2017; Fogt and Wovrosh, 2015; Raphael et al., 2016).

ENSO has also been linked to sea ice variability, through its influence on meridional atmospheric circulation and associated temperature advection (Baba and Renwick, 2017; Gloersen, 1995; Isaacs et al., 2021; Kwok and Comiso, 2002; Kwok et al., 2016; Renwick, 2002). In particular, El Niño phases have been linked with positive sea ice anomalies in the Weddell and Ross Seas, and negative anomalies in the Amundsen-Bellingshausen Seas and Dronning Maud Land, while La Niña are linked to the opposite (Isaacs et al., 2021; Kwok and Comiso, 2002; Yuan, 2004). These impacts have been attributed to the atmospheric wave train associated with El Niño, which drives anomalous cold southerly winds over the Weddell and Ross Sea regions and anomalous warm northerly winds over the AmundsenBellingshausen Seas and Dronning Maud Land (Isaacs et al., 2021; Yuan, 2004), in a similar manner as the SAM.

Interestingly, ENSO has been observed to work synergistically with the SAM to affect change in the sea ice in summer. A positive (negative) SAM phase coinciding with a La Niña (El Niño) ENSO state tends to favour an increase (decrease) in sea ice growth 

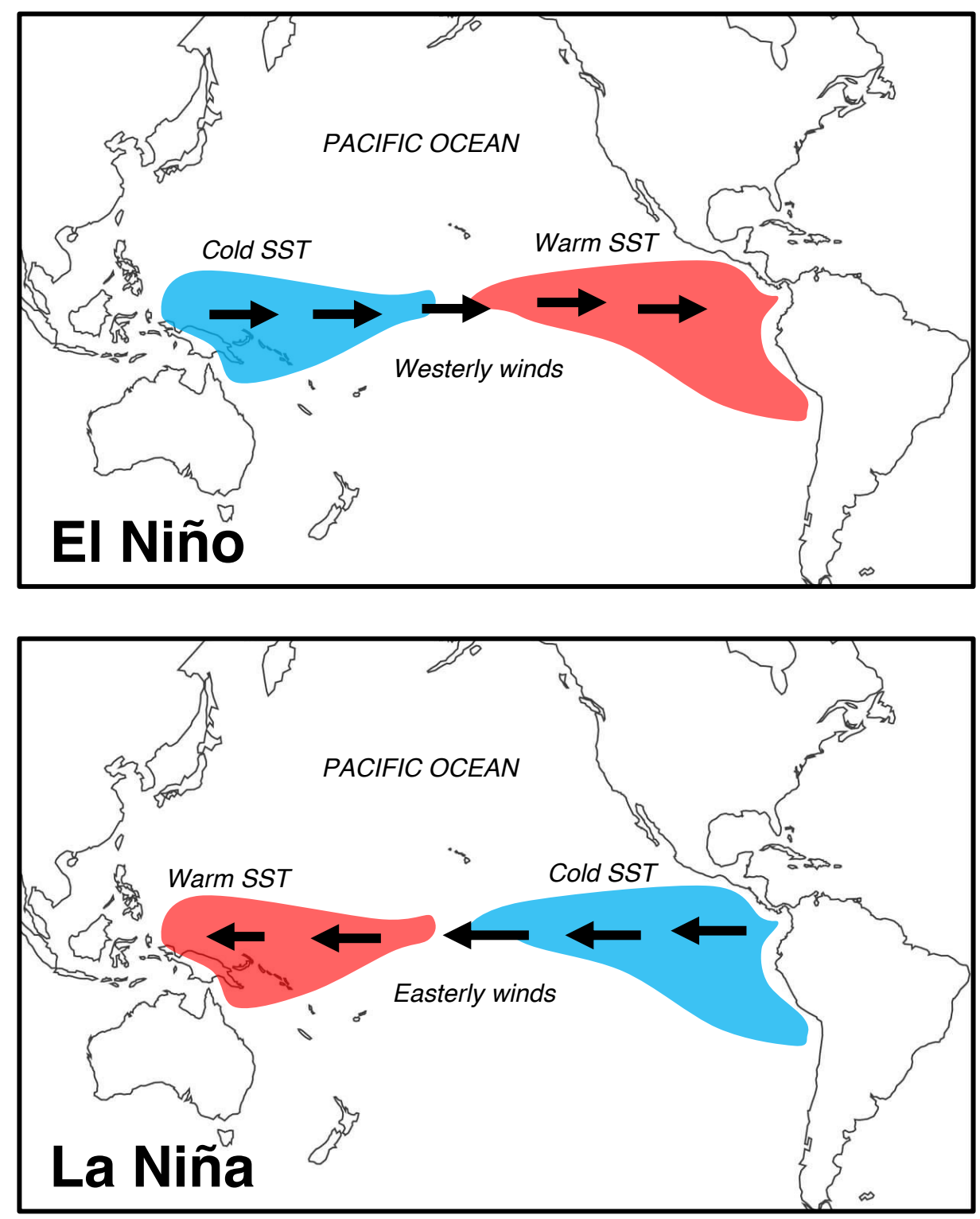

Fig. 1.4 Schematic showing the positive (El Niño) and negative (La Niña) phases of El Niño-Southern Oscillation.

(Pezza et al., 2012; Stammerjohn et al., 2008), and the impact of both modes tends to be substantially reduced when a positive (negative) SAM coincides with an El Niño (La Niña) phase. Stammerjohn et al. (2008) additionally identified that the strengthening of the Bellingshausen/Ross sea ice dipole coincides with decadal changes in the mean state of the SAM, possibly due to changes in wind fields and heat transport. 


\subsubsection{Zonal Wave 3}

The influence of Zonal Wave 3 (ZW3) in the Antarctic has been less researched than the SAM and ENSO. Initially described in van Loon and Jenne (1972), ZW3 is a quasi-stationary planetary wave characterised by a series of three nodes of alternating high and low pressure anomalies encircling the Antarctic continent and dominating atmospheric circulation in the region of $45^{\circ} \mathrm{S}-55^{\circ} \mathrm{S}$ (Figure 1.5). The longitudinal location of each node experiences some seasonal variation, particularly between austral autumn and winter, and at sub-monthly to monthly timescales (Raphael, 2004; Renwick, 2005; Turner et al., 2017a). ZW3 dominates extra-tropical circulation variability in the Southern Hemisphere on a range of timescales from daily to inter-annual (e.g. Karoly, 1989; Kidson, 1988; Mo and White, 1985; Trenberth, 1980), and is associated with variability in geopotential height and wind fields, along with meridional heat, moisture, and momentum transport. As a result of these associations, ZW3 is also linked to Antarctic sea ice variability (Baba and Renwick, 2017; Raphael, 2007; Raphael and Hobbs, 2014; Yuan and Li, 2008; Yuan et al., 1999). Raphael (2007) suggested that ZW3 drives changes in sea ice growth and melt by altering meridional heat fluxes, which results in strongly regional changes to sea ice concentration around Antarctica. These are particularly apparent in the sea ice zone in the Ross and Weddell Seas, and around the region of the Amery Ice Shelf (Raphael, 2007). Raphael (2007) further identified that the association between ZW3 and sea ice concentration exhibited seasonal variability, and was strongest in the austral autumn and early winter.

\subsubsection{Indian Ocean Dipole}

The Indian Ocean Dipole (IOD) is a recurring pattern in equatorial Indian Ocean SST, characterised by a dipole in SST anomalies between the eastern and western equatorial Indian Ocean (Li et al., 2003). As depicted in Figure 1.6, during a positive phase of the IOD, SST is anomalously cold in the east and anomalously warm in the west (and vice versa in a negative phase), which drives a reversal of the equatorial surface winds from westerlies to easterlies (Rao et al., 2002; Saji et al., 1999; Saji and Yamagata, 2003). As a direct result of these changes, it has been variously suggested that the IOD modulates precipitation (Behera and Yamagata, 2003; Black et al., 2003; Clark et al., 2003), atmospheric pressure (Behera and Yamagata, 2003), sea level variations (Han and Webster, 2002) and surface temperature (Saji and Yamagata, 2003) in the regions around the Indian Ocean. The IOD has also been linked to variability in aspects of the climate and ocean further afield in the midand high-latitudes (Ashok et al., 2003; Meyers et al., 2007; Saji and Yamagata, 2003). These 


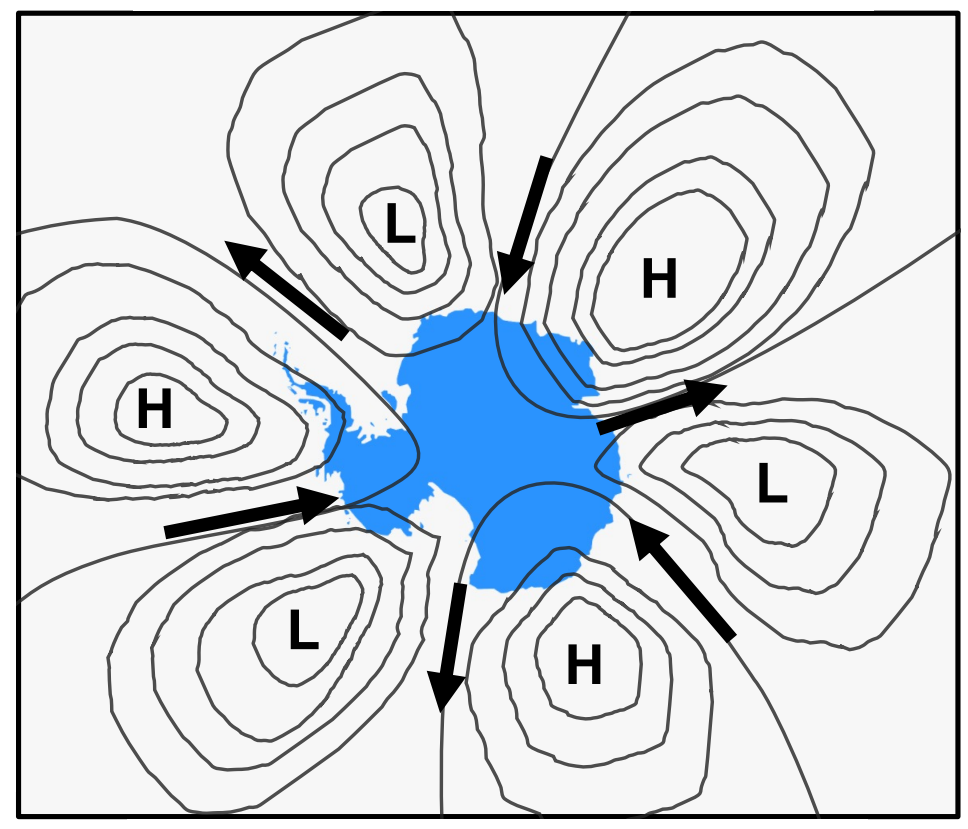

Fig. 1.5 Schematic showing the signature of Zonal Wave 3 (ZW3) in geopotential height around Antarctica.

links are thought to be driven by a similar mechanism as ENSO, namely the perturbation of larger-scale atmospheric circulation at the Equator, which then propagates poleward in the form of Rossby waves (McIntosh and Hendon, 2018; Nuncio and Yuan, 2015).

Two studies (Feng et al., 2019; Nuncio and Yuan, 2015) have found evidence for a relationship between the IOD and sea ice around Antarctica. Associations were found predominantly with sea ice around East Antarctica, though Feng et al. (2019) also described relationships with sea ice in the adjacent Weddell and Ross Seas. The authors suggest that IOD-driven anomalies in regional circulation and meridional heat/moisture transport may be responsible for the links with sea ice, driving changes in the process of sea ice growth and decline. However, more research in this area is needed to confirm these mechanisms.

\subsection{Links between Antarctic sea ice, climate, and ice sheets}

Alongside the interactions between sea ice and climate, there are recent suggestions that changes in sea ice may propagate into other aspects of the Antarctic cryosphere, or that climate variability may induce cross-cryospheric changes. A number of studies have suggested a 

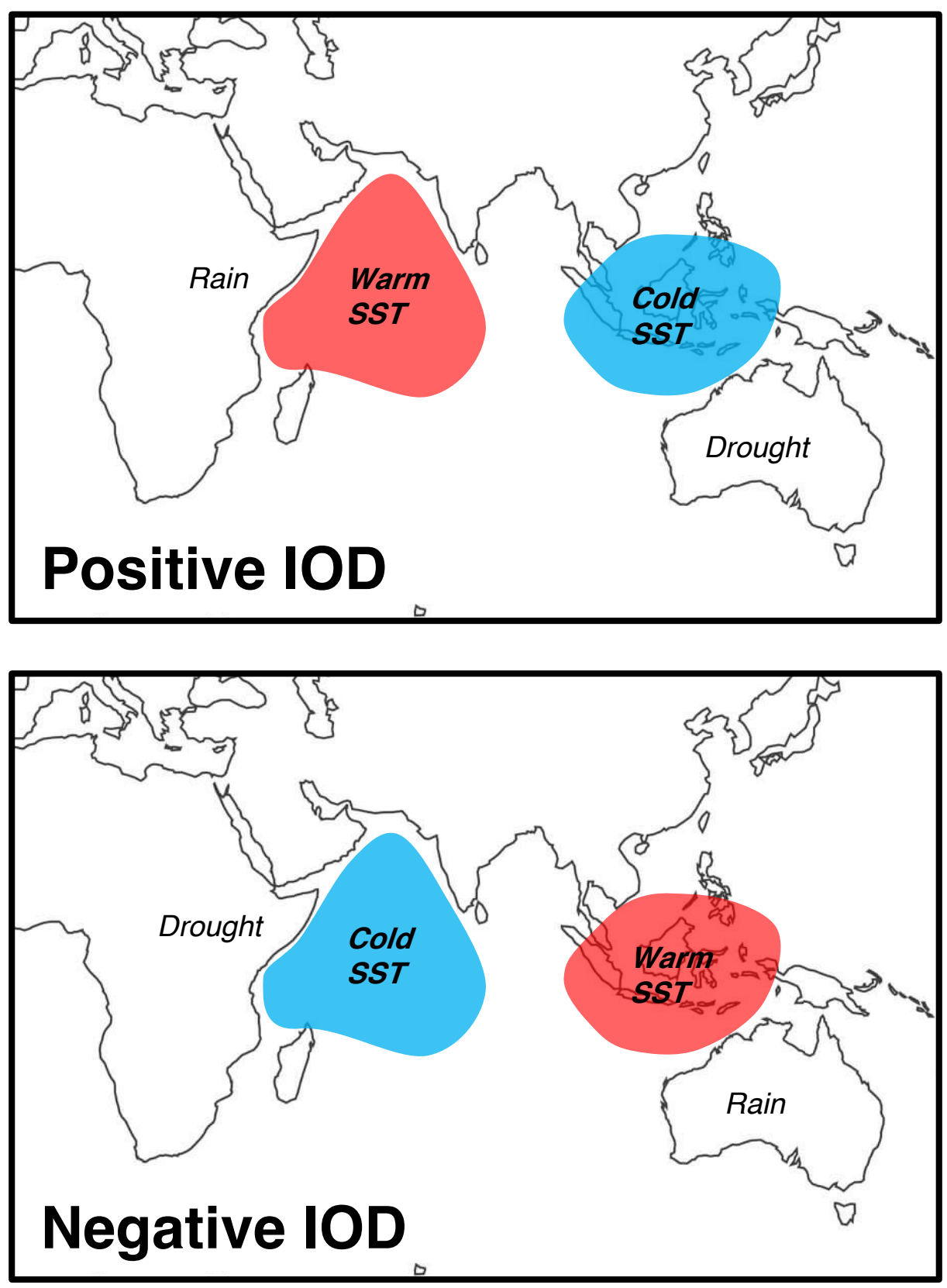

Fig. 1.6 Schematic showing the positive and negative phases of the Indian Ocean Dipole (IOD).

relationship between sea ice and the mass balance of Antarctic ice shelves and outlet glaciers, through the modulation by sea ice of both dynamic and thermodynamic processes. Miles et al. (2016) linked an anomalous retreat of glaciers in Wilkes Land to a reduction of land-fast sea ice cover, suggesting that this reduction likely led to disruption in ocean stratification, and an increased incursion of warm water towards the glacier termini. Additionally, Miles et al. (2013) found an association between changes in outlet glaciers along the Pacific coast 
of Antarctica, sea ice trends, and variability in the SAM. These findings are supported by similar research carried out in the Arctic, most notably in northeast Greenland, where sea ice has been linked to the stability of marine-terminating glaciers, through its influence on calving rates (Bendtsen et al., 2017; Reeh et al., 2001).

Studies in the Arctic have also suggested that sea ice variability may affect ice sheet and glacier mass balance via its influence on atmospheric processes. Liu et al. (2012) found that reduced summer sea ice in the Arctic contributes to stronger and more frequent occurrences of large blocking-high pressure systems over Greenland, bringing warm moist air to the area and altering snowfall patterns. Liu et al. (2016) further suggested that these sea-ice-induced changes to atmospheric patterns cause more extensive surface melting of the Greenland ice sheet, directly affecting the ice sheet mass balance. These findings are supported by studies such as Day et al. (2013), whose experiments with regional climate models indicated that the surface mass balance of the Greenland ice sheet would likely decrease in response to sea ice decline, due to the changes it would induce in temperature and precipitation. These findings pose interesting questions for Antarctica, where no similar research has been published to date.

\subsection{Aims and organisation of thesis}

Research into the influence of large-scale climate variability on Antarctic sea ice has predominantly focused on West Antarctica, where cryospheric and climatic change is occurring at a more rapid pace than in East Antarctica (e.g. Bromwich et al., 2013; Harig and Simons, 2015; Rignot et al., 2019; Schneider et al., 2012). Recent research, however, has identified that the East Antarctic environment is more vulnerable to change than previously thought. This includes studies of increasing mass loss and thinning in parts of the East Antarctic Ice Sheet (Miles et al., 2013; Pritchard et al., 2009; Rignot et al., 2019; Shen et al., 2018), air temperature changes (Clem et al., 2020), and climatic drying (Robinson et al., 2018). Increasing our understanding of recent sea ice changes around East Antarctica, and their relationship with the climate, is therefore vitally important, and forms the key motivation for this body of research.

The overarching aim of this thesis is to fill in a major knowledge gap by exploring the relationships between recent East Antarctic sea ice variability and climate variability, and how these vary both spatially and temporally. This is achieved through statistical analysis of the HadISST satellite-derived sea ice record (Titchner and Rayner, 2014), along with ERA5 
atmospheric reanalysis (Copernicus Climate Change Service (C3S), 2017), over the period 1979-2018.

These relationships are explored in both directions, i.e. the influence of climate variability on sea ice (Chapters 3 and 4), and the influence of sea ice variability on the climate (Chapter 5). While the overarching research aim was formulated out of the literature review above, the specific research questions/focuses of each of the three key research chapters were informed by a body of preliminary exploratory work. In particular, the first two research chapters were formulated from the results of initial broad scale correlation analysis, presented in Figure 1.7. Chapters 3 and 4 build upon two key points of interest [noted] in Figure 1.7, namely significant correlations between both the SAM and the IOD with SIC around the Western Pacific sector $\left(90-170^{\circ} \mathrm{E}\right)$ of East Antarctica (Chapter 3), and a significant inverse correlation between ENSO and SIC around Dronning Maud Land (10-70 E) in summer and autumn (Chapter 4). This figure will be discussed in more detail in Chapters 3 and 4.
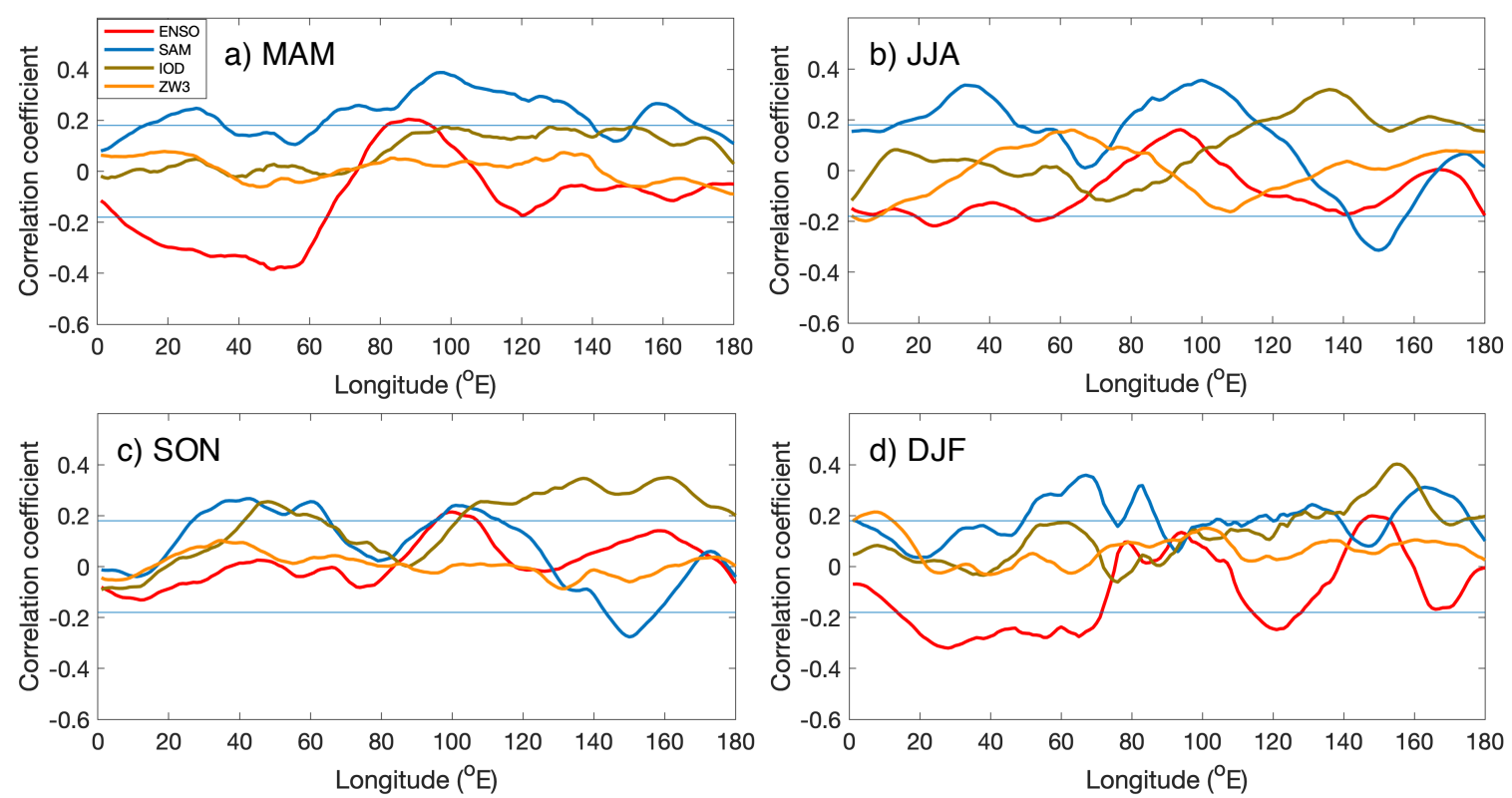

Fig. 1.7 Correlation between seasonally averaged indices of the SAM, IOD, ENSO, and ZW3, with average HadISST monthly mean sea ice concentration in latitudes south of $50^{\circ} \mathrm{S}$, and in $10^{\circ}$ sliding sectors of longitude (each data point marks the start of a sector) between $0-180^{\circ} \mathrm{E}$ around the coast of East Antarctica over 1979-2018. (a) is MAM, (b) JJA, (c) SON, and (d) DJF. Horizontal black lines mark statistical significance at the $5 \%$ level.

Informed by the literature review and exploratory analysis described above, the overarching aim of this thesis is achieved through the exploration of three key objectives/topics, making up the three research chapters. These objectives are: 
1. To determine how the Southern Annular Mode and the Indian Ocean Dipole affect interannual variability in sea ice concentration around the Western Pacific sector of East Antarctica (Chapter 3).

2. To determine how El Niño Southern Oscillation is linked to interannual variability in sea ice concentration around Dronning Maud Land, and what mechanisms are driving this correlation (Chapter 4).

3. To characterise the large-scale and spatially-varying relationship between East Antarctic sea ice, precipitation over the East Antarctic Ice Sheet, and climate variability (Chapter 5).

This introduction (Chapter 1) provides the rationale for this research, with a broad overview of the current knowledge around Antarctic sea ice and its interactions with largescale climate. A more detailed overview relevant to each of the three pieces of research is given at the beginning of each research chapter.

In Chapter 2, I outline the methodological approach to achieve the aims listed above. This includes a description of the data and statistical analysis techniques, as well as a discussion of potential limitations and uncertainty associated with each.

Chapters 3-5 describe the research toward each of the three key aims. These chapters have been written for publication as peer-reviewed journal articles and have been structured accordingly, with the exception of methods sections which are combined in Chapter 2 to avoid repetition. Of the three research chapters, Chapter 4 has already been published prior to submission in the Journal of Geophysical Research: Atmospheres, and is presented here in the same form, although the methods have been incorporated into Chapter 2. It is published as:

Isaacs, F.E., Renwick, J.A., Mackintosh, A.N., and Dadic, R. (2021). ENSO modulates summer and autumn sea ice variability around Dronning Maud Land, Antarctica. Journal of Geophysical Research: Atmospheres, doi: 10.1029/2020JD033140

Chapter 6 provides a summary and synthesis of the key findings in this thesis. The implications and importance of these findings are discussed, alongside a brief exploration of possible future avenues of research that could build on this work. 


\section{Chapter 2}

\section{Data and Methods}

This chapter outlines the data and methods I used to achieve the aims listed in Chapter 1. Section 2.1 describes the data used in this thesis, including sea ice concentration (Section 2.1.1) and sea ice motion data (Section 2.1.2), atmospheric reanalysis (Section 2.1.3), and climate mode indices (Section 2.1.4). Data sources, justifications, limitations, and uncertainties are discussed. Section 2.2 describes the analytical techniques used throughout the thesis. These include linear correlation (Section 2.2.1) and composite analysis (Section 2.2.2). The methods presented here apply to the entire thesis, due to the similarity in the data and methods being used across all three research components of this thesis. Any difference in the use of analysis techniques between chapters has been highlighted.

\subsection{Data}

This thesis considers recent sea ice and climate variability, using data from the period between 1979-2018. 1979 marks the earliest point at which gridded satellite-derived sea ice concentration data are available, and the earliest point at which atmospheric reanalysis products are considered relatively reliable (Bracegirdle and Marshall, 2012).

\subsubsection{Sea ice concentration}

Common parameters used in research on sea ice distribution include sea ice area (SIA), sea ice extent (SIE), and sea ice concentration (SIC). SIA is the total area covered by sea ice, SIE is the area of ocean determined as being ice-covered (usually areas which have at least a 
15 percent coverage of sea ice), and SIC is the fraction of a given area that is covered by sea ice. In this thesis I used area-averaged SIC, although initial analysis suggested that it would also be possible to use the parameters of sea ice area (SIA) or sea ice extent (SIE), as they were perfectly (SIA) or highly (SIE) correlated with the area-averaged SIC, and showed no significant difference when correlated with ERA5 reanalysis climate fields.

The sea ice data used in this study were monthly mean sea ice concentrations obtained from the Met Office Hadley Centre Sea Ice and Sea Surface Temperature data set (HadISST.2.2.0.0; Titchner and Rayner, 2014). HadISST2 SIC is derived from brightness temperatures recorded by satellite-based passive microwave multichannel sensors. These sensors include the Scanning Multichannel Microwave Radiometer (SMMR) on the NASA Nimbus 7 satellite for retrievals between 1978 and 1987, and the Special Sensor Microwave/Imager (SSM/I) and Special Sensor Microwave Imager/Sounder (SSMI/S) sensors on the Defense Meteorological Satellite Program (DMSP) satellites for retrievals post 1987 (Titchner and Rayner, 2014). SIC concentrations are derived from these brightness temperature data using the European Organisation for the Exploitation of Meteorological Satellites (EUMETSAT) Ocean and Sea Ice Satellite Application Facility (OSI SAF) hybrid algorithm, which combines the Bootstrap algorithm in frequency mode (Comiso, 1986) with the Bristol algorithm (Hanna and Bamber, 2001; Smith, 1996). The HadISST2 dataset was chosen for this study as it is highly accessible, and is one of only a few complete observation-derived records of sea ice for the period from 1979 to present (National Center for Atmospheric Research Staff (Eds), 2019). This study utilised HadISST2 SIC on a $1^{\circ} \times 1^{\circ}$ latitude-longitude grid, for the period 1979-2018.

\subsubsection{Sea ice motion}

Sea ice motion data were obtained from the National Snow and Ice Data Center (NSIDC), using the Polar Pathfinder Daily 25 km EASE-Grid Sea Ice Motion Vectors (Version 4) data set (Tschudi et al., 2019). The NSIDC sea ice motion data set was used here as it has been shown to have lower associated uncertainties and higher correlation with in situ data in comparison to other commonly-used sea ice motion products, such as the OSI SAF and Centre ERS d'Archivage et de Traitement (CERSAT) data sets (Gui et al., 2020; Sumata et al., 2014). The NSIDC sea ice motion data are derived from three key sources: gridded satellitebased passive microwave data, reanalysis wind fields, and buoy position data. The passive microwave data are derived from the NIMBUS-7 SMMR Pathfinder Brightness Temperatures, DMSP SSM/I-SSMIS Daily Polar Gridded Brightness Temperatures, and AMSR-E/Aqua L2A Global Swath Spatially-Resampled Brightness Temperatures (Tschudi et al., 2019). 
Buoy position data are from the International Arctic Buoy Program, and reanalysis wind fields are sourced from NCEP-NCAR reanalysis (Kalnay et al., 1996). These inputs are then combined using an optimal interpolation scheme to produce complete daily gridded sea ice motion as $\mathrm{u}$ and $\mathrm{v}$ vectors within the EASE grid. For this study, daily average sea ice motion vectors were remapped by linear interpolation from the original $25 \mathrm{~km}$ EASE Grid onto the same $1^{\circ} \times 1^{\circ}$ latitude-longitude grid used for the reanalysis and sea ice concentration data. Monthly averages were derived from daily averages.

\subsubsection{Atmospheric reanalysis data}

This study used the latest iteration of reanalysis from the European Centre for Medium-Range Weather Forecasts (ECMWF), ERA 5 (Copernicus Climate Change Service (C3S), 2017), spanning the period 1979-2018. Reanalysis combines past short-range weather forecasts from numerical weather prediction models with observational data through data assimilation, producing spatially continuous gridded atmospheric data at high temporal resolutions. ERA 5 is produced using the CY41r2 Integrated Forecast System (IFS) and a four-dimensional variational assimilation system. ERA 5 reanalysis was chosen for this study as it has been shown to perform particularly well over Antarctica, with a smaller bias relative to observations than many other reanalysis products (Gossart et al., 2019; Jones and Lister, 2015).

Data were accessed from the Copernicus Climate Data Store from https://cds.climate. copernicus.eu/. The atmospheric parameters of sea surface temperature (SST; ${ }^{\circ} \mathrm{C}$ ), $2 \mathrm{~m}$ air temperature $\left(\mathrm{T} 2 \mathrm{M} ;{ }^{\circ} \mathrm{C}\right), 500 \mathrm{hPa}$ geopotential height $(\mathrm{H} 500 ; \mathrm{m})$, vertically integrated horizontal rate of northward heat flux (NthHF; $\mathrm{W} \mathrm{m}^{-1}$ ), and vertically integrated horizontal rates of northward moisture flux (NthMF; $\mathrm{kg} \mathrm{m}^{-1} \mathrm{~s}^{-1}$ ) were all analysed as monthly means. Precipitation and evaporation were analysed as monthly totals. More detail on specific parameters can be found in the ERA5 Data Documentation (https://confluence.ecmwf.int/ display/CKB/ERA5\%3A+data+documentation). All data were downloaded at a spatial resolution of $1^{\circ} \times 1^{\circ}$, on a latitude-longitude grid.

\subsubsection{Climate mode indices}

The four key modes of climate variability examined in this thesis (ENSO, SAM, IOD, ZW3) were considered using common indices of their activity. ENSO activity was examined using the ESRL/NOAA Nino 3.4 index sourced from the National Oceanic and Atmospheric Administration (NOAA) (https://psl.noaa.gov/gcos_wgsp/Timeseries/Nino34/), which is an 
average of sea surface temperature anomalies in the region $5^{\circ} \mathrm{N}-5^{\circ} \mathrm{S}, 170^{\circ} \mathrm{W}-120^{\circ} \mathrm{W}$. The index is calculated using the HadISST1 SST dataset (Rayner et al., 2003) with a 1981-2010 climatological base period.

Variability in the SAM was examined using the index described by Marshall (2003). This index is based on the zonal pressure difference between $40^{\circ} \mathrm{S}$ and $65^{\circ} \mathrm{S}$, and the monthly time-series was accessed from https://legacy.bas.ac.uk/met/gjma/sam.html. The IOD was examined using a timeseries of the NOAA ESRL Dipole Mode Index (DMI) downloaded from http://psl.noaa.gov/gcos_wgsp/Timeseries/DMI/index.html. The DMI is derived from SST differences across the equatorial Indian Ocean first described by Saji et al. (1999), and is sourced from HadISST1.0 SST data.

Finally, initial analysis concerning the impact of ZW3 on sea ice was done by computing an index of ZW3 activity proposed by Raphael (2004), using the ERA5 monthly H500 field. This ZW3 index is the average of three values calculated using the formula below for three specific grid points $\left(50^{\circ} \mathrm{E}, 166^{\circ} \mathrm{E}\right.$ and $76^{\circ} \mathrm{W}$, all at latitude $\left.49^{\circ} \mathrm{S}\right)$.

$$
I_{i}=\frac{\left(X_{m t h l y}-X_{c l i m}\right)}{\sigma_{m t h l y}}
$$

where $I_{i}$ is the value for a given grid point, $X_{m t h l y}$ is the 3-monthly moving mean $500 \mathrm{hPa}$ geopotential height for a given grid point, $X_{\text {clim }}$ is the climatological 3-monthly mean 500 hPa geopotential height (calculated with a 1981-2010 climatological base period), and $\sigma_{m t h l y}$ is the standard deviation of the 3-monthly moving mean. The ZW3 index is calculated by taking the average of the I value across each of the three grid points. More detail about the derivation of this equation can be found in Raphael (2004).

\subsection{Analysis techniques}

Relationships between sea ice around East Antarctica and larger scale climate variability were explored using linear statistical techniques, including linear correlation, covariance, and composite analyses.

\subsubsection{Linear correlation}

Linear correlation analysis was conducted to determine the association between interannual SIC variability and time-series of each of the four climate mode indices, as well as with the 
ERA5 reanalysis parameters listed above in Section 2.1.2. Pearson correlation coefficients were used to determine the strength and direction of each given association (Wilks, 2011). To examine interannual variability only, the seasonal cycle was removed from all reanalysis and sea ice data, with monthly anomalies calculated using a 1981-2010 climatological base period. Seasonal averages were calculated according to austral autumn (March-April-May), winter (June-July-August), spring (September-October-November), and summer (DecemberJanuary-February).

For much of this analysis, SIC was divided into 18 sectors around the East Antarctic coast between $0-180^{\circ} \mathrm{E}$, with each covering 10-degrees of longitude, and the area south of $50^{\circ} \mathrm{S}$ (Figure 2.1). Within each 10 degree sector, an area-weighted average was calculated of SIC at all grid points in the sector, producing a single time-series to be correlated with the gridded climate data and climate mode timeseries. The number of divisions between sea ice sectors used here is much greater than is typically used in research on large-scale sea ice variability (e.g. Raphael and Hobbs, 2014). This approach was taken to allow a more precise examination of how sea-ice-climate associations vary spatially around East Antarctica and, as discussed in Chapters 3-5, has been crucial in identifying that closely adjacent areas can have markedly different relationships between the ice and climate.

Statistical significance of the associations identified in the correlation analysis was determined using a two-tailed Student's T-test (Wilks, 2011). A significance level of 5\% was used throughout all the analysis in this thesis.

The correlation analysis in this thesis examines the relationships between SIC and climate variables with no lag between the two. This approach was taken based on sensitivity tests which showed that no lag, or a lag of less than one month considering the use of monthly data, produced on average the strongest correlation between SIC and climate variables. While this assertion is in contradiction to Yuan (2004), it is supported by Renwick (2002), who found no substantial lag in the associations between sea ice, ENSO and SST.

\subsubsection{Composite analysis}

Composite analysis was also used throughout this thesis. Composite analysis involves averaging a subset of available data based on a specified set of criteria, for example, averaging sea ice concentration fields only for summer months when the SAM index is above +1 .

In Chapter 3, composite analysis was used to examine the SIC response to different combinations of SAM and IOD phases (for example, +SAM/-IOD, -SAM/-IOD etc). SIC was averaged over all the months in which a given SAM/IOD combination occurred. For 


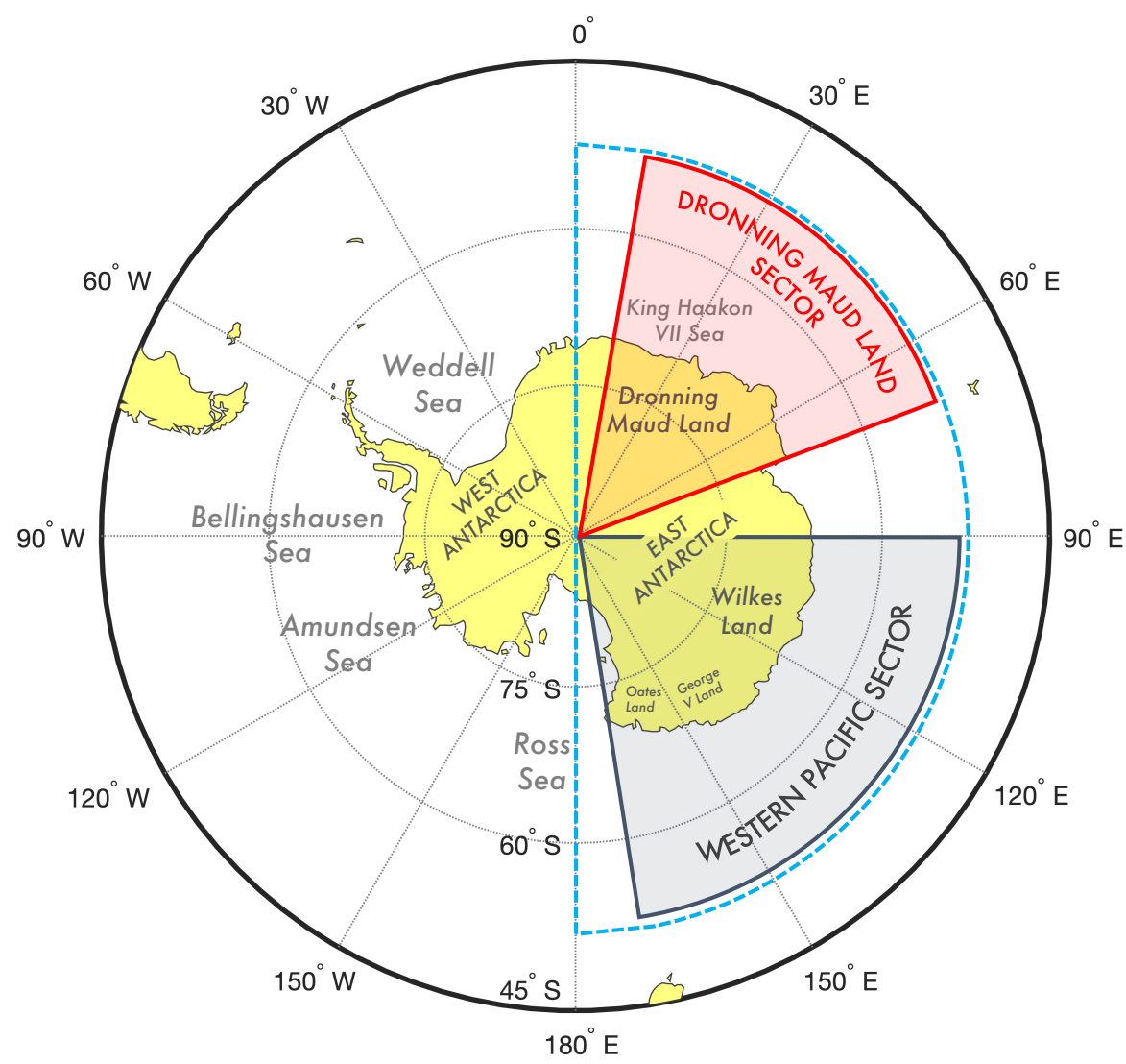

Fig. 2.1 a) Map of the East Antarctic study area including key locations discussed throughout this thesis. Blue dashed line encloses the broader East Antarctic sea ice area examined, between $0-180^{\circ} \mathrm{E}$, and south of $50^{\circ} \mathrm{S}$. Red shading denotes the Dronning Maud Land sector discussed in Chapter 4, while grey shading marks the Western Pacific sector discussed in Chapter 3.

each mode, a positive event was defined by an index value greater than the 60th percentile, and negative events with an index value below the 40th percentile. This allowed more neutral SAM states to be excluded, to enable greater visibility of a SAM signal within the SIC.

Composite analysis was used in Chapter 4 to identify asymmetry in the SIC-climate associations. Composites of various ERA5 climate parameters were calculated for periods when SIC in a given sector was either above the 60th percentile or below the 40th percentile. Composite analysis was also used in Chapter 5, to determine the influence of SIC on the relationship between large-scale circulation anomalies and precipitation over Antarctica. Composites of precipitation were calculated for periods when mean meridional moisture flux over a given sea ice sector was southward, and when SIC was either anomalously high (above the 60th percentile) or anomalously low (below the 40th percentile). The number of members making up each composite figure are listed in the figure captions. 


\section{Chapter 3}

\section{SAM and IOD influence sea ice variability around Western Pacific sector of East Antarctica}

This chapter explores satellite-era interannual sea ice variability around the Western Pacific sea ice sector of East Antarctica, and its relationship with variability in the Indian Ocean Dipole (IOD) and the Southern Annular Mode (SAM). This research was motivated by the recent recognition of possible links between sea ice, climate variability, and the vulnerability of coastal glaciers and ice shelves in this region to mass loss. The Western Pacific sector (WPS) is here considered to be the region between $90^{\circ} \mathrm{E}$ and $170^{\circ} \mathrm{E}$, encompassing Wilkes Land, George V Land, and Oates Land, and is marked on the map in Figure 3.1. Focus was given to this region after initial broad-scale analysis (described in more detail in Section 3.2) suggested that it was a site of particularly strong correlation between sea ice concentration (SIC) and climate variability.

While a broader review of the impacts of the SAM and the IOD on Antarctic sea ice was given in Chapter 1, Section 3.1 in this chapter provides a more in-depth background on the Western Pacific sector of East Antarctica, and what is currently known about the roles that the SAM and IOD play in determining sea ice concentration within this region. The results of this study are presented in Section 3.2. A discussion of these results is presented in Section 3.3, and conclusions in Section 3.4. 
24 I SAM and IOD influence sea ice variability around Western Pacific sector of East Antarctica

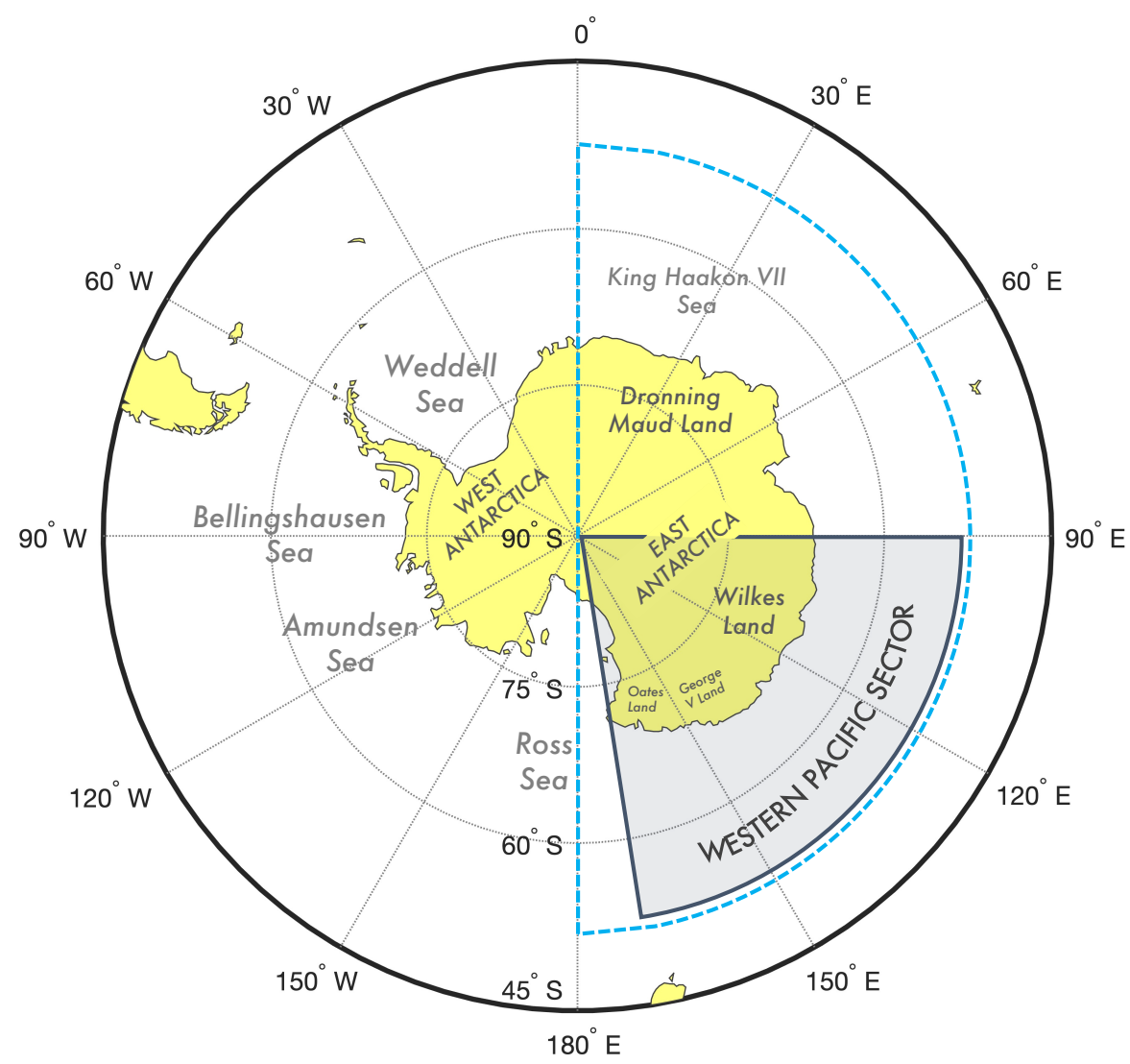

Fig. 3.1 Map of the study area including key locations discussed in this chapter (Chapter 3), and with the Western Pacific sector of East Antarctica (south of $50^{\circ} \mathrm{S}$ and between $90^{\circ} \mathrm{E}$ and $180^{\circ} \mathrm{E}$ ) shaded in grey, including Wilkes Land, George V Land, and Oates Land. Blue dashed line encloses the broader East Antarctic sea ice area examined.

\subsection{Introduction}

The WPS has been identified as an area of distinct vulnerability for the East Antarctic Ice Sheet (EAIS), in terms of its susceptibility to mass loss (Shen et al., 2018). Recent studies have revealed substantial ice sheet mass loss across the WPS over the satellite era (McMillan et al., 2014; Rignot et al., 2019; Sasgen et al., 2013; Shepherd et al., 2018), with a total loss of $4.4 \pm 0.9-\mathrm{mm}$ sea level rise equivalent since 1979 (Rignot et al., 2019). This loss is thought to be partially the result of reduced buttressing of the EAIS outlet glaciers by ice shelves, due to increased basal melting from the intrusion of warm Circumpolar Deep Water (CDW) onto the continental shelf (Rignot et al., 2019; Rintoul et al., 2016). There have been recent suggestions that CDW intrusion under ice shelves in Wilkes Land is linked to changes in the surrounding sea ice, via the influence that sea ice production has on the stratification 
of ocean water (Khazendar et al., 2013; Miles et al., 2016). Sea ice in Wilkes Land has also been linked to ice sheet mass balance via ice shelf and outlet glacier velocity, where a loss of sea ice acts to reduce buttressing of the shelf/glacier terminus, driving increased glacier velocity and thus increased calving and mass loss (Greene et al., 2018; Miles et al., 2017). It is therefore important to understand variability in the sea ice around the WPS, as it may have implications for the stability of the region's ice shelves, and more broadly for the mass balance of the EAIS itself.

The links between sea ice variability and large-scale atmospheric circulation have been discussed in Chapter 1. In short, large scale modes of climate variability (such as the SAM, ENSO, and IOD) can affect change within Antarctic sea ice through their modulation of regional circulation, which affects local scale winds, heat and moisture fluxes, and sea ice drift. A number of studies have discussed the influence of the SAM on sea ice around Antarctica (e.g. Ferreira et al., 2015; Hall and Visbeck, 2002; Lefebvre and Goosse, 2008; Liu et al., 2004; Purich et al., 2016), and a few have addressed the influence of the IOD (e.g. Feng et al., 2019; Nuncio and Yuan, 2015; Rai et al., 2008).

Antarctic sea ice is thought to respond to both the annular and non-annular component of the SAM. The annular component of the SAM is thought to provoke a two-stage response in Antarctic sea ice. Initially, positive SAM phases are associated with higher sea ice concentration as the intensification of polar westerly winds drives increased northward Ekman transport of ice and cold surface water, allowing the expansion of the sea ice coverage (Doddridge and Marshall, 2017; Hall and Visbeck, 2002; Purich et al., 2016; Sen Gupta and England, 2006). However, this northward displacement of surface water eventually triggers upwelling of warmer deepwater near the coast, increasing SST and thus decreasing SIC (Ferreira et al., 2015).

The non-annular component of the SAM is thought to be particularly important in affecting sea ice around Antarctica (Lefebvre et al., 2004), via its influence on atmospheric circulation features, with the most well-studied of these being the Amundsen Sea Low (ASL). The ASL is a quasi-stationary low pressure system in the Amundsen Sea, which deepens during positive SAM phases and weakens during negative phases (Clem et al., 2017; Turner et al., 2013c). The strength of the ASL affects SIC in zones directly east and west of its centre, by altering the intensity of meridional winds over the sea ice, which then, as discussed above, drive changes in SIC (Raphael et al., 2019; Turner et al., 2016).

The role that the SAM plays in determining sea ice change around Antarctica is spatially variable, with each region being affected by a different interplay of annular and zonal impacts. Most of the focus in research on the influence of the SAM on Antarctic sea ice has been 
26 I SAM and IOD influence sea ice variability around Western Pacific sector of East Antarctica

given to the region surrounding the ASL, or a broader scale continent-wide approach. In the WPS, Lefebvre et al. (2004) found indications of a small positive correlation between the SAM and observed annual sea ice area between 1980-1999, and Miles et al. (2016) suggested that the SAM may have influenced variability of land-fast sea ice. However, little is known about the influence of SAM on the seasonal pack ice.

As described in Chapter 1, our understanding of the influence that the IOD has on Antarctic sea ice is limited. Some studies (Feng et al., 2019; Nuncio and Yuan, 2015; Rai et al., 2008) have found evidence for a link between the IOD and sea ice in the Southern Hemisphere. These studies theorise that this is due to the excitation of an atmospheric Rossby wave train by tropical Indian ocean SSTs, which then propagates southward to Antarctica, altering regional circulation and thus driving changes in the sea ice.

A specific link between the IOD and sea ice around Wilkes Land was identified by Nuncio and Yuan (2015). The authors proposed that Wilkes Land was one of two zones of sea ice in the East Antarctic to be particularly affected by the IOD, due to its position in relation to certain components of the IOD-associated Rossby wave train extending from the tropics to Antarctica, and the associated changes in meridional circulation that this can drive. I advance from these findings by addressing seasonal variability in the influence of the IOD on sea ice in Wilkes Land and the broader WPS in all seasons (prompted by the findings that the correlation between sea ice in Wilkes Land and the IOD is not limited to austral spring, but extends to winter and summer), as well as addressing the possible interactions with the SAM.

In this chapter, I explore the influence of both the IOD and the SAM on sea ice concentration around the WPS. I approach this through the use of correlation and composite analysis of the HadISST satellite sea ice record, alongside timeseries of the SAM and IOD indices and ERA5 reanalysis data, covering the period from 1979-2018, and described in more detail in Chapter 2. The links between sea ice and each climate mode are considered both separately and together, to determine how they may interact to produce different forcings on the sea ice. Possible mechanisms driving these links are also explored, using a range of ERA5 climate fields, alongside NSIDC sea ice motion data.

\subsection{Results}

Initial broad-scale analysis of the links between key climate modes and sea ice around the East Antarctic coastline indicated several significant correlations, as well as substantial spatial and seasonal variability. Figure 3.2 shows the correlation between the indices of 
the four climate modes examined in this thesis, with average SIC around the coast of East Antarctica. Two of the most prominent features of this figure form the basis of the research in this chapter, and in Chapter 4. The first of these is the significant inverse correlation between the Niño 3.4 index and SIC between 10-70 ${ }^{\circ} \mathrm{E}$ in summer and autumn only, which is addressed in more detail in Chapter 4. The second, which is addressed in this chapter, is the significant correlation between SIC around the coast of Wilkes Land $\left(100-136^{\circ} \mathrm{E}\right)$, George V Land (142-154 ${ }^{\circ} \mathrm{E}$ ), and Oates Land (154-160 ${ }^{\circ} \mathrm{E}$ ), and the DMI (Dipole Mode Index) IOD index in winter and spring (reaching $\mathrm{r}=0.4, \mathrm{p}<0.05$; Figure 3.2b,c). In this same region, SIC is inversely correlated with the SAM index in winter and spring (Figure 3.2b,c), and positively correlated with the SAM index in summer and autumn (Figure 3.2a,d).
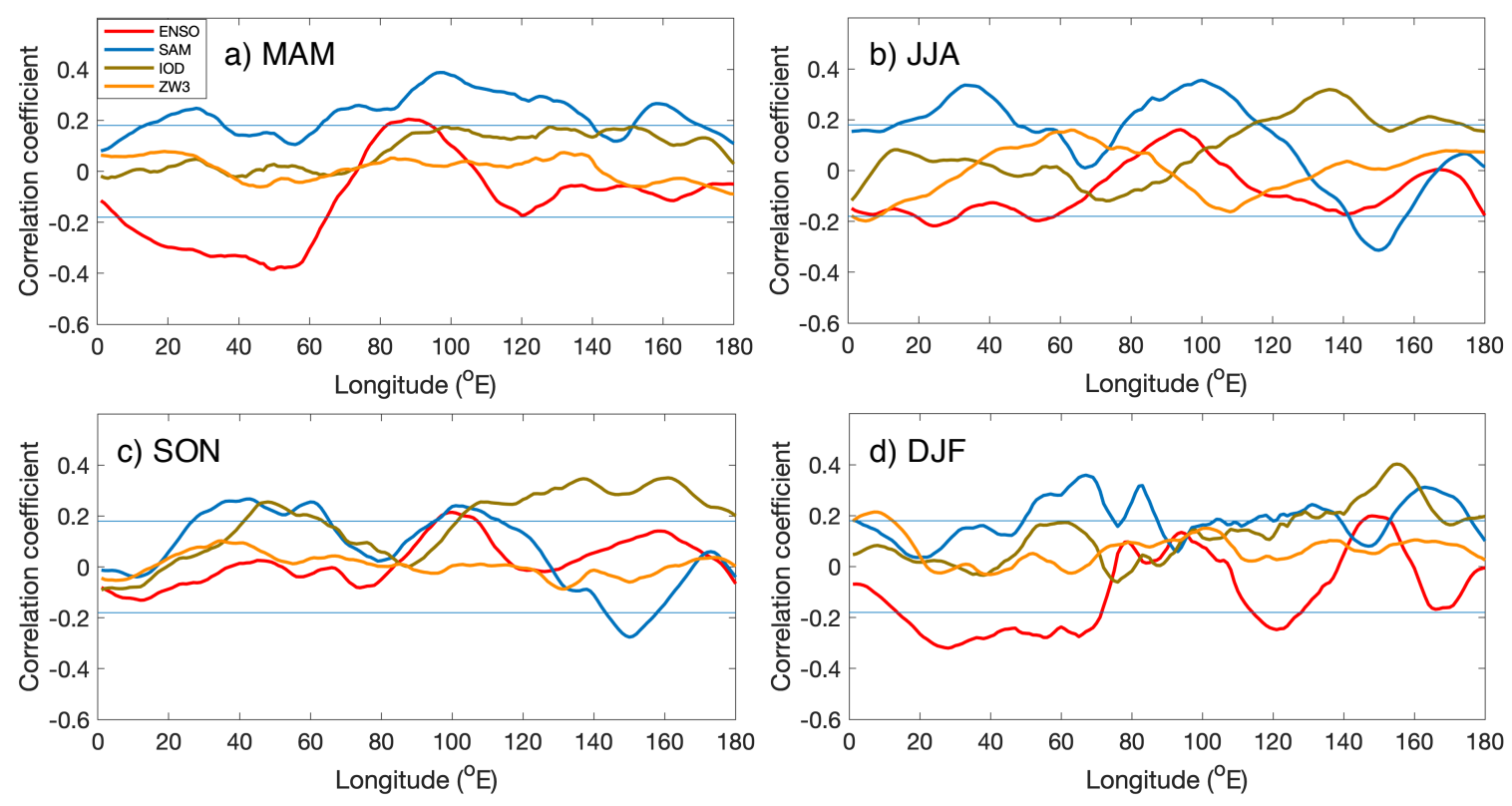

Fig. 3.2 Correlation between seasonally averaged indices of the SAM, IOD, ENSO, and ZW3, with average HadISST monthly mean sea ice concentration in latitudes south of $50^{\circ} \mathrm{S}$, and in $10^{\circ}$ sliding sectors of longitude (each data point marks the start of a sector) between $0-180^{\circ} \mathrm{E}$ around the coast of East Antarctica over 1979-2018. (a) is MAM, (b) JJA, (c) SON, and (d) DJF. Horizontal black lines mark statistical significance at the $5 \%$ level.

To provide some context for the links with large-scale climate variability that this chapter will discuss, Figure 3.3 shows the average seasonal sea ice concentration in the WPS, around the coastline of Wilkes Land, George V Land, and Oates Land, between $90{ }^{\circ} \mathrm{E}$ and 180 ${ }^{\circ} \mathrm{E}$. Sea ice in this region of East Antarctica occurs in a narrow band around the coastline, extending just north of $60{ }^{\circ} \mathrm{S}$ in some areas during SON (Figure 3.3c), and retreating almost to the coast during DJF (Figure 3.3d). The highest concentrations occur east of $150{ }^{\circ} \mathrm{E}$ 
28 SAM and IOD influence sea ice variability around Western Pacific sector of East Antarctica

towards the Ross Sea, while sea ice to the west is generally more spatially variable, with lower concentrations, and occurring only in a narrow band around the coast.
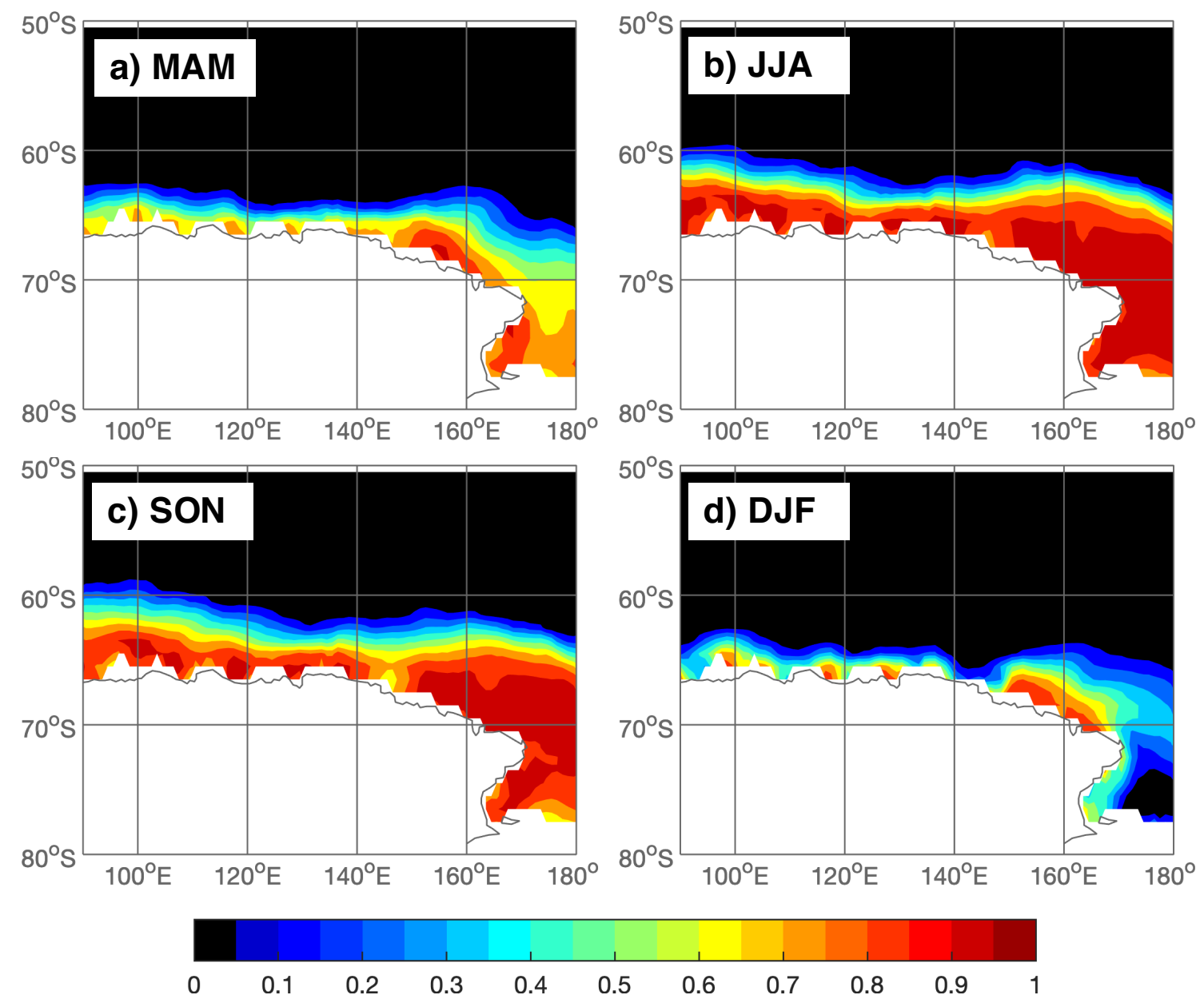

Fig. 3.3 Average seasonal HadISST sea ice concentration in the Western Pacific sector of East Antarctica, around the coast of Wilkes Land, George V Land, and Oates Land (90-180 E), over the 40-year period 1979-2018 for MAM (a), JJA (b), SON (c), and DJF (d).

The spatial pattern of the correlation between SIC and the IOD index is visible in Figure 3.4. A significant positive correlation is observed around some sectors in the WPS in all seasons, though is particularly weak in autumn. The correlation is most extensive in spring (Figure 3.4c), when the zone of significant positive correlation with the IOD stretches from $90-180^{\circ} \mathrm{E}$ (reaching $\mathrm{r}=0.38$ ), extending northward to the approximate maximum sea ice edge, but excluding the area closest to the coastline itself. In winter (Figure 3.4b) the positive correlation stretches from $115-190^{\circ} \mathrm{E}$ (reaching $\mathrm{r}=0.35$ ) in a narrow band around the approximate sea ice edge, and extending south to the coastline in the area from $115-145^{\circ} \mathrm{E}$. In 
summer, the zone of positive correlation encompasses SIC from the ice edge to the coastline, but only between $140-180^{\circ} \mathrm{E}$ (reaching $\mathrm{r}=0.42$ ).
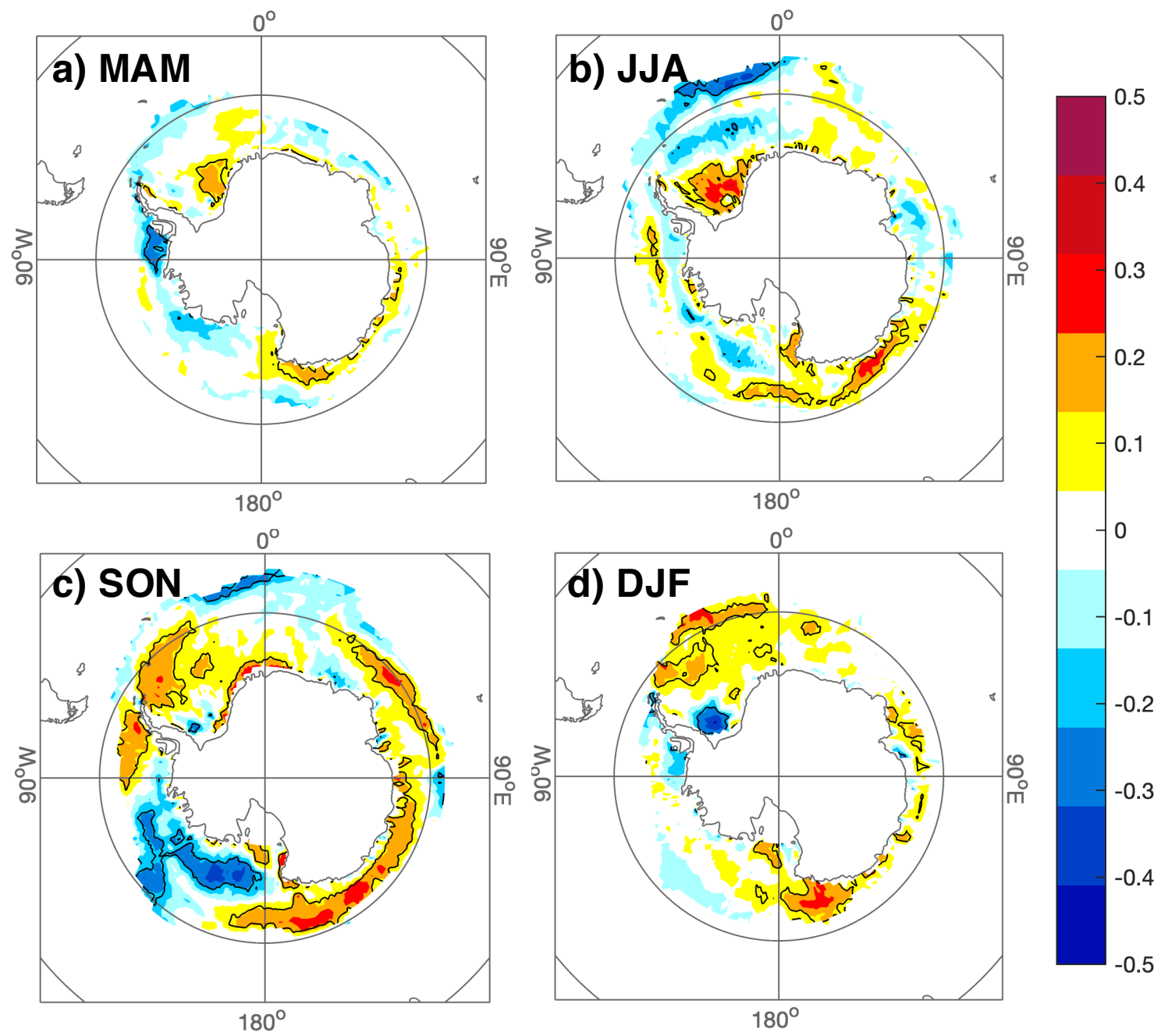

Fig. 3.4 Correlation between the DMI IOD index and HadISST seasonal sea ice concentration anomalies around Antarctica, in MAM (a), JJA (b), SON (c), and DJF (d), over the period 1979-2018. Areas outlined in black are statistically significant at the $5 \%$ level.

SIC that showed significant correlation with the IOD index in each season, also showed evidence of a teleconnection to the equatorial Indian Ocean when correlated against gridded H500 and SST fields (Figure 3.5). In austral spring and summer (Figures 3.5b \& 3.5c), SIC that was positively correlated with the IOD index was also positively and significantly correlated (reaching $\mathrm{r}=0.5$ ) with SST anomalies around the equator in the Indian Ocean (between $10^{\circ} \mathrm{N}$ and $10{ }^{\circ} \mathrm{S}$ ), while in winter this correlation shifted south to the region between $20-30^{\circ} \mathrm{S}$ (Figure 3.5a). In winter and spring, IOD-correlated SIC was also correlated 
30 I SAM and IOD influence sea ice variability around Western Pacific sector of East Antarctica

with two negative H500 anomalies, the first centred in the southern Indian Ocean (between $30-60^{\circ} \mathrm{S}$ ), and the second centred directly to the east of the SIC-IOD correlation, either just north of the Ross Sea $\left(180^{\circ} \mathrm{E}\right)$ in SON, or at the coast of George V Land at around $150^{\circ} \mathrm{E}$ in JJA (Figures 3.5b \& 3.5a, respectively).

Within Wilkes Land, Figure 3.6 shows that the IOD index is associated with increased meridional wind north of the coast between $110-150^{\circ} \mathrm{E}$ in JJA, $130-180^{\circ} \mathrm{E}$ in $\mathrm{SON}$, and $90-140^{\circ} \mathrm{E}$ in DJF. The IOD index was also associated with northward heat flux anomalies (reaching $\mathrm{r}=0.4$ ) and negative $2 \mathrm{~m}$ air temperature (T2M) anomalies (reaching $\mathrm{r}=-0.4$ ) in the same regions in SON and DJF.

Sea ice around the George V Land area was also associated with variability in the SAM index, although the correlation between the two was positive during summer and autumn, but negative during winter and spring. Figure 3.7 (b,c) shows that in winter and spring, a moderate negative correlation exists between the SAM index and SIC in the sectors between $145-165^{\circ} \mathrm{E}$ (correlation coefficient between -0.2 and $-0.4, \mathrm{p}<0.05$ ) beginning slightly offshore and extending to the approximate ice edge. In summer and autumn, the sign of the correlation in this same area shifts to weakly positive (coefficient reaches 0.2 in autumn and 0.25 in summer, $\mathrm{p}<0.05)$, and extends slightly to include the area directly adjacent to the coastline (Figure 3.7a,d).

The association between the SAM index and SIC around the Western Pacific sector appeared to be the product of broader links between the SAM and regional circulation and climate. Figure 3.8 shows the correlation between the SAM index in each season and T2M, sea ice motion, NthHF, and 10m wind over the Western Pacific sector from 90-180 E. In winter and spring (Figures $3.8 \mathrm{c} \& 3.8 \mathrm{e}$ ), the SAM index is correlated with strong positive T2M anomalies $(r=0.6)$ over the same area in which SAM was negatively correlated with SIC in Figure $3.7(b, c)$. In summer and autumn (when the SAM is positively correlated with to SIC), the SAM is either only weakly correlated with positive T2M anomalies in this region (MAM; Figure 3.8a), or is correlated with negative T2M anomalies (DJF; Figure 3.8d). In winter and spring, SAM is correlated with either westward or southwestward sea ice motion in this same region, where summer and autumn show much weaker associations with sea ice motion. Figures $3.8 \mathrm{~b}, \mathrm{~d}$,f,h show that the SAM is associated with increased northwesterly winds over the WPS in all seasons, and with anomalous southward heat flux in all seasons but summer, in the area between $120^{\circ} \mathrm{E}$ and $160^{\circ} \mathrm{E}$.

The relationship between the IOD and the SAM was examined here, on the basis that the two modes were both associated with sea ice in the same regions of the WPS and in the same seasons (Figure 3.10). While correlation analysis between the two modes yielded 

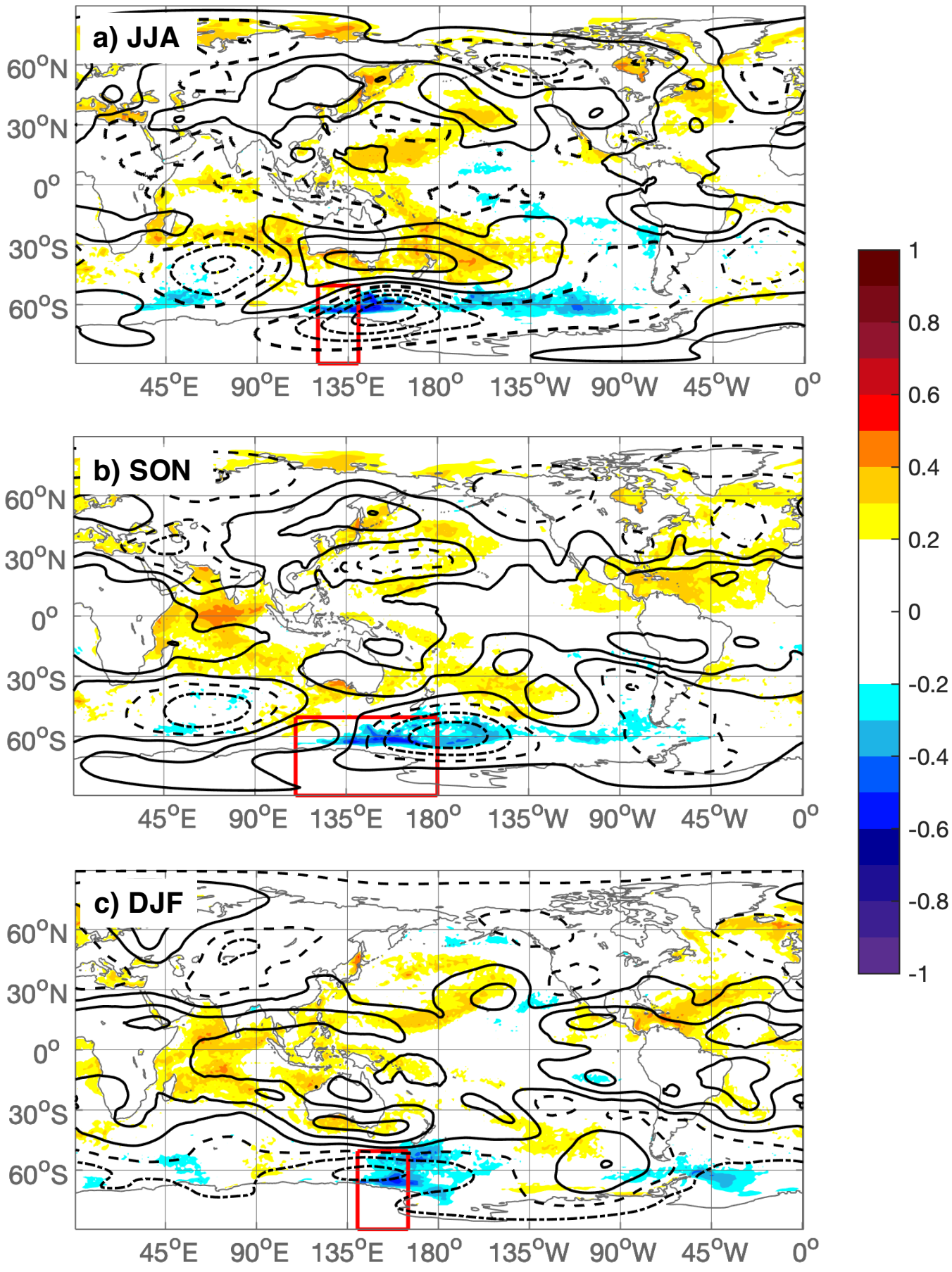

Fig. 3.5 Correlation between average SIC in IOD-correlated sectors, with ERA5 sea surface temperature (coloured shading) and 500hPa geopotential height (contour lines with an interval of 0.1 , where solid lines denote a positive correlation, dash-dot lines denote a negative, and dashed line indicates zero contour) anomalies in JJA (a), SON (b), and DJF (c). The areas over which SIC is averaged for each season $\left(120-140^{\circ} \mathrm{E}\right.$ in JJA, $110-180^{\circ} \mathrm{E}$ in SON, and $140-165^{\circ} \mathrm{E}$ in DJF) are outlined in red, and were determined from initial correlation analysis between SIC and the DMI IOD index. 
32 I SAM and IOD influence sea ice variability around Western Pacific sector of East Antarctica
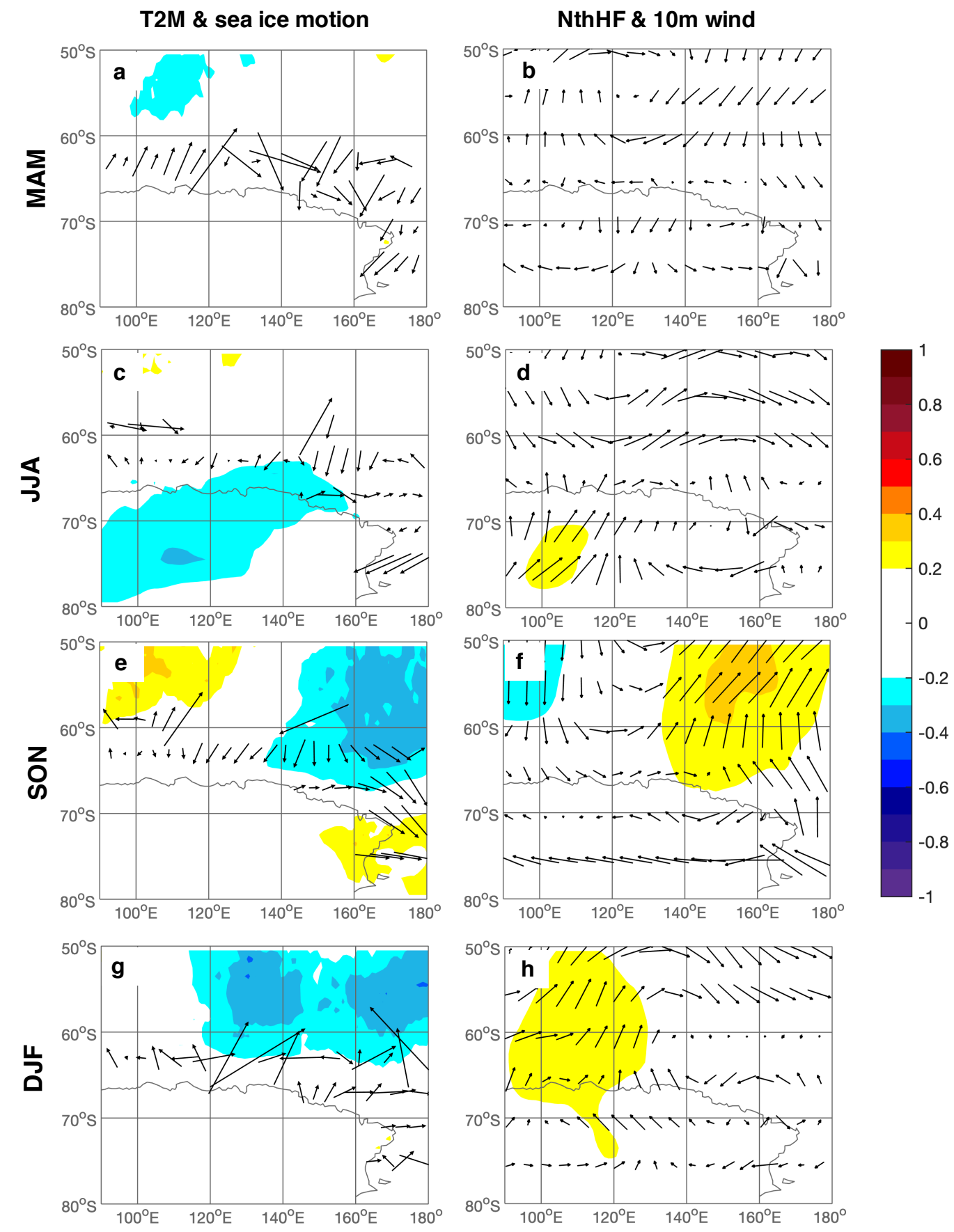

Fig. 3.6 Correlation between DMI IOD index with ERA5 2m air temperature (T2M) and NSIDC sea ice motion in MAM (a), JJA (c), SON (e), and DJF (g), and with ERA5 mean northward heat flux and 10m wind direction in MAM (b), JJA (d), SON (f), and DJF (h). Coloured shading shows coefficients for correlation with T2M in first column and NthHF in second column, while vectors show correlation coefficients for sea ice motion in first column, and $10 \mathrm{~m}$ wind direction in second column. 

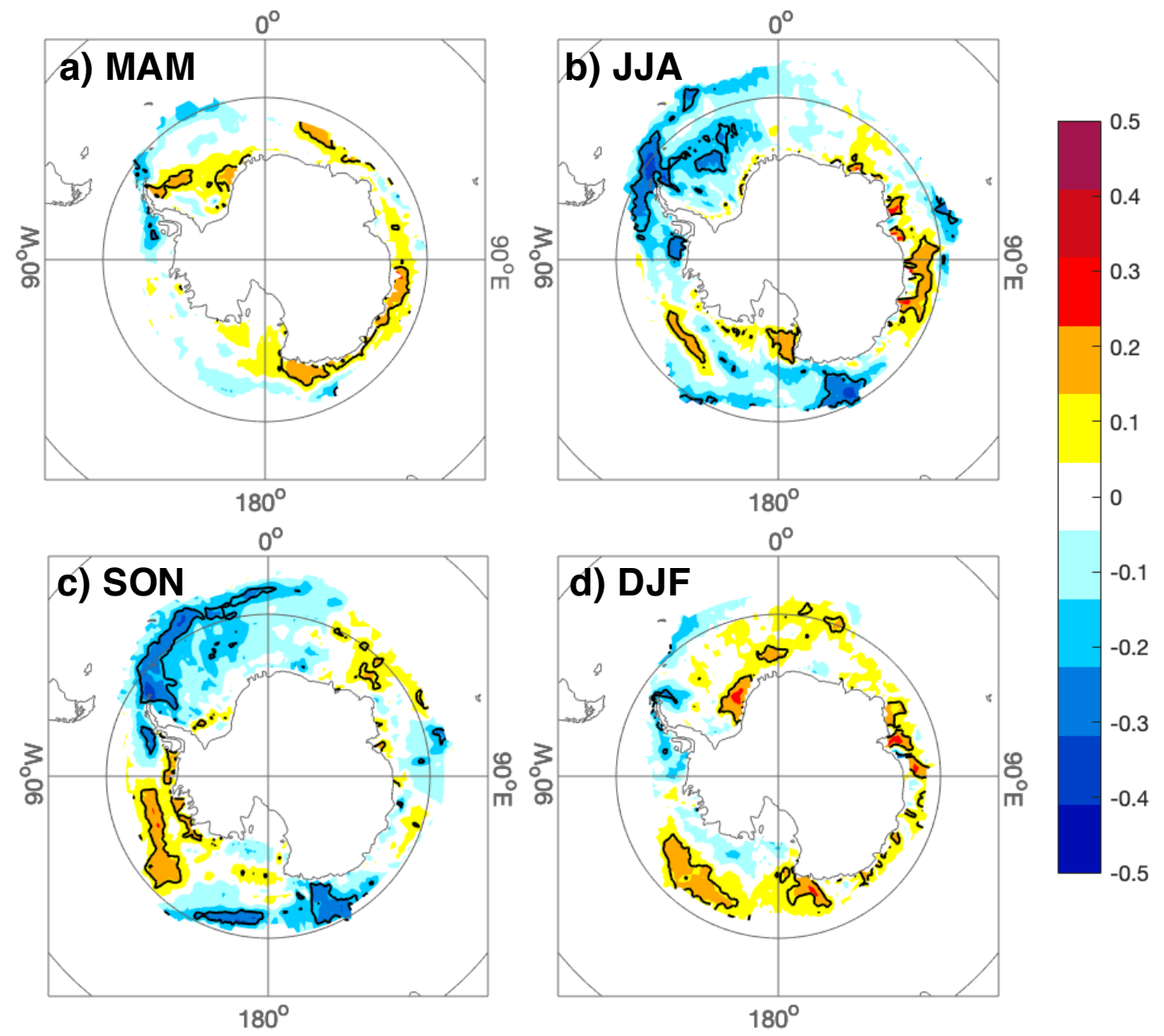

Fig. 3.7 Correlation between the Marshall SAM index and HadISST seasonal sea ice concentration anomalies around Antarctica, in MAM (a), JJA (b), SON (c), and DJF (d), over the period 1979-2018. Areas outlined in black are statistically significant at the $5 \%$ level. 
34 I SAM and IOD influence sea ice variability around Western Pacific sector of East Antarctica
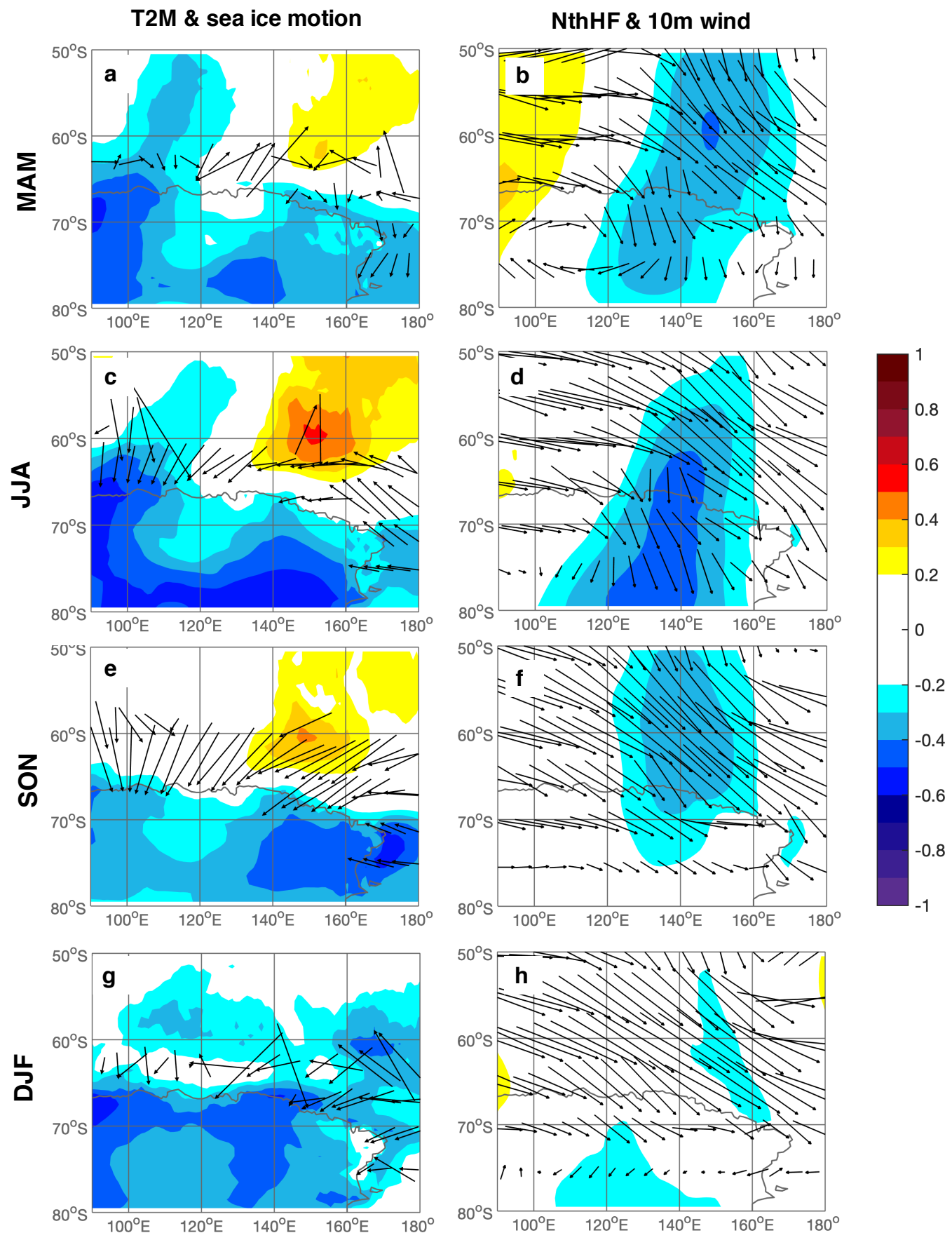

Fig. 3.8 Correlation between Marshall SAM index with ERA5 2m air temperature (T2M) and NSIDC sea ice motion in MAM (a), JJA (c), SON (e), and DJF (g), and with ERA5 mean northward heat flux and 10m wind direction in MAM (b), JJA (d), SON (f), and DJF (h). Coloured shading shows coefficients for correlation with T2M in first column and NthHF in second column, while vectors show correlation coefficients for sea ice motion in first column, and 10m wind direction in second column. 


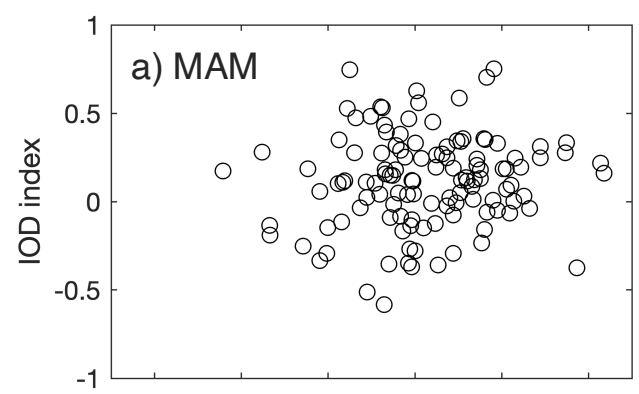

b) JJA
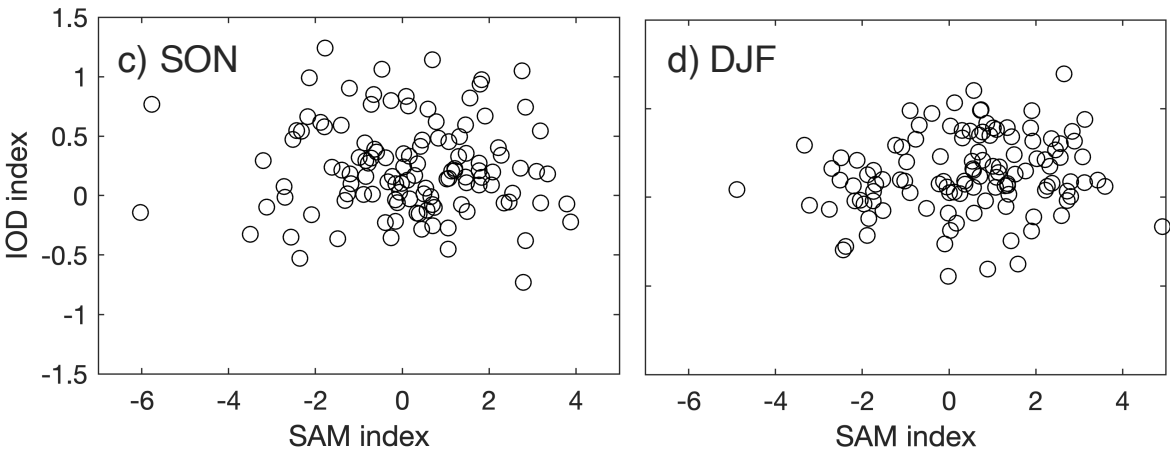

Fig. 3.9 Scatterplots showing seasonal average DMI IOD index plotted against seasonal average Marshall SAM index for the period 1979-2018. Seasons are MAM (a), JJA (b), SON (c) and DJF (d).

no statistically significant relationship (Figure 3.9), composite analysis showed different responses within the sea ice depending on the combination of different SAM and IOD phases. Figure 3.10 shows that sea ice anomalies around the WPS in winter and spring are strongest when the modes are out of phase (i.e. +SAM/-IOD and vice versa), while the anomalies in summer and autumn are strongest when the modes are in phase (i.e. +SAM/+IOD and vice versa). In each of these cases the anomalies are stronger than when SAM or IOD are considered alone, though it must be noted that the sample size for the each of the joint composites was substantially smaller (19) than the single mode composites (105).

One final point of interest was that in instances where the combination of mode phases is associated with opposing responses in the sea ice around Wilkes Land, the sea ice anomalies that are visible are more in line with the IOD-associated response. In spring, for example, an -IOD phase is associated with negative SIC anomalies in Wilkes Land (Figure 3.4), while a -SAM phase is associated with positive SIC anomalies in the same region (Figure 3.7), however when both these phases occur together (as in Figure 3.10) we only see negative sea ice anomalies. 
36 I SAM and IOD influence sea ice variability around Western Pacific sector of East Antarctica
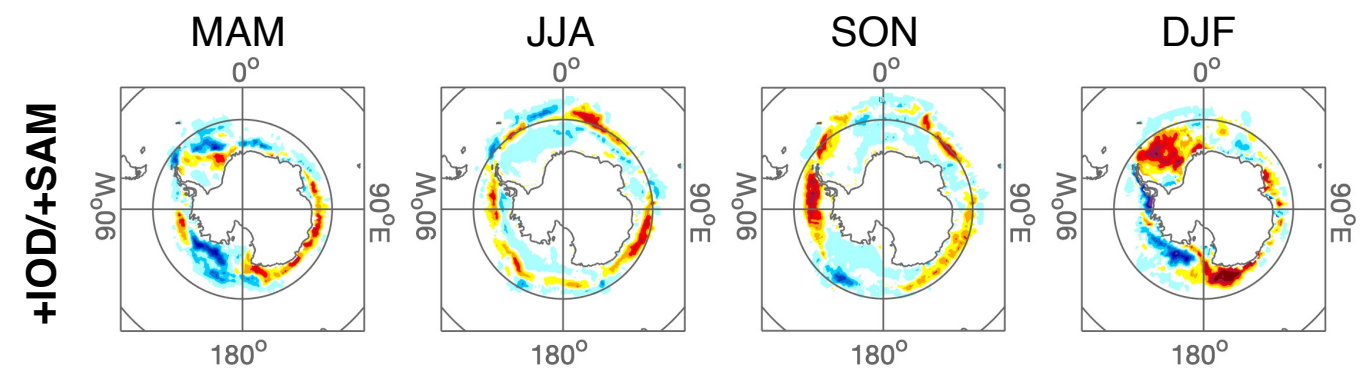

$\bar{Z}$
0
$\frac{1}{D}$
0
$m$
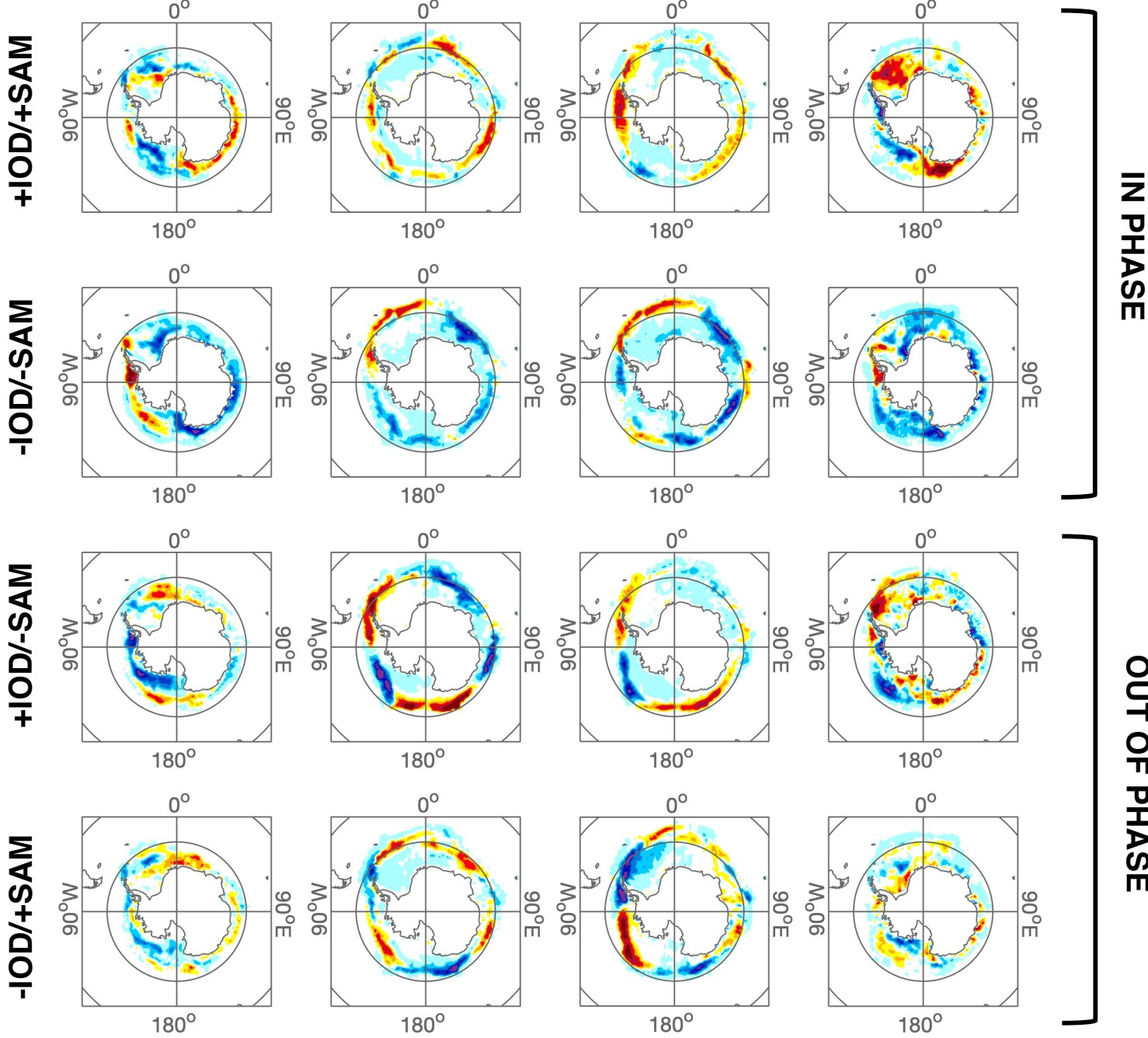

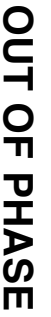

Fig. 3.10 Composite seasonal HadISST sea ice concentration anomalies around Antarctica during each possible combination of positive (+) and negative (-) SAM and IOD phases, averaged over the period 1979-2018. Each composite has between 12-26 members.

\subsection{Discussion}

The results presented in this chapter highlight a link between sea ice concentration around the Western Pacific sector of East Antarctica, and large-scale atmospheric forcing connected to the IOD and the SAM. Here I discuss the coupling between sea ice and atmosphere in the WPS, and consider the possible pathways and mechanisms linking sea ice in this region to variability in the polar and extra-polar atmosphere. I first consider the positive correlation between the IOD and sea ice in winter, spring, and summer, and the processes and 
mechanisms linking Wilkes Land to the tropical Indian Ocean. I then explore the relationship between the SAM and sea ice in the George V Land sector, with particular attention given to the seasonal shift in the sign of the correlation. Finally, I will consider whether the SAM and the IOD interact with one another to affect change in East Antarctica.

\subsubsection{IOD influence on SIC}

As described in section 3.2, correlation analysis shows that SIC around Wilkes Land is significantly and positively correlated with the DMI IOD index in winter, spring, and summer, and weakly correlated around George V Land in autumn. The correlation is strongest and most extensive during austral spring (Figure 3.2c), limited to a narrow band around the ice edge during winter (Figure 3.2b), and concentrated in the area around George V Land during summer and weakly in autumn (Figure 3.2d,a). The spring component of these results are in agreement with Nuncio and Yuan (2015) who found a positive correlation when they examined the relationship between the DMI IOD index and spring sea ice concentration in a similar area around Wilkes Land. The results presented in this thesis, however, extend these findings to include a relationship between the IOD and SIC in both winter and summer, as well as spring.

The mechanism connecting Wilkes Land with the tropical Indian Ocean in each of these seasons is similar to that suggested by Nuncio and Yuan (2015). The mechanism involves springtime IOD-associated tropical SST anomalies exciting an atmospheric wave train that propagates southward to Antarctica, altering regional circulation and climate, and inducing changes in the sea ice field around the Pacific sector of East Antarctica. Several studies have theorised the occurrence of such a wave train, and of it driving the teleconnection between the tropical Indian Ocean and the extra-tropics (e.g. Ambrizzi et al., 1995, 1998; Cai et al., 2011b; Saji and Yamagata, 2003). Studies show that SST anomalies associated with the IOD trigger convective heating anomalies over the equatorial Indian Ocean, driving upper level atmospheric divergence and the poleward propagation of a Rossby wave train (e.g. Ambrizzi et al., 1995, 1998; Cai et al., 2011b; Saji and Yamagata, 2003). By perturbing mean regional circulation, this wave train explains SST and precipitation anomalies over southern Australia, and alongside the findings of Nuncio and Yuan (2015), has been linked various aspects of the sea ice system in Antarctica (Meehl et al., 2019; Purich and England, 2019; Wang et al., 2019).

The results in this study fit with the theory outlined in Nuncio and Yuan (2015), and suggest that this wave train may also operate during austral winter and summer. In winter, 
38 I SAM and IOD influence sea ice variability around Western Pacific sector of East Antarctica

spring and summer, Figure 3.5 shows that SIC in the zones that are correlated with the IOD are also correlated with warm SST anomalies in the western equatorial Indian Ocean (although these occur 20 degrees south of the equator in winter). SIC in this zone is also correlated with an alternating pattern of high and low pressure anomalies linking Wilkes Land to the southern Indian Ocean (Figure 3.5). This suggests that variability in Indian Ocean SST may trigger an atmospheric wave train response, which then affects regional atmospheric circulation around East Antarctica.

Wilkes Land sits at the meeting point of two of these pressure anomalies, with anomalously low pressure to its east during a positive IOD event, and anomalously high pressure to its west (e.g. Figure 3.5b). This would act to enhance southerly winds over Wilkes Land during a positive IOD, and enhance northerly winds during a negative IOD. Figure 3.6 supports the idea that the IOD is associated with changes in meridional winds around Wilkes Land, showing that in the seasons where the IOD is correlated with Wilkes Land SIC (i.e. JJA, SON and DJF), the IOD is also associated with anomalous meridional winds (namely an increase in southerly winds during a positive IOD phase, when SIC is high, and vice versa).

Evidence in Figure 3.6 suggests that in JJA, SON, and DJF, the enhancement of meridional winds by the IOD may then drive changes in northward heat transport and local air temperature, which in turn affect sea ice growth and decay, and therefore sea ice concentration. This is particularly visible in Figure 3.6c-h, which shows that positive IOD phases are associated with negative air temperature anomalies off the coast of Wilkes Land, along with southward heat transport anomalies.

\subsubsection{SAM influence on SIC}

A statistically significant correlation is evident between the SAM index and sea ice concentration in parts of the WPS. For the most part, this correlation is positive, however around

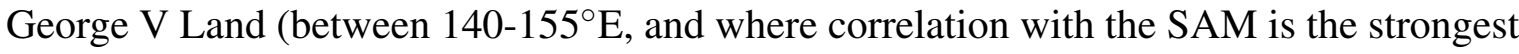
and most extensive) it changes from positive during summer and autumn, to negative in winter and spring.

The positive correlation between the SAM and sea ice around the WPS in autumn and summer is in line with studies such as Hall and Visbeck (2002), Sen Gupta and England (2006), Purich et al. (2016), and Doddridge and Marshall (2017) who suggest that at a broad scale the SAM can drive an increase in sea ice concentration during its positive phases, by increasing northward transport of ice and colder surface water. However, this theory conflicts 
with the finding in this thesis that sea ice around George V Land that shifts and experiences a negative correlation with the SAM during winter and spring (Figure 3.2).

The switch from positive to negative correlation around George V Land over JJA and SON observed in Figure 3.7 could be related to the non-annular component of the SAM; namely its relationship with the ASL. The ASL, as discussed in detail in Chapter 1, is deepened during positive SAM phases and weakened during negative phases, which has flow on effects for the surrounding sea ice field. The position of George $V$ Land in relation to the average location of the ASL (i.e. to its west), means that it could be affected by the meridional flow associated with the western side of the ASL. This would result in increased southerly winds (and so increased SIC) over George V Land when the ASL deepens during a positive SAM event, and reduced southerly winds (reduced SIC) when the ASL weakens during a negative SAM event. However, during austral winter and spring, the average location of the ASL shifts eastward, and consequently drives an eastward shift in the location of its associated sea ice anomalies (Simpkins et al., 2012). The eastward shift could result in reduced meridional flow over George V Land, reducing sea ice concentration during a positive SAM event rather than increasing it, and explaining the shift from positive to negative SAM correlation in the results discussed here.

This theory, while plausible, does not fit with the patterns of $10 \mathrm{~m}$ wind and northward heat flux that are correlated with the SAM in Figure 3.8. Neither $10 \mathrm{~m}$ wind direction nor northward heat flux show significant differences in their correlation with the SAM in winter/spring vs summer/autumn; in all cases the SAM is correlated with northwesterly winds over the WPS, and a moderate correlation with southward heat flux over the coast between $120-160^{\circ}$ E. If the seasonal shift in position of the ASL were responsible for the change in sign in the SAM/SIC correlation, we would expect to see seasonal changes in the meridional wind and heat flux fields, but this is not the case.

Another explanation for this seasonal switch may lie in the SAM's relationship to polynyas around George V Land, and subsequent influence on sea ice. Polynyas are stretches of open water surrounded by a body of sea ice, with rates of sea ice formation up to 10 times higher than in the surrounding sea ice zone (Zwally et al., 1985). Antarctic coastal polynyas often form as a result of forcing by katabatic winds, which act to constantly advect sea ice away from the coast and expose open ocean, encouraging the formation of new sea ice (Barber and Massom, 2007; Maqueda et al., 2004). Around East Antarctica, and particularly around Wilkes Land/George V Land, high rates of sea ice production are driven by a number of large and intense wind-driven polynyas (Campagne et al., 2015; Massom et al., 2013; Tamura et al., 2008). 
40 I SAM and IOD influence sea ice variability around Western Pacific sector of East Antarctica

The SAM is known to affect katabatic winds around Antarctica, whereby the intensification of the polar vortex during a positive SAM phase serves to isolate the continent and reduce northward katabatic airflow, while in a negative phase the opposite occurs, with weaker circumpolar westerly winds allowing more intense katabatic flow (Marshall et al., 2013; Van Den Broeke and Van Lipzig, 2004). Of particular relevance to the location of the strong seasonally-variable SAM correlation in the results $\left(140-155^{\circ} \mathrm{E}\right)$, SAM variability has been directly linked to sea ice production in the Mertz Glacier Polynya, located in this same region, offshore from the Mertz Glacier in George V Land (Campagne et al., 2015).

This offers a potential explanation for the negative winter/spring correlation with SAM around George V Land presented in Figure 3.7. During winter and spring the sea ice edge migrates northward (Figure 3.3), expanding the total sea ice area. As the edge of the sea ice zone is where it is most sensitive to atmospheric and oceanic forcing (Stroeve et al., 2016), its expansion northward means that a greater proportion of the total sea ice zone is made up of more stable interior pack ice. During this time the sea ice production in the Mertz polynya would offer one of the only sources of sea ice variability south of the sea ice edge, and so would be an important control on sea ice concentration for the broader region. SAM-associated alteration to katabatic wind-flow during these seasons would therefore be reflected in sea ice variability via its influence on polynya size and variability. During the MAM and DJF, when the sea ice extent is at its minimum (Figure 3.3), polynya sea ice productivity would play a less important role in driving sea ice variability.

The possibility that the SAM is linked to sea ice around George V Land differently in winter and spring due to its influence on polynya activity is consistent with the results from this study in Figure 3.8. Figure 3.8 shows that the main differentiating features between the summer/autumn and winter/spring correlations between the SAM and key climate variables, are within the air temperature and sea ice motion fields. In winter/spring, the SAM is correlated with consistent southwest sea ice motion anomalies around the coast of George $\mathrm{V}$ Land along with positive T2M anomalies centred between $140-160^{\circ} \mathrm{E}$, and around $60^{\circ} \mathrm{S}$, directly north of the Mertz Glacier Polynya (Figure 3.8c,e). In summer/autumn, however, the SAM is correlated with weaker sea ice motion in more variable directions, and to weaker positive or strong negative T2M anomalies (Figure 3.8a,g). These shifts occur despite no significant change in the $10 \mathrm{~m}$ wind or northward heat flux fields between seasons (Figures $3.8 b, d, f, h)$.

These results could suggest that in winter/spring, when the sea ice is at its maximum, the strengthening of katabatic winds associated with a negative SAM phase drive increased northward sea ice transport. Coupled with the associated increased sea ice productivity of the 
Mertz Glacier Polynya, this results in anomalously high sea ice concentration in the region north of the Mertz Glacier Polynya. The anomalously high SIC then drives anomalously low temperatures in the same region, due to the cooling effect that sea ice can has on local air temperatures (e.g. Kumar et al., 2010; Screen and Simmonds, 2010; Serreze et al., 2009). During summer/autumn when the sea ice extent is much smaller and the Mertz Glacier Polynya plays a less important role in determining broader sea ice variability, the same changes in atmospheric circulation do not induce the same response from the sea ice and air temperature fields.

\subsubsection{SAM/IOD interaction}

The fact that sea ice around Wilkes Land correlates with both the SAM and the IOD (Figures $3.4 \& 3.7$ ), and both were strongest in winter and spring, prompted questions around whether the impact of each mode was influenced by the other. This analysis yielded no statistically significant correlation between indices of the two modes in any season. This supports the findings of studies such as Cai et al. (2011a) and Purich and England (2019), who despite suggestions that the SAM may force the IOD (Lau and Nath, 2004; Meehl et al., 2019), found no significant links between the two modes.

Composite analysis (Figure 3.10) of average SIC for periods with each combination of mode phases (i.e. $+\mathrm{SAM} /+\mathrm{IOD},+\mathrm{SAM} /$-IOD etc), however, showed that the response of SIC to each phase of one mode was altered depending on the phases of the other, despite the two modes varying independently. In winter and spring, SIC anomalies in the WPS were strongest when the two modes were out of phase with each other (i.e. when +IOD coincided with -SAM and vice versa), while summer and autumn saw stronger SIC anomalies when the modes were in phase with one another (i.e. +IOD with +SAM). This agrees with the results of the correlation analysis in Figures 3.4 and 3.7, which indicated that SIC in Wilkes Land would increase as the IOD index increased and the SAM index decreased. Most interestingly, in cases where the phase of the IOD and SAM would elicit opposite responses in the sea ice (i.e. when + SAM and +IOD occur together in SON or JJA), the composite analysis yielded anomaly patterns most similar to those associated with the IOD. These findings imply that the influence exerted by the IOD on SIC in Wilkes land is perhaps stronger than that exerted by the SAM. 
42 I SAM and IOD influence sea ice variability around Western Pacific sector of East Antarctica

\subsection{Conclusions}

This study of sea ice concentration over the 40 year period between 1979-2018 reveals that sea ice variability in the Western Pacific sector of East Antarctica is influenced by both polar and tropical climate variability, in the form of the SAM and the IOD. This chapter shows that sea ice around Wilkes Land is correlated with the IOD and teleconnected to the equatorial Indian Ocean in winter, spring and summer. Further correlation analysis showed that the IOD is associated with anomalous meridional winds over Wilkes Land, and accompanying northward heat flux and air temperature anomalies, which likely drive changes in the sea ice. Correlation between Wilkes Land sea ice and SST in the equatorial Indian Ocean, and with a sequence of H500 pressure anomalies extending from Wilkes Land to the southern Indian Ocean, support the theory that IOD-associated tropical SST anomalies drive a Rossby wave train that propagates southward, altering regional circulation over Wilkes Land. These findings suggest that the IOD influence on Antarctic sea ice is not limited to austral spring as previously thought, but also extends to winter and summer.

This chapter documented a strong correlation between sea ice around George V Land and the SAM that switched from positive in summer/autumn to negative in winter/spring. Correlation analysis suggested that the SAM may affect sea ice in this region through its influence on wind-driven coastal polynyas such as the Mertz Glacier Polynya. A negative SAM phase is associated with increased katabatic wind strength at the coast, which then enhances polynya sea ice productivity, and northward advection of sea ice, with the opposite occurring during a positive SAM. In winter/spring during the sea ice maximum (when sea ice concentration experiences less overall change), polynya-associated sea ice production would provide an important source of variability in sea ice concentration for the broader region. During summer and autumn, when sea ice in the WPS reaches its minimum and the marginal ice zone almost reaches the coastline, polynya-driven sea ice variability would play a less important role in driving sea ice concentration.

In this chapter, I demonstrated that the SIC in the WPS responds differently to each of the two climate modes dependent on the phase of the other. In particular, I found that the impact of the IOD on SIC appeared to be stronger than that of the SAM on SIC, as a combination of IOD/SAM phases that would elucidate opposite responses in the sea ice tended to result in anomalies closer to those expected from the IOD phase. To my knowledge, this possibility has not been addressed in other research, and provides an interesting avenue for future work.

Each of these findings highlight the significant connection between sea ice in the WPS and Southern Hemisphere atmospheric variability. Given the possibility that the SAM may 
be trending toward a higher occurrence of positive events, the correlation between SAM and SIC here could suggest that we may see less sea ice around George V Land in the future. Considering the role that sea ice plays in the stability of ice shelves and outlet glaciers in the Western Pacific region, and the increasing vulnerability of the East Antarctic Ice Sheet in this region to climate change, more research on these relationships is needed. 



\section{Chapter 4}

\section{ENSO modulates summer and autumn sea ice variability around Dronning Maud Land}

This chapter has been published prior to submission as:

Isaacs, F.E., Renwick, J.A., Mackintosh, A.N., and Dadic, R. (2021). ENSO modulates summer and autumn sea ice variability around Dronning Maud Land, Antarctica. Journal of Geophysical Research: Atmospheres, doi: 10.1029/2020JD033140

Author contributions: F Isaacs performed the analysis and wrote the manuscript. $\mathbf{J}$ Renwick, A Mackintosh, and R Dadic advised on the analysis and contributed to the editing and refining of the text.

\subsection{Introduction}

Antarctic sea ice is an important component of the global climate system, modulating global circulation through changes to heat and moisture fluxes (Grotzner et al., 1996; Rind et al., 1995; Walsh, 1983), surface albedo (Curry et al., 1995), and production of deep ocean waters (Ferrari et al., 2014; Jacobs, 2004). Changes in sea ice distribution therefore have far-reaching consequences, and are critically important to understand in the context of broader earthatmosphere system change. However, coupled sea-ice-climate models are currently unable to replicate current sea ice trends and variability in the Southern Ocean, predicting a negative trend where observations show a positive one (e.g. Comiso and Nishio, 2008; Polvani and 
Smith, 2013; Turner et al., 2013c), highlighting the limitations in our understanding of the processes that drive sea ice change.

Several studies have suggested that climate variability and tropical teleconnections such as those associated with El Niño Southern Oscillation (ENSO) may play a role in determining recent sea ice variability and trends (e.g. Meehl et al., 2016; Purich et al., 2016; Raphael and Hobbs, 2014; Simmonds and Jacka, 1995; Simpkins et al., 2012; Yuan and Li, 2008). ENSO is a pattern of large-scale atmospheric and oceanic variability manifesting most prominently in a dipole in tropical Pacific SST anomalies and the perturbation of tropical convection. Changes in the tropical atmospheric circulation then propagate further into the global circulation, driving variability in precipitation (e.g. Barlow et al., 2001; Dai and Wigley, 2000; Ropelewski and Halpert, 1986), air temperatures (e.g. Power et al., 1999; PozoVazquez et al., 2001; Smith and Sardeshmukh, 2000), local winds (e.g. Romero-Centeno et al., 2003) and storm activity (e.g. Camargo and Sobel, 2005; Wang and Chan, 2002).

The influence of ENSO extends to Antarctica, affecting regional circulation (e.g. Bromwich et al., 2004; Harangozo, 2004; Schneider et al., 2012; Turner, 2004), air temperature (e.g. Ding and Steig, 2013; Ding et al., 2011; Kwok and Comiso, 2002), and precipitation (e.g. Bromwich et al., 2000; Cullather et al., 1996; Genthon and Cosme, 2003; Noone et al., 1999). The influence of ENSO is shown to affect sea ice formation, melt, and transport, leading to some covariability between ENSO and sea ice concentration (Kwok and Comiso, 2002; Liu et al., 2002; Renwick, 2002; Yuan, 2004). This signal has been identified in sea ice around West Antarctica, most prominently in the Ross, Bellingshausen, Amundsen, and Weddell Seas (e.g. Kwok et al., 2016; Simmonds and Jacka, 1995; Simpkins et al., 2012; Yuan and Li, 2008).

In East Antarctica, an ENSO signal has been identified in other components of the climate and cryosphere, including ice sheet accumulation (Boening et al., 2012), precipitation (Schlosser et al., 2010), air temperature (Schneider et al., 2012; Welhouse et al., 2016) and landfast ice (Aoki, 2017). Raphael and Hobbs (2014) and Stammerjohn et al. (2008) examined the broad links between climate variability and the sea ice advance and retreat cycle, which included sea ice averaged across East Antarctica. However there has been little direct research into the role that ENSO and other large-scale modes of climate variability play in influencing sea ice concentration (SIC) around East Antarctica.

Our research aim was to bridge this gap by investigating the role of ENSO in influencing the past four decades of sea ice variability around East Antarctica. We approached this by correlating the satellite sea ice record with atmospheric reanalysis data over 1979-2018 and the Niño 3.4 ENSO index, and with composite analysis of atmospheric circulation during 


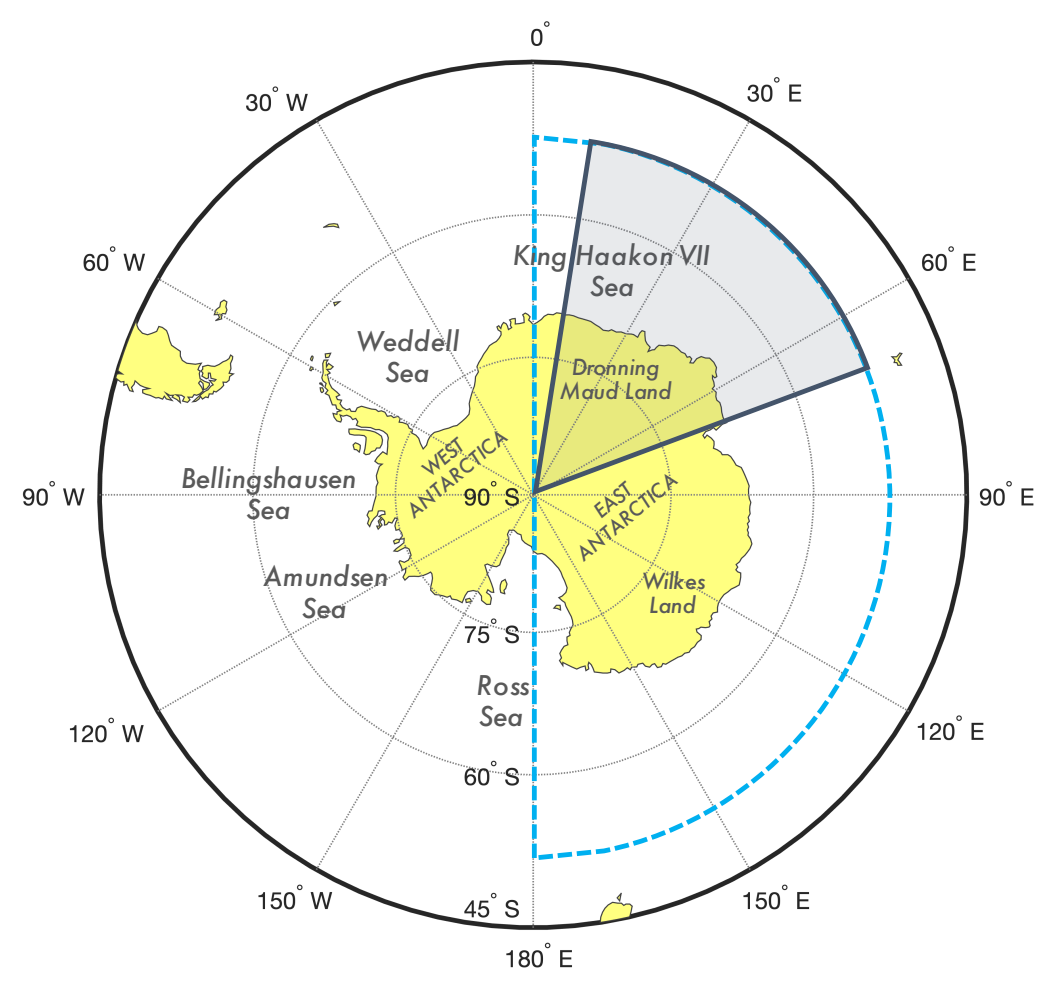

Fig. 4.1 Map of the study area including key locations discussed in this chapter (Chapter 4), and with the Dronning Maud Land/ Enderby Land sector of interest (south of $50^{\circ} \mathrm{S}$ and between $10^{\circ} \mathrm{E}$ and $70^{\circ} \mathrm{E}$ ) shaded in grey. Blue dashed line encloses the broader East Antarctic sea ice area examined.

periods of high and low SIC. Our study focused on the region south of $50^{\circ} \mathrm{S}$ and between $10^{\circ} \mathrm{E}$ and $70^{\circ} \mathrm{E}$, encompassing part of Dronning Maud Land (DML) and Enderby Land (Figure 4.1a).

\subsection{Results}

\subsubsection{Sea ice correlation with Niño 3.4 index}

Correlation analysis showed that the most significant association between the Niño 3.4 index and SIC around East Antarctica occurred in the region of Dronning Maud Land and Enderby Land between $10^{\circ} \mathrm{E}$ and $70^{\circ} \mathrm{E}$ (Figure 4.2). In this region, Niño 3.4 and both summer (DJF) and autumn (MAM) SIC were moderately and negatively correlated (on average $r=-0.25$ in DJF and $\mathrm{r}=-0.38$ in MAM, $\mathrm{p}<0.05)$. The correlation was strongest in autumn, reaching a peak of -0.38 at around $55^{\circ} \mathrm{E}$ (Figure 4.2). Other weak but statistically significant correlations between Niño 3.4 and SIC occurred in isolated regions along the rest of the East Antarctic 


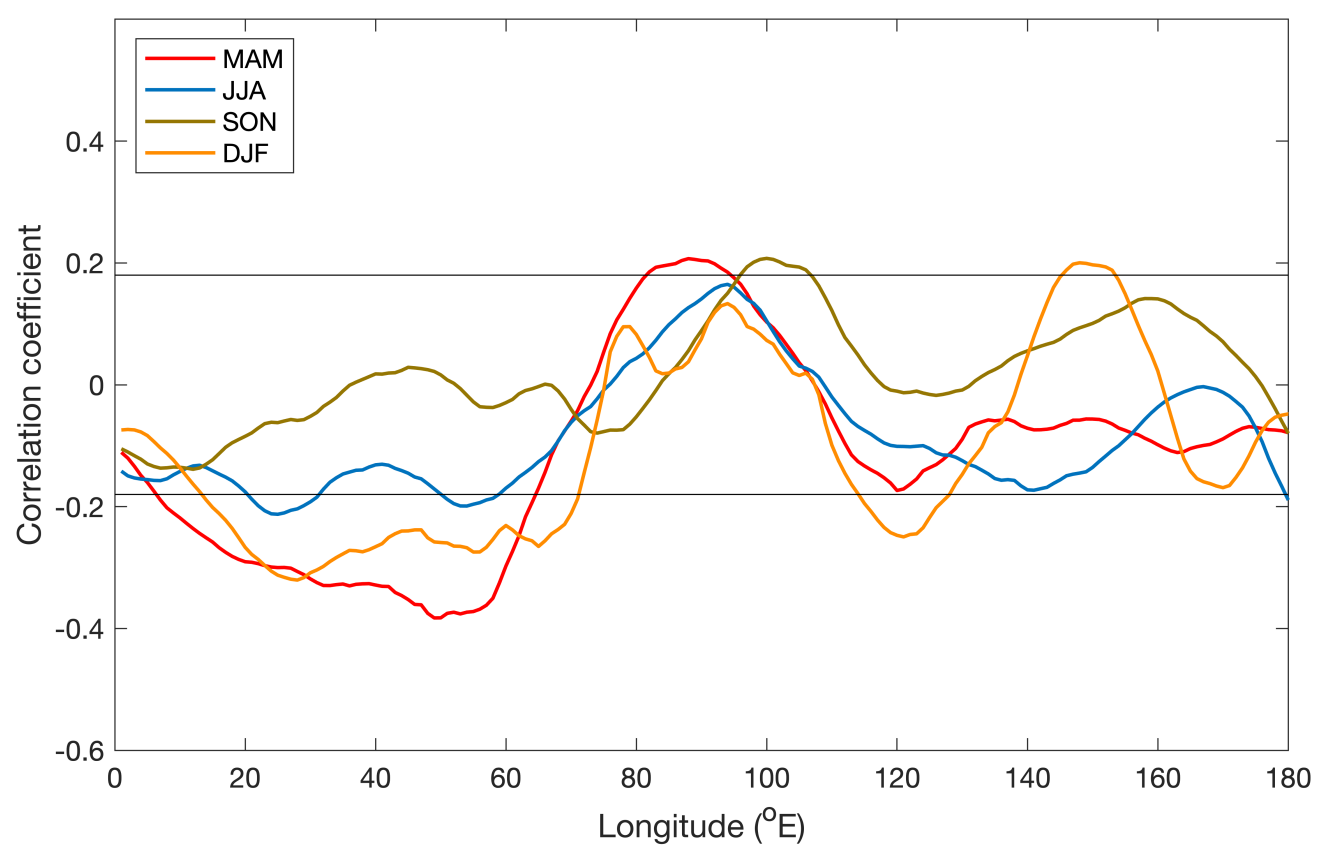

Fig. 4.2 Correlation between Niño 3.4 index and average seasonal sea ice concentration in latitudes south of $50^{\circ} \mathrm{S}$, and in $10^{\circ}$ sliding sectors of longitude (each data point marks the start of a sector) between $0-180^{\circ} \mathrm{E}$ around the coast of East Antarctica over 1979-2018. Horizontal black lines mark statistical significance at the $5 \%$ level.

coastline; positive correlations with SIC around $80-95^{\circ} \mathrm{E}$ (autumn), $95-110^{\circ} \mathrm{E}$ (spring), and $145-155^{\circ} \mathrm{E}$ (summer), and a negative correlation from $110-130^{\circ} \mathrm{E}$ (summer).

\subsubsection{Sea ice correlation and composites with atmospheric reanalysis}

In the region around DML where sea ice was significantly correlated with ENSO, the sea ice zone demonstrated substantial seasonal and interannual variability. Figure 4.3 shows average seasonal SIC in the region between $0-90^{\circ}$ E over the period $1979-2018$. Sea ice concentration around the Dronning Maud Land/ Enderby Land region was highest and most spatially extensive in JJA and SON (Figure 4.3c,d), when SIC was $>0.8$ from the coastline to approximately $60^{\circ} \mathrm{S}$ and $>0.15$ (the commonly used threshold of sea ice presence/absence) to $55^{\circ} \mathrm{S}$ in some places. In contrast, sea ice concentrations were greater than 0.15 in MAM and DJF only in a narrow band around the coastline, extending northward by 1 or 2 degrees (Figure 4.3b,e). SIC in the DML region also demonstrated substantial interannual variability, as shown in Figure 4.3a. Interannual variability was strongest in JJA and SON. The strongest positive (0.09) and negative (-0.07) SIC anomalies occurred in SON, in 2011 and 1997 
respectively. In MAM and DJF (the seasons in which SIC was most strongly correlated with ENSO), interannual variability was more subdued, with the highest SIC anomaly occurring in $2011(0.05)$ and the lowest in 1987 (-0.02).

SIC in DML was also significantly correlated with aspects of both local-scale climate around DML, and larger-scale Southern Hemisphere circulation. SIC in DML was inversely correlated with localised T2M and SST in all seasons (Figures $4.4 \& 4.5$ ), and positively correlated with a pattern of H500 consistent with anomalously southerly airflow over DML in all seasons but DJF. This pattern consisted of a positive correlation with $\mathrm{H} 500$ to the west of the DML region, and an inverse correlation with H500 to the east (Figure 4.4). All correlations were strongest and most extensive in MAM (maximum correlation magnitudes of $\mathrm{r}=-0.7,0.3$, and -0.6 for T2M, H500 and SST respectively).

At a broader scale, Figures 4.4 and 4.5 also show the presence of a second centre of negative correlation between DML SIC and SST or T2M in all seasons (though strongest in autumn), centred on the opposite side of the continent to DML in the Amundsen Sea region (reaching $\mathrm{r}=0.5$ for SST and T2M). There was also a significant correlation between SIC in Dronning Maud Land and a distinct wave train in the H500 field (Figure 4.4a and 4.4b), linking DML to the Amundsen Sea during autumn and winter. This consisted of a positive correlation around $0^{\circ} \mathrm{E}$ (reaching $\mathrm{r}=0.4$ ), a negative correlation in the Amundsen Sea region (reaching $\mathrm{r}=-0.3$ ), and a positive correlation north of the Ross Sea region (reaching $r=0.3$ ). In areas where DML SIC was positively correlated with a pattern of H500 that would be conducive to equatorward air flow (i.e. high pressure to the west, low pressure to the east), SIC was also inversely correlated with air temperature (Figure 4.4), and vice versa. Figure 4.4 also shows evidence of a Southern Annular Mode (SAM)-like pattern in the H500 fields in JJA and most prominently in DJF, where SIC is inversely correlated with H500 over the continent, and positively correlated with H500 around the continent.

In addition to the correlations in the Southern Ocean, Figure 4.5 also showed a moderate inverse correlation between autumn and summer SIC in Dronning Maud Land and SST in the equatorial Pacific Ocean. The correlation was strongest and most spatially extensive in summer ( $\mathrm{r}=-0.47)$, extending across the equatorial Pacific Ocean just south of the equator, from $180^{\circ} \mathrm{E}$ to the coast of South America (Figure 4.5). In SON and JJA there was only a weak negative correlation with equatorial Pacific SST covering a much smaller region than in autumn and summer (Figure 4.5b,c).

Anomaly composites of SST during periods when sea ice concentration was in the upper or lower quartile again showed links to the equatorial Pacific Ocean (Figure 4.6), though also revealed a degree of asymmetry in this relationship. When sea ice was particularly low in 

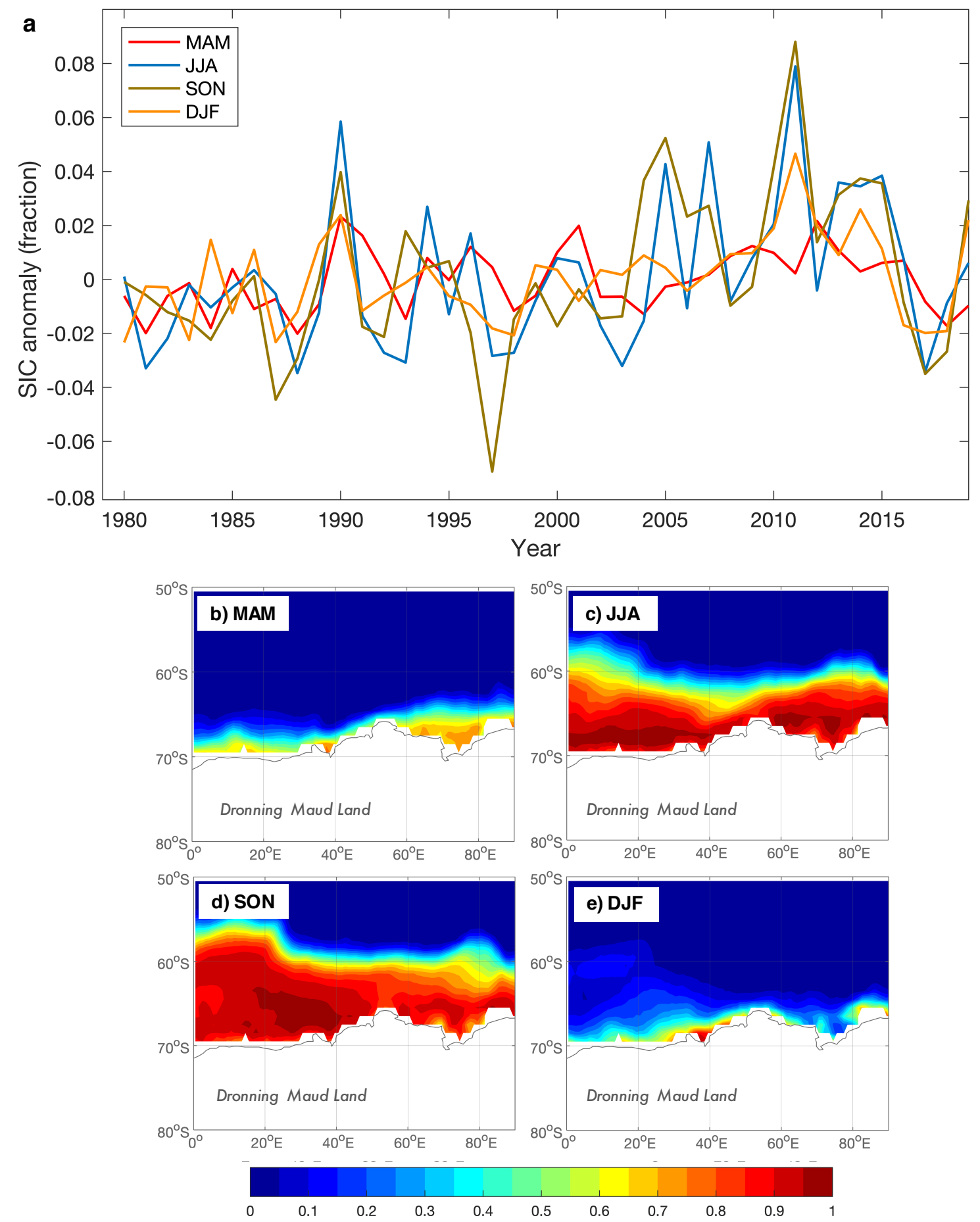

Fig. 4.3 (a) Timeseries of seasonal HadISST sea ice concentration anomaly averaged over the Dronning Maud Land/ Enderby Land sector of interest (south of $50^{\circ} \mathrm{S}$ and between 10-70 ${ }^{\circ}$ ) for the 40-year period 1979-2018; and (b-e) average seasonal HadISST sea ice concentration around the coast of Dronning Maud Land and Enderby Land, for the same time period, and where the seasons are MAM (b), JJA (c), SON (d), and DJF (e). 

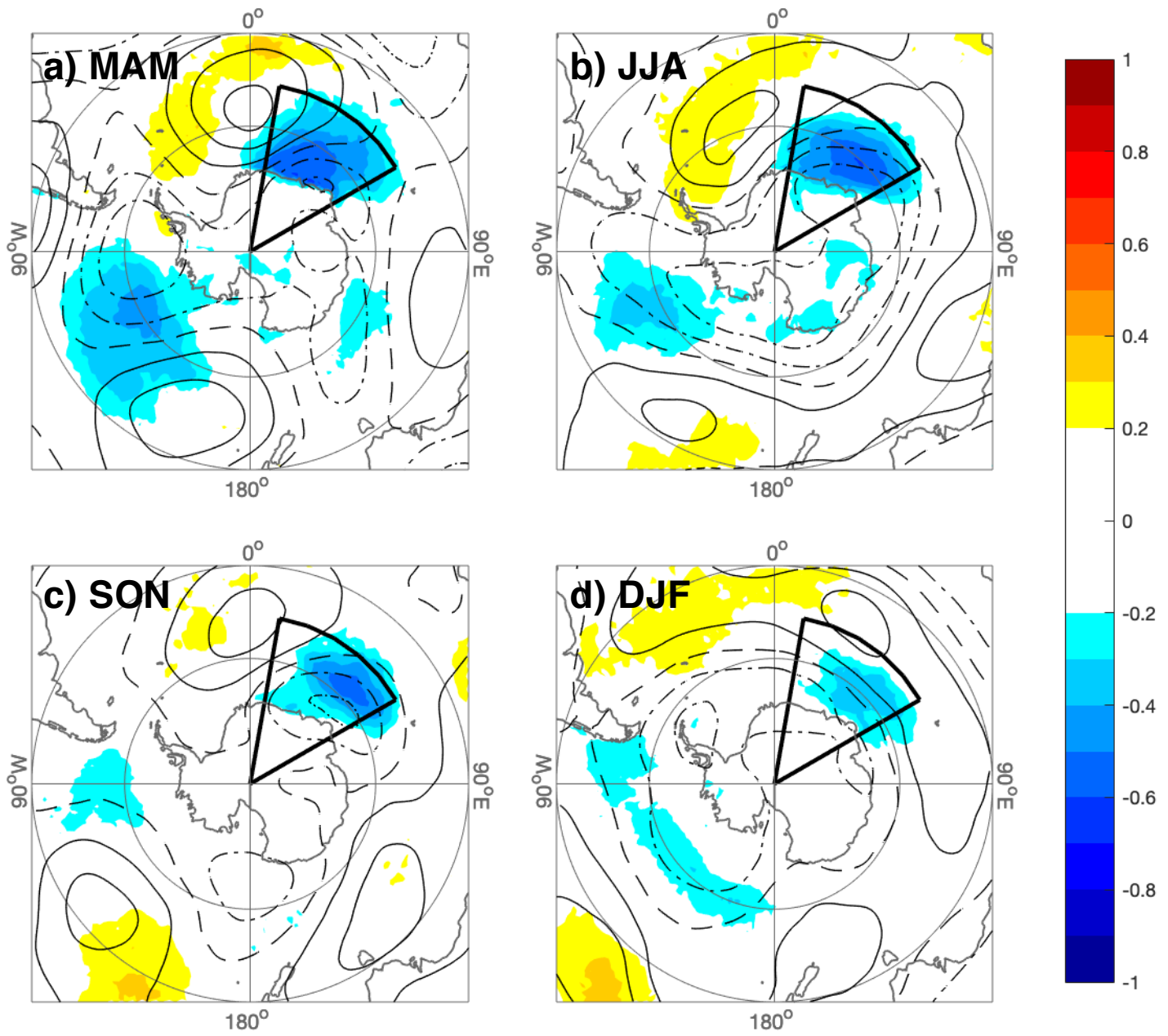

Fig. 4.4 Correlation between SIC averaged around Dronning Maud Land $\left(10^{\circ} \mathrm{E}-70^{\circ} \mathrm{E}\right.$, south of $50^{\circ} \mathrm{S}$, area outlined in black) with T2M (shading) and H500 (contour lines, where solid lines show positive correlation coefficients, dash-dot lines show negative, and dashed line indicates zero contour, all with contour intervals of 0.1) during MAM (a), JJA (b), SON (c), DJF (d). All T2M correlations shown are significant at the $5 \%$ level. 

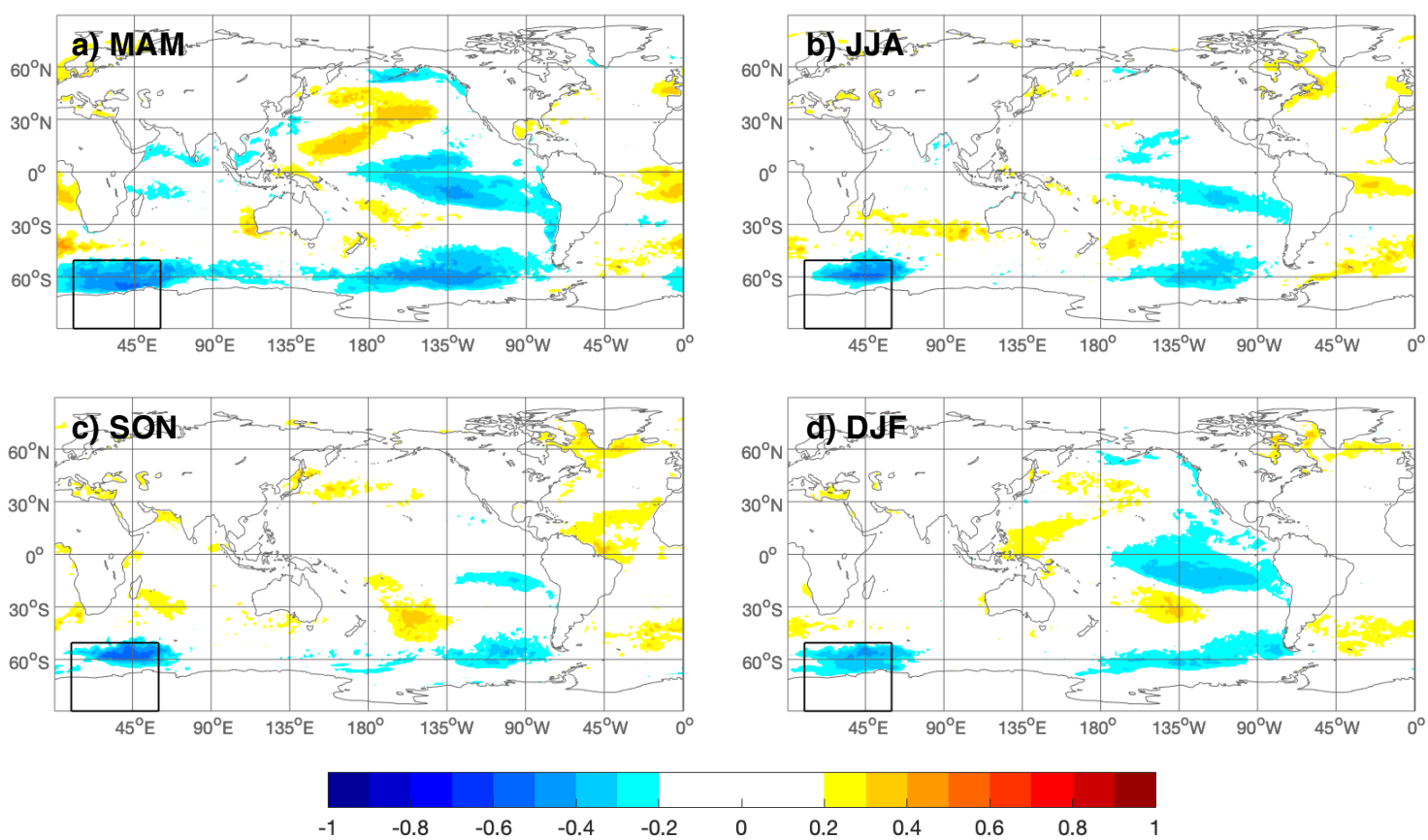

Fig. 4.5 Correlation between SIC around Dronning Maud Land $\left(10^{\circ} \mathrm{E}-70^{\circ} \mathrm{E}\right.$, south of $50^{\circ} \mathrm{S}$, area outlined in black) and SST during MAM (a), JJA (b), SON (c), DJF (d). All correlations shown are significant at the $5 \%$ level.

DML during autumn and summer, SST in the equatorial Pacific Ocean and off the coast of equatorial South America showed a positive anomaly of up to $0.6^{\circ} \mathrm{C}$ (Figure $4.6 \mathrm{~b}$ and $4.6 \mathrm{~h}$ ). While this relationship was fairly symmetrical during DJF, it was markedly asymmetrical during MAM, with SST anomalies much weaker (between 0.1 and $0.4{ }^{\circ} \mathrm{C}$ ) when SIC was in the upper quartile compared to the lower quartile. Figure 4.6 additionally showed stronger SST anomalies in all seasons in the DML and Amundsen/Bellingshausen sea regions when DML SIC was in the upper quartile compared to the lower quartile.

In Figures 4.7a and 4.6a, the anomaly composites of H500 during periods of higher than usual autumn SIC in DML showed the same wave train as is visible in the correlations in Figure 4.4 (namely a high pressure anomaly northeast of the Weddell Sea, a low pressure anomaly in the Amundsen Sea, and a high pressure anomaly north of the Ross Sea), but the composites of low SIC do so only to a much weaker extent (Figure 4.7e and 4.6b). These patterns were accompanied by anomalously high T2M over DML and over the Ross Sea $\left(+2^{\circ} \mathrm{C}\right)$ when SIC was low, and smaller negative anomalies in $\mathrm{T} 2 \mathrm{M}\left(<-1.0^{\circ} \mathrm{C}\right)$ in the Amundsen Sea, along with in DML itself $\left(-2.5^{\circ} \mathrm{C}\right)$ when SIC is high. In DJF (Figure $4.7 \mathrm{~d}$ and $4.7 \mathrm{~h}$ ), there were no substantial T2M anomalies when SIC was particularly high or low. 

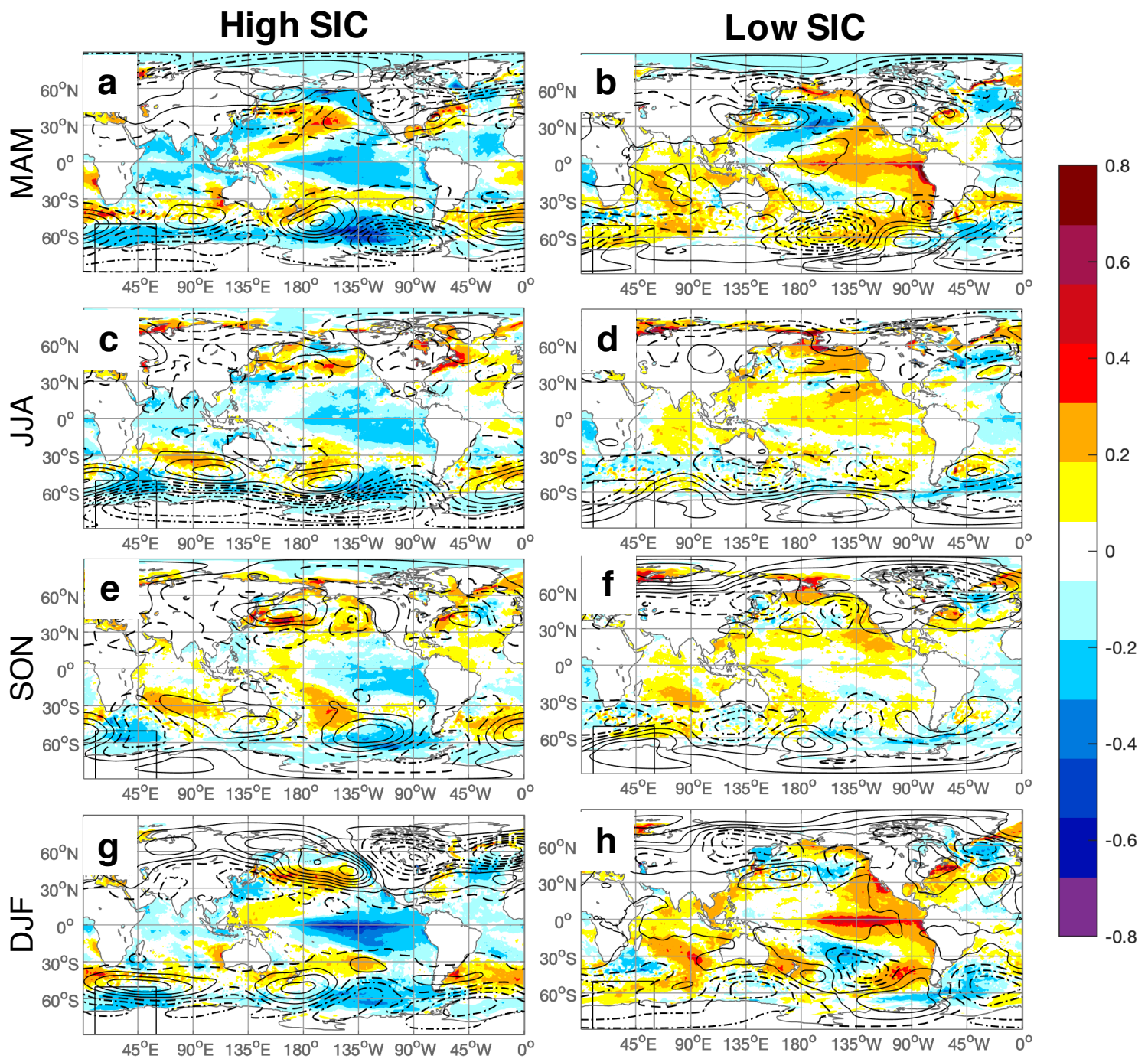

Fig. 4.6 Anomaly composite mean for the upper (High SIC) and lower (Low SIC) quartiles of SIC around Dronning Maud Land $\left(10^{\circ} \mathrm{E}-70^{\circ} \mathrm{E}\right.$, south of $50^{\circ} \mathrm{S}$, area outlined in black) over 1979-2018. Shading is sea surface temperature anomalies $\left({ }^{\circ} \mathrm{C}\right)$. Contour lines show $500 \mathrm{hPa}$ geopotential height anomalies (m) at 50m intervals. Solid contours are positive anomalies, dash-dot contours are negative. 
54 I ENSO modulates summer and autumn sea ice variability around Dronning Maud Land
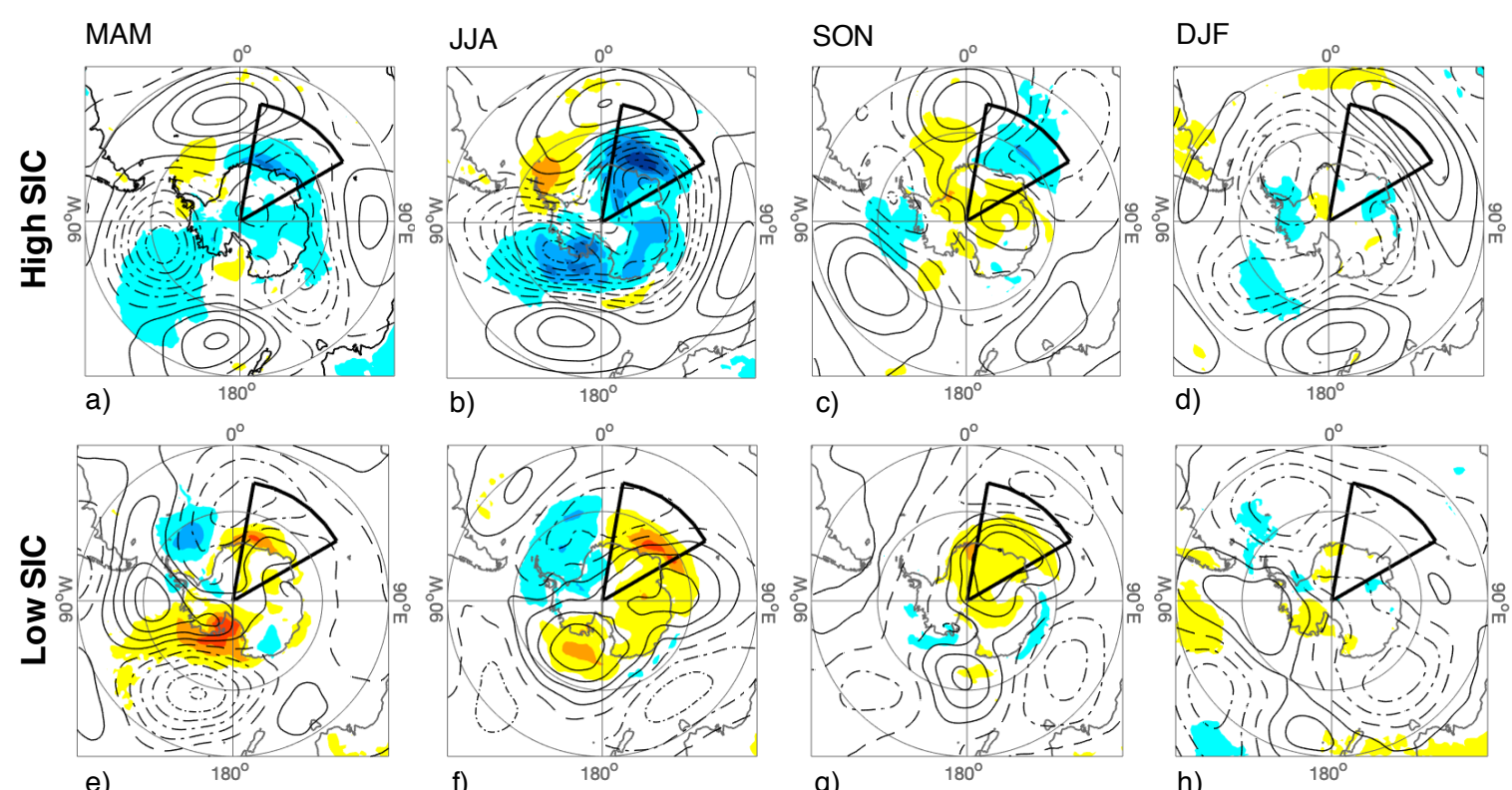

e)
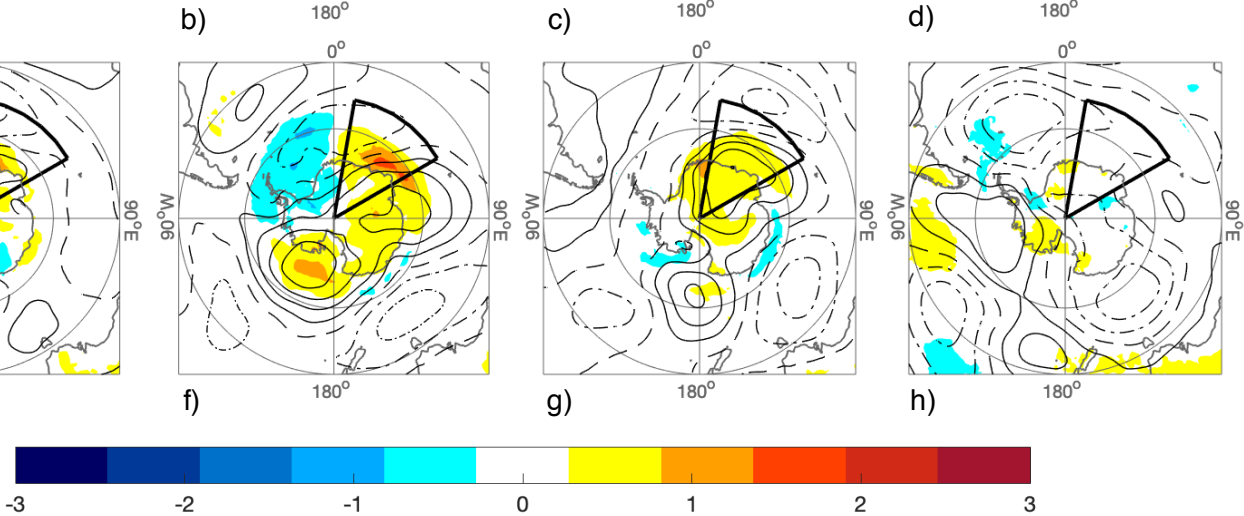

Fig. 4.7 Anomaly composite mean for the upper (High SIC) and lower (Low SIC) quartiles of SIC around Dronning Maud Land $\left(10^{\circ} \mathrm{E}-70^{\circ} \mathrm{E}\right.$, south of $50^{\circ} \mathrm{S}$, area outlined in black) over 1979-2018. Shading is $2 \mathrm{~m}$ air temperature anomalies $\left({ }^{\circ} \mathrm{C}\right)$. Solid contours are positive $500 \mathrm{hPa}$ geopotential height anomalies (m) at $50 \mathrm{~m}$ intervals, dash-dot contours are negative, dashed line indicates zero contour. 

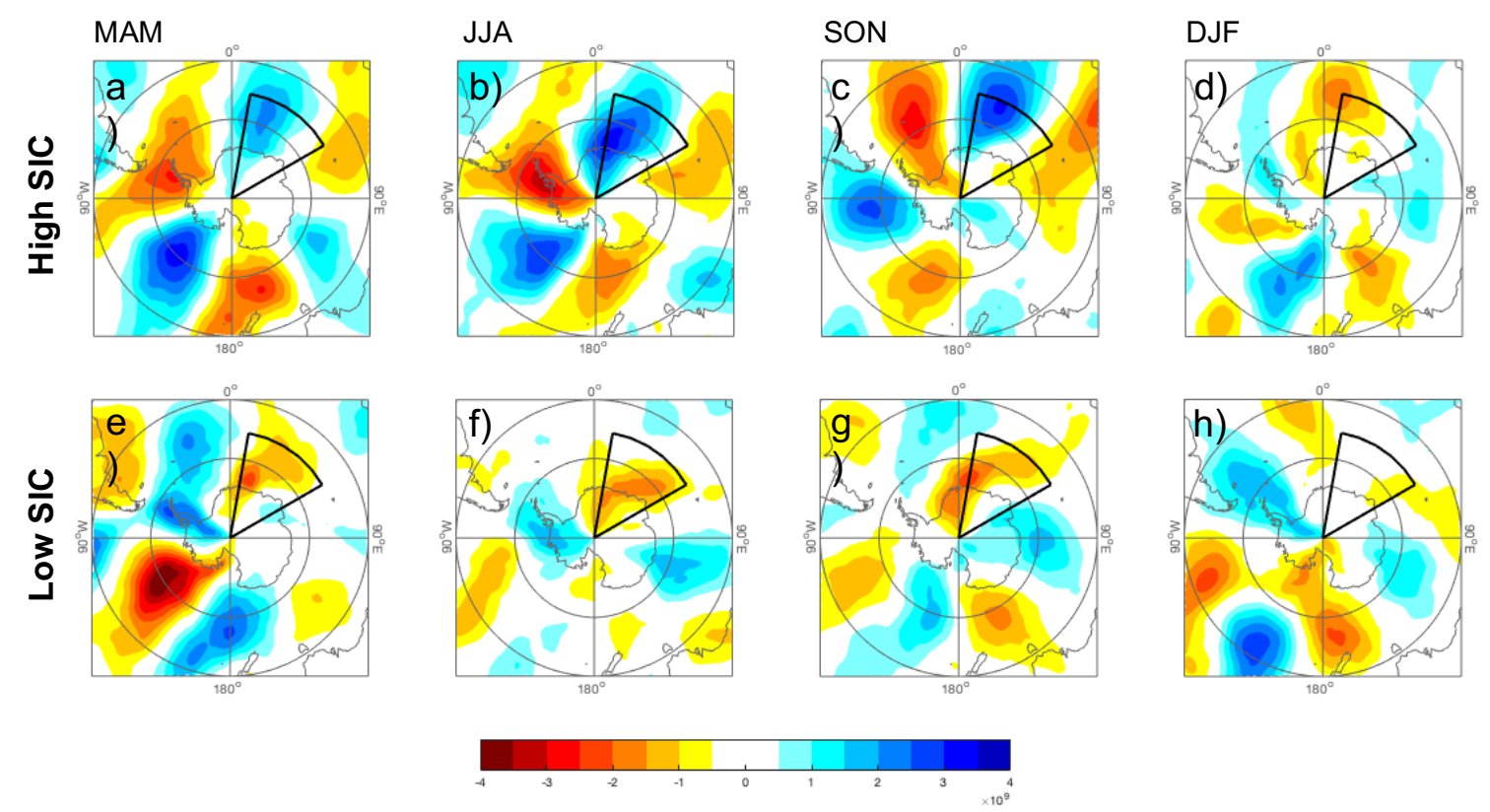

Fig. 4.8 Anomaly composite mean vertical integral of the northward heat flux $\left(\mathrm{W} \mathrm{m}^{-1}\right)$ for the upper (High SIC) and lower (Low SIC) quartiles of SIC averaged around Dronning Maud Land $\left(10^{\circ} \mathrm{E}\right.$ $70^{\circ} \mathrm{E}$, south of $50^{\circ} \mathrm{S}$, area outlined in black) over 1979-2018.

To more closely examine the mechanisms by which SIC in DML is affected by largescale climate variability, average northward heat flux and average sea ice motion during periods when sea ice in DML was in the upper and lower quartiles of concentration were also examined. Figure 4.8 (a-d) shows a strong positive northward heat flux anomaly (i.e. increased northward transport of heat) in the western half of the DML study area when SIC in DML was particularly high, in all seasons but DJF (reaching $4 \times 10^{9} \mathrm{~W} \mathrm{~m}^{-1}$ in JJA and SON, and $2.5 \times 10^{9} \mathrm{~W} \mathrm{~m}^{-1}$ in MAM). When SIC in DML was particularly low, however, the reverse of this pattern was not reflected to the same magnitude. Smaller negative northward heat flux anomalies $\left(-2.5 \times 10^{9} \mathrm{~W} \mathrm{~m}^{-1}\right.$ in MAM and SON, and $-2 \times 10^{9} \mathrm{~W} \mathrm{~m}^{-1}$ in JJA) were present in all seasons but DJF (Figure 4.8e-h), though in JJA the anomalies were present in the eastern half of the DML study area rather than the west.

Sea ice motion anomalies during periods of both high and low SIC were strongest in the western half of the DML study area, between $10-40^{\circ} \mathrm{E}$ (Figure 4.9). When SIC in DML was particularly high, sea ice motion in this zone exhibited a consistent eastward anomaly, particularly toward the outer edge of the sea ice (Figure 4.9a,c,g,e). This pattern was most prominent in JJA and SON. When SIC in DML was particularly low, ice motion anomalies were weaker, and showed greater variability in the direction of motion (Figure 4.9b,d,f,h). 
56 I ENSO modulates summer and autumn sea ice variability around Dronning Maud Land

The exception to this was in DJF, where sea ice motion was anomalously westward when SIC was low, in contrast to the anomalous eastward motion when SIC was high.

\subsubsection{Niño 3.4 correlation with atmospheric reanalysis}

In a more direct examination of the role that ENSO plays in determining SIC in DML, Figures 4.10-4.12 show the correlation between ENSO and various aspects of the regional circulation and climate around DML. Many of the patterns evident in these figures are the same as those seen in the associations between DML SIC and climate variability, particularly in the H500, SST, and T2M fields (Figures $4.5 \& 4.4$ ). In both MAM and DJF, when ENSO and SIC were most strongly linked, ENSO variability was correlated with positive T2m (Figures 4.10a \& $4.10 \mathrm{~d}$, correlation reaching $\mathrm{r}=0.47$ ) and SST (Figures $4.11 \mathrm{a} \& 4.11 \mathrm{~d}$, correlation reaching $\mathrm{r}=0.49$ ) anomalies centred between $20-50^{\circ} \mathrm{E}$, and stretching from the coastline to $50^{\circ} \mathrm{S}$. These correlations were either much weaker or not visible during JJA (Figures $4.10 \mathrm{~b} \& 4.11 \mathrm{~b}$ ) and SON (Figures 4.10c \& 4.11c), when ENSO was not significantly correlated with SIC.

In MAM ENSO was also correlated with anomalously negative H500 over the coastline to the west of DML (centred on $0^{\circ} \mathrm{E}$ ) with an accompanying positive anomaly in northerly winds when regressed against the Niño 3.4 index and negative correlation with northward heat flux on the eastern side of this system, extending across DML (Figures 4.11a \& 4.12a). In DJF this low pressure correlation was centred again over the meridian but further north than MAM, coupled with a positive correlation with H500 over the continent (Figure 4.11d). This was accompanied by increased zonal winds over the DML sea ice zone (Figure 4.12 south of $55^{\circ} \mathrm{S}$ ) when regressed against the Niño 3.4 index, more northeasterly between $30-60^{\circ} \mathrm{E}$, and more southeasterly in all other longitudes, along with significant anomalous northwestward sea ice motion off the coast of DML (Figure 4.10d). In JJA and SON, when ENSO and SIC were not significantly correlated, ENSO was associated with much weaker patterns of H500 (Figure 4.11b,c) that did not match those that were correlated with DML SIC (Figure 4.4b,c).

\subsection{Discussion}

Our results show a clear statistical link between ENSO and SIC around the coast of DML and provide new insight into the role of climate variability in determining SIC in East Antarctica. There was a significant correlation between the Niño 3.4 index and sea ice concentration between $10^{\circ} \mathrm{E}$ to $70^{\circ} \mathrm{E}$ in summer and autumn, where SIC increases during a negative ENSO 
High SIC
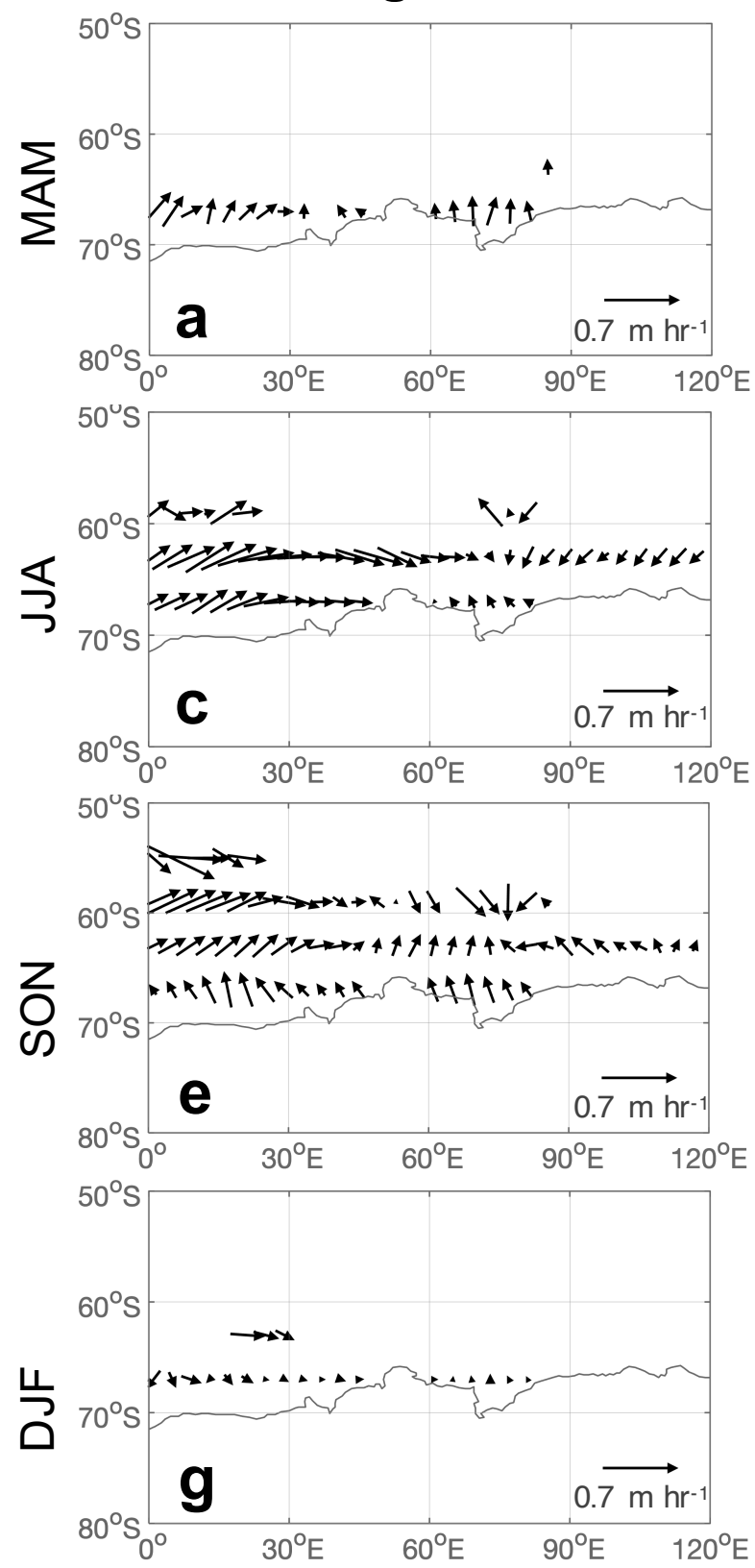

Low SIC
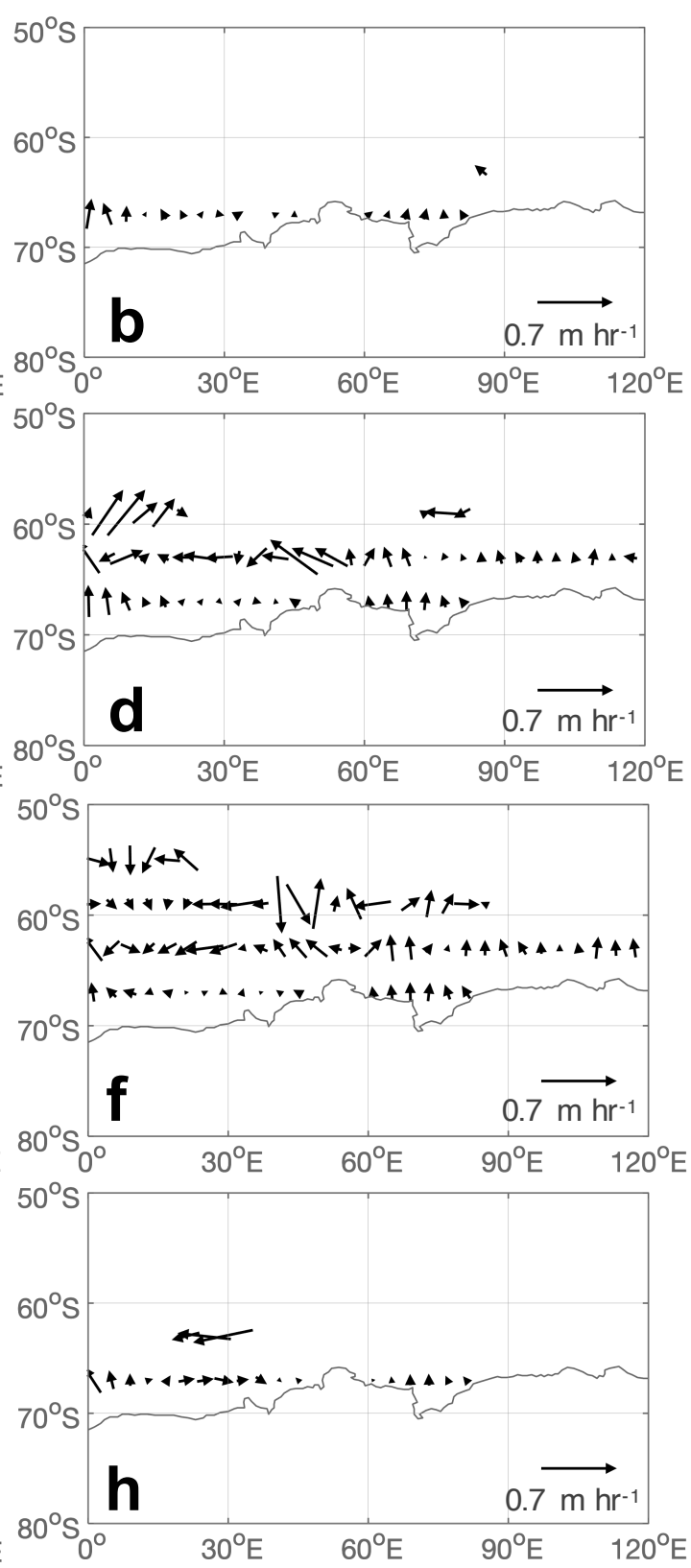

Fig. 4.9 Anomaly composite mean sea ice motion $\left(\mathrm{m} \mathrm{hr}^{-1}\right.$ ) vectors for the upper (High SIC) and lower (Low SIC) quartiles of SIC averaged around Dronning Maud Land $\left(10^{\circ} \mathrm{E}-70^{\circ} \mathrm{E}\right.$, south of $\left.50^{\circ} \mathrm{S}\right)$. Reference arrow shows a rate of $0.7 \mathrm{~m} \mathrm{hr}^{-1}$. 

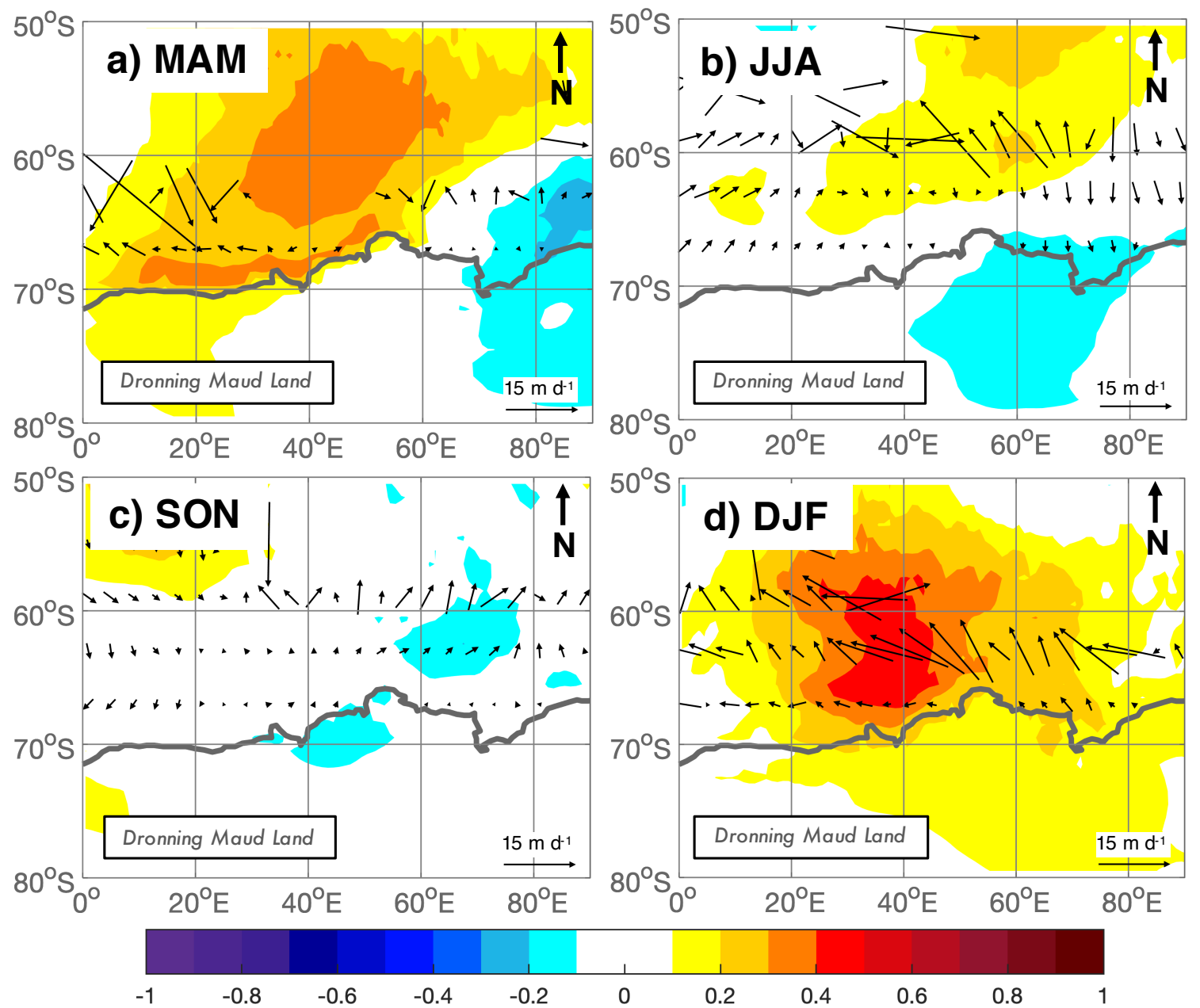

Fig. 4.10 Correlation between the Niño 3.4 index and ERA 5 monthly average $2 \mathrm{~m}$ air temperature anomalies (coloured shading), and regression of the NSIDC sea ice motion anomalies (vectors) against the Niño 3.4 index during MAM (a), JJA (b), SON (c), and DJF (d), across the Dronning Maud Land/ Enderby Land region $\left(0-90^{\circ} \mathrm{E}\right)$. Reference arrow shows a rate of $15 \mathrm{~m} \mathrm{~d}^{-1}$. 

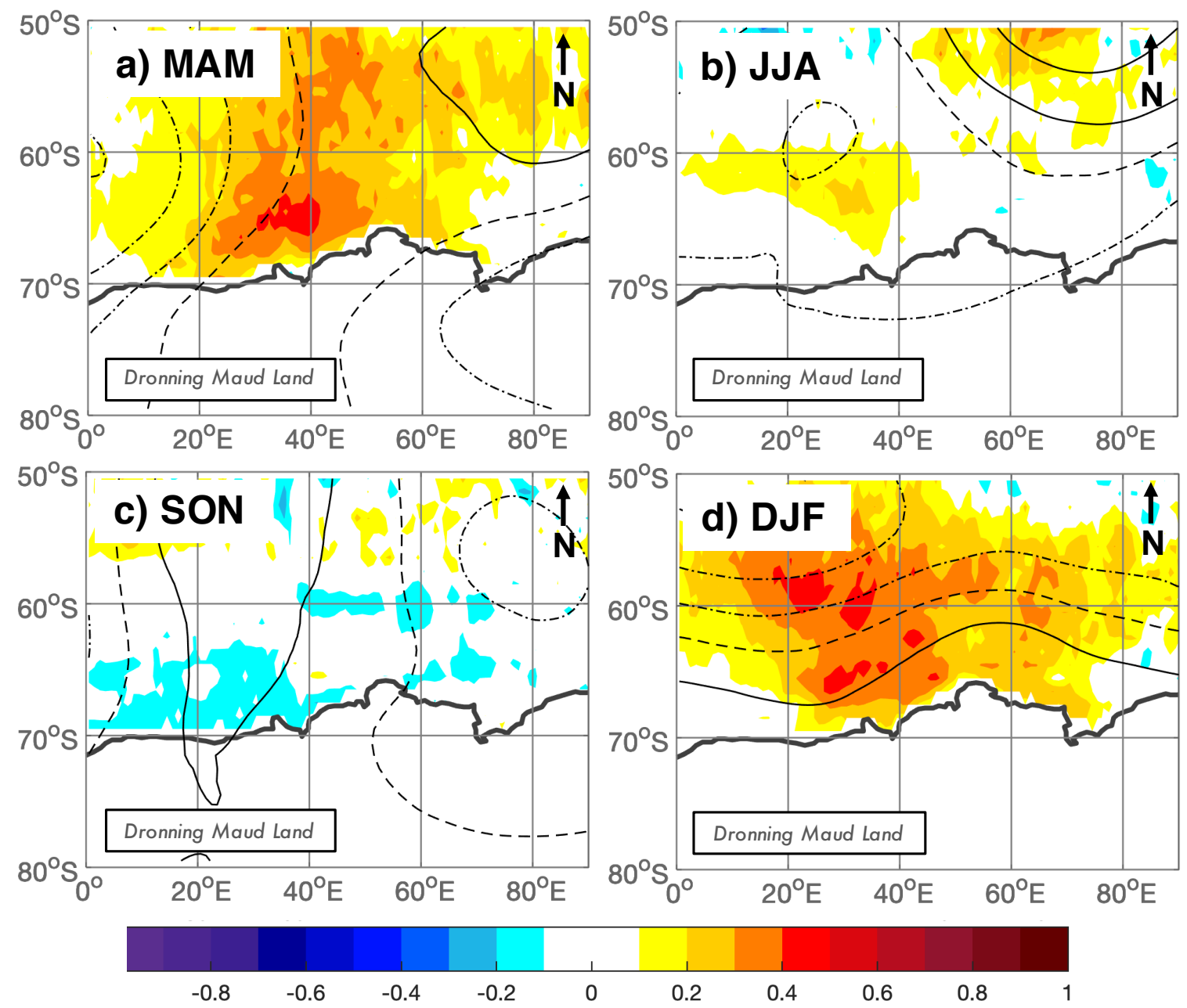

Fig. 4.11 Correlation between the Niño 3.4 index and both ERA 5 monthly average SST anomalies (coloured shading), and $500 \mathrm{hPa}$ geopotential height anomalies (contour lines, where solid lines show positive correlation coefficients, dash-dot lines show negative, and dashed lines indicate zero contour, all with contour intervals of 0.1) during MAM (a), JJA (b), SON (c), and DJF (d), across the Dronning Maud Land/ Enderby Land region $\left(0-90^{\circ} \mathrm{E}\right)$. 
60 I ENSO modulates summer and autumn sea ice variability around Dronning Maud Land
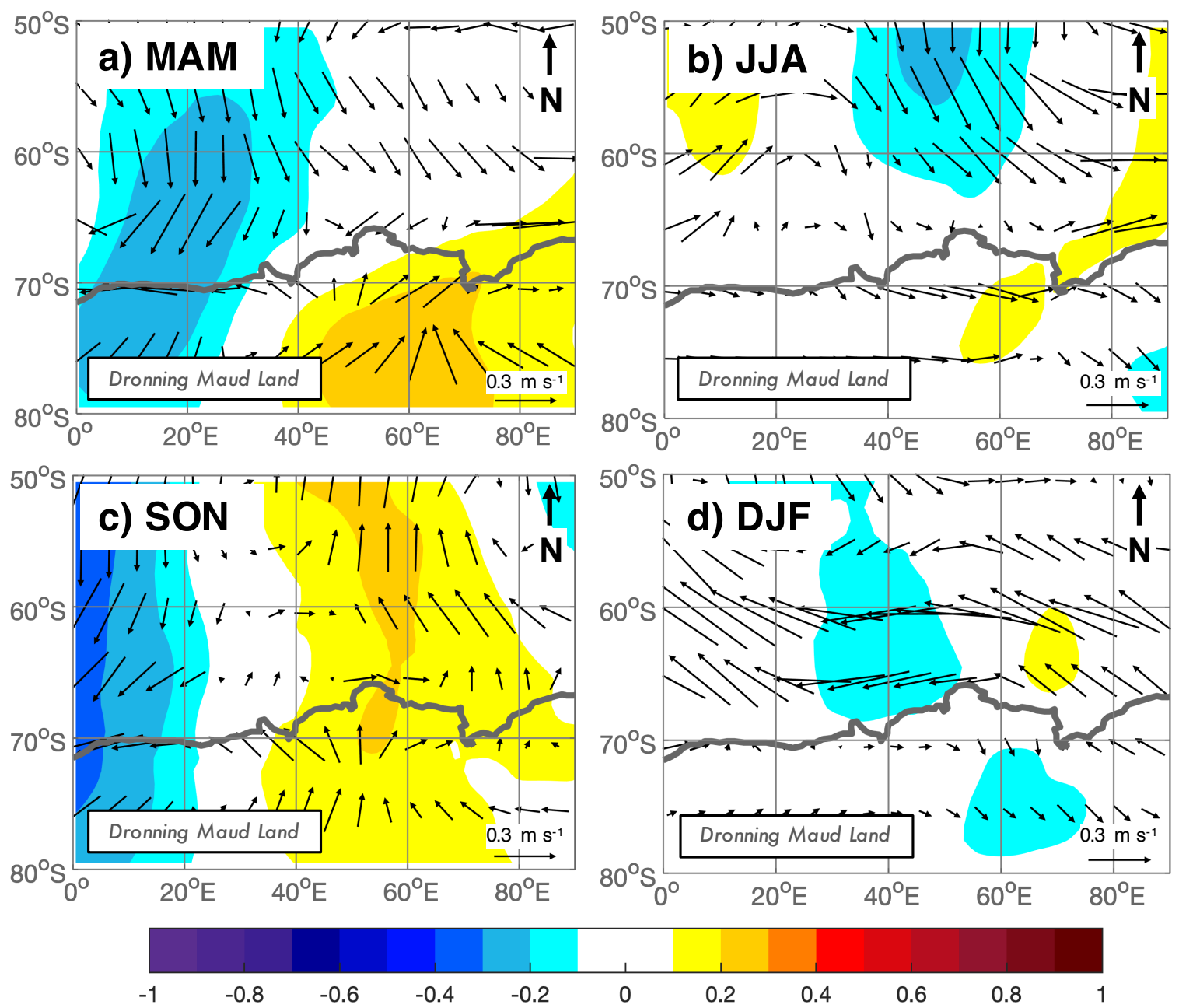

Fig. 4.12 Correlation between the Niño 3.4 index and ERA 5 vertically integrated average northward heat flux anomalies (coloured shading), and regression of $10 \mathrm{~m}$ wind anomalies (vectors) against the Niño 3.4 index during MAM (a), JJA (b), SON (c), and DJF (d), across the Dronning Maud Land/ Enderby Land region $\left(0-90^{\circ} \mathrm{E}\right)$. Reference arrow shows a rate of $0.3 \mathrm{~m} \mathrm{~s}^{-1}$. 
phase, and decreases during a positive one. Analyses of SST, T2M, and H500 fields, as discussed below, illustrate the mechanisms by which this link occurs. While past studies (e.g. Aoki, 2017; Boening et al., 2012; Noone et al., 1999) have found evidence of an ENSO signal in other aspects of the DML ice-ocean-atmosphere system, our findings extend this to include sea ice concentration, suggesting that the influence of ENSO on Antarctic sea ice is more geographically extensive than previously reported.

We suggest that ENSO exerts an influence over SIC in Dronning Maud Land through similar mechanisms as the well-established link between ENSO and sea ice in West Antarctica (e.g. in the Ross and Amundsen Seas). The West Antarctic link is driven by the perturbation of large-scale atmospheric circulation by tropical Pacific SST anomalies, and the development of a southward-propagating wave train which results in low or high pressure anomalies in the Amundsen Sea region during a La Niña or El Niñ respectively, and vice versa in the Weddell Sea (Kwok and Comiso, 2002; Yuan, 2004). These circulation changes affect local heat fluxes and advection in these regions (e.g. the Antarctic Peninsula, Amundsen/Bellingshausen Seas, and the Ross Sea), in turn influencing SIC.

We find that SIC in Dronning Maud Land was significantly correlated with SST in the Niño 3.4 region of the eastern tropical Pacific Ocean (Figure 4.5a,b,c), and similarly to a wave train in the H500 field that extends into the south Pacific sector of the Southern Ocean, and then eastward around Antarctica (Figure 4.4). These patterns were also clearly visible within the SST and H500 anomalies when SIC in DML was particularly high, and to some extent when it was particularly low (Figures 4.6a,b,g,h and 4.7a,e). The wave train appears similar to the Pacific South American pattern (PSA), a pattern of climate variability triggered by equatorial SST anomalies which is considered to be the dominant mechanism by which ENSO influences high southern latitude climates (Harangozo, 2004; Karoly, 1989; Mo and Higgins, 1998; Mo and Paegle, 2001).

The pattern in our H500 correlations (Figure 4.4) included a correlation with the Antarctic Dipole, a well-known feature of geopotential height and sea ice anomalies in the Amundsen and Weddell Seas (Yuan and Martinson, 2000, 2001). The dipole is driven by the PSA/ENSO, and typically consists of a negative geopotential height anomaly in the Amundsen Sea (the Amundsen Sea Low) and a positive anomaly in the Weddell Sea during La Niña, and vice versa with El Niño (Kidson and Renwick, 2002; Renwick, 2002; Yuan and Martinson, 2000, 2001). These results support the findings of Aoki (2017) and Noone et al. (1999) who suggest that the Weddell Sea component of this wave train directly affects certain aspects of the DML climate are linked to ENSO variability. Its proximity just to the west of DML means anomalous high or low pressure would alter local scale wind speeds and direction, in 
particular the north-south airflow across DML (Hirasawa et al., 2000; Noone et al., 1999; Welhouse et al., 2016). Low pressure in the Weddell Sea (El Niño) would increase poleward (northerly) airflow across DML, while high pressure (La Niña) would increase equatorward (southerly) flow. This theory is supported by the findings in Figure 4.11 which show that in MAM and DJF, the H500 wave train associated with ENSO includes a centre of anomalous low pressure over the meridian with the eastern limb extending over DML. Accompanying this in MAM, El Niño is associated with anomalous northerly airflow and lower than usual SIC in DML, while La Niña is associated with anomalous southerly airflow and increased SIC in DML (Figure 4.12).

Increased northerly airflow could be expected to drive changes in SIC through two different mechanisms. Thermodynamically, more northerly airflow would increase the advection of warm air from lower latitudes, increasing air temperature and thus increasing the surface melt of existing sea ice or decreasing the formation of new ice. Dynamically, northerly air flow would decrease transport of sea ice from the south, increasing concentration close to the coastline, but reducing overall extent (Lefebvre and Goosse, 2005; Liu et al., 2004; Turner et al., 2009). Increased southerly airflow exerts the opposite influence on sea ice e.g. bringing cooler polar air over the region, and encouraging northward advection of new ice.

The covariance of the dynamic and thermodynamic impacts of meridional flow mean it is generally difficult to discern which of these mechanisms dominate. Figure 4.8 shows a strong association between meridional heat transport and SIC in Dronning Maud Land in all seasons but DJF, particularly when SIC is high. However, the links between SIC and sea ice motion in DML appeared to favour zonal transport over meridional transport. The association between SIC in the western side of DML and zonal sea ice motion in Figure 4.9, where westward transport is linked with higher SIC in all seasons, and eastward transport is additionally linked with low SIC in DJF, suggests that sea ice import from the east contributes to the sea ice pack in Dronning Maud Land. This finding supports those of Kimura and Wakatsuchi (2011), who identified that SIC in the western most part of Dronning Maud Land $\left(0^{\circ} \mathrm{E}-30^{\circ} \mathrm{E}\right)$, is strongly contributed to by the eastward import of sea ice from the Weddell Sea. In relation to ENSO, Figures 4.10-4.12 show that in MAM, ENSO is positively correlated with anomalous northerly winds, T2M, SST, and NthHF over the DML sea ice zone, and not substantially correlated with sea ice motion. This suggests that in MAM, the link between ENSO and SIC around DML is driven by the anomalous northward transport of heat over DML and subsequent T2M anomalies. As MAM encompasses the beginning of the sea ice growth season, these T2M anomalies would serve to either enhance (La Niña, 
negative T2M anomaly) or slow (El Niño, positive T2M anomaly) sea ice growth processes, driving anomalously high (La Niña) or low (El Niño) SIC around DML.

In DJF, the processes connecting DML SIC to ENSO-associated circulation anomalies appear to be different. The positive correlation with anomalous H500 centred over the meridian is much further north in DJF than in MAM. This means that ENSO is correlated with easterly and southeasterly winds over the DML sea ice zone (Figure 4.11), as opposed to the northerly winds associated with ENSO in MAM, and is not significantly correlated with northward heat flux. However, in DJF ENSO remains strongly correlated with SST and $\mathrm{T} 2 \mathrm{M}$ anomalies between the coastline and $55^{\circ} \mathrm{S}$, and is associated with northward sea ice transport across the DML sea ice zone.

One possible explanation is that the increased zonal component of the wind flow associated with ENSO in DJF (increased easterly winds during an El Niño and increased westerly winds during a La Niña) results in anomalous Ekman flow (southward during El Niño, northward during La Niña), which acts to advect either warm water southward in an El Niño or cold water northward in a La Niña (Ferreira et al., 2015). As DJF is the Southern Hemisphere sea ice melt season, overall variability in SIC would be driven by variability in the amount of sea ice melt. Consequently, the warmer SST associated with an El Niño phase would then increase the rate of sea ice melt, and decrease sea ice concentration around DML. During a La Niña phase, the advection of cooler water northward would do the opposite, slowing the rate of sea ice melt and thus drive anomalously high SIC.

In addition, the positive correlation between ENSO and northeastward sea ice motion during DJF could be explained by the influence that sea ice concentration has on sea ice motion. Higher SIC means a more consolidated sea ice pack that is more resistant to windor ocean-forced advection (Kimura, 2004; Steele et al., 1997). This could mean that the increased northward transport of sea ice during El Niño phases (southward transport during La Niña) that we see in Figure 4.10 may be a product of the anomalously low SIC (high SIC during La Niña) driven by the process described above.

In terms of the seasonality of the ENSO signal in DML, its prevalence in austral summer and autumn but not throughout the rest of the year is broadly consistent with the findings of e.g. Yuan (2004), Okumura and Deser (2010), and Pope et al. (2017). These studies identified that the teleconnection between ENSO and the Antarctic climate is at its strongest during summer (Okumura and Deser, 2010; Yuan, 2004) when ENSO activity peaks, before decaying further into winter. However, the impact of the teleconnection on sea ice has been suggested to be strongest in autumn, when sea ice is expanding (Pope et al., 2017; Yuan, 2004), explaining the strong correlation we see between DML SIC and ENSO in autumn. 
64 I ENSO modulates summer and autumn sea ice variability around Dronning Maud Land

One factor not investigated by this study was the covariance of ENSO with other modes of climate variability. The influence of ENSO on SIC in West Antarctica is known to work in tandem with the Southern Annular Mode (SAM), working to enhance or diminish the effects of ENSO depending on its phase (Fogt and Bromwich, 2006; L'Heureux and Thompson, 2006; Zhou and Yu, 2004). Results in Figure 4.4 showed evidence of a SAM-like pattern in the correlation between SIC and H500 geopotential height in JJA and DJF, suggesting some SAM influence around DML. Further research is needed to determine whether ENSO and SAM interact in this region, and work similarly as in West Antarctica to influence SIC change.

\subsection{Conclusions}

To our knowledge, our study identifies the first clear link between ENSO and SIC in East Antarctica in the Dronning Maud Land sector. Our results showed a strong negative linear correlation between satellite-derived SIC and the Niño 3.4 index in austral summer and autumn persisting between $10-70^{\circ} \mathrm{E}$, around the coast of Dronning Maud Land and Enderby Land. Using ERA5 reanalysis, we found that within this same region SIC is strongly correlated with tropical Pacific SST, and to a wave train in SST and H500 bearing similarity to the PSA-1 pattern, resulting in a strong correlation with H500 in the Weddell Sea. These results suggest that an atmospheric wave train triggered by ENSO SST anomalies in the Pacific alters North-South flow over DML, driving changes to local scale heat fluxes and advection, and affecting the formation, melt, and transport of sea ice in the region.

These findings underscore the importance of atmospheric circulation in determining Antarctic SIC, and suggest that the influence of ENSO on SIC is more extensive than previously thought, extending into the East Antarctic region. Further research is needed to identify the precise mechanisms by which these links occur, and how this tropical-polar teleconnection may be affected by projected climate change. 


\section{Chapter 5}

\section{Sea ice modulates precipitation response to large-scale climate variability across East Antarctica}

Chapter 5 explores the relationship between sea ice variability and precipitation across East Antarctica. This chapter builds on the work presented in Chapters 3 and 4, which examined the influence of climate variability on sea ice, by exploring whether this relationship also occurs in the opposite direction, and how it changes around the entire East Antarctic coastline. Section 1 adds to the broad review of sea ice and climate interactions given in Chapter 1, providing a more in-depth summary of current knowledge around Antarctic precipitation variability and its interactions with sea ice variability, along with the chapter aims. Results are presented in Section 5.2, and discussed in Section 5.3. Section 5.4 details the main conclusions of this study.

\subsection{Introduction}

There is increasing evidence that changes in Arctic sea ice distribution directly impact precipitation in both the Arctic and at lower latitudes (e.g. Alexander et al., 2004; Bintanja and Selten, 2014; Higgins and Cassano, 2009; Kopec et al., 2016; Liu et al., 2012; Screen, 2013). This has implications for accumulation rates over nearby glaciers and ice sheets, and has been directly linked to the surface mass balance of the Greenland Ice Sheet (Deser et al., 2000; Liu et al., 2012; Noel et al., 2014; Singarayer et al., 2006). Sea ice in the Antarctic is projected to decrease in the future (IPCC, 2019), however little is known about 
66 I Sea ice modulates precipitation response to large-scale climate variability across East Antarctica

how precipitation responds to sea ice change in the Southern Hemisphere, and how this may in turn affect accumulation rates over the Antarctic Ice Sheet. Understanding these relationships is particularly important around the East Antarctic Ice Sheet (EAIS), which holds the equivalent of $53 \mathrm{~m}$ of global sea level rise and which is demonstrating increasing vulnerability to atmospheric forcing (Miles et al., 2013).

As the coldest and driest continent on Earth, Antarctica has a particularly low local moisture flux, meaning that precipitation is largely dependent on the intrusion of moisture transported from the Southern Ocean (Schlosser et al., 2004; Suzuki et al., 2008; Tietavainen and Vihma, 2008). Antarctic precipitation is highest in austral winter (Tietavainen and Vihma, 2008), and experiences strong spatial variability, though this can broadly be separated into two distinct regimes covering the coastal and continental regions. Precipitation in the coastal regions of the continent is largely associated with synoptic scale weather (Marshall, 2009; Marshall et al., 2017; Turner et al., 1995), and is often orographic, occurring when stormdriven intrusions of moist maritime air are forced to rise up the steep slopes that flank most of the East Antarctic coastline (Orr et al., 2008). In the interior of the continent, maritime moisture intrusions are less frequent and annual precipitation is much lower (Marshall et al., 2017), mostly occurring as very light but near-continuous 'clear-sky' precipitation (Casey et al., 2014; Ekaykin et al., 2004; Fujita and Abe, 2006; Stenni et al., 2016; Walden et al., 2003). When large weather systems are occasionally forced on to the plateau, they can account for as much as $25 \%$ of the annual precipitation in a single event (Massom et al., 2004). While the moisture for coastal precipitation is sourced primarily from the adjacent part of the Southern Ocean south of $50^{\circ} \mathrm{S}$ (Delaygue et al., 2000; Noone and Simmonds, 2002), precipitation in the continental interior tends to be sourced from lower latitudes, a product of moisture transported higher in the atmosphere in response to the topographic barrier of the steep coastline (Delaygue et al., 2000; Sodemann and Stohl, 2009).

In the Arctic, the relationship between sea ice and precipitation is thought to be driven primarily by the influence of sea ice on surface heat and moisture fluxes (Bintanja and Selten, 2014; Higgins and Cassano, 2009; Kopec et al., 2016; Liu et al., 2012). A reduction in sea ice means reduced surface albedo, and an increase in the amount of open water at the surface, which increases the transfer of heat and moisture from the ocean to atmosphere (Alexander et al., 2004; Bhatt et al., 2008; Rinke et al., 2013). As a result, a reduction in sea ice leads to a rise in near surface air temperatures (e.g. Screen and Simmonds, 2010; Serreze et al., 2009) and a significant increase in evaporation rates, both increasing atmospheric moisture content and thus precipitation (Alexander et al., 2004; Barry and Serreze, 2000; Bintanja et al., 2011; Bintanja and Selten, 2014; Higgins and Cassano, 2009; Kopec et al., 2016). 
Sea ice is additionally thought to drive changes in precipitation via an influence on atmospheric circulation and synoptic scale weather systems. In changing surface heat fluxes and thus the temperature gradient between the pole and the lower latitude, a reduction in sea ice is thought to induce a poleward shift of the jet stream/circumpolar storm track (Orme et al., 2017; Screen, 2013). At a smaller scale Mesquita et al. (2011) and Brayshaw et al. (2009) have also suggested that sea ice-driven changes in surface heat fluxes alter atmospheric stability and baroclinicity, which then impact precipitation.

Several studies have connected this relationship between sea ice and precipitation to changes in ice sheet mass balance. Bintanja and Selten (2014), Deser et al. (2000), Liu et al. (2012), Noel et al. (2014), and Singarayer et al. (2006) all showed that a loss of Arctic sea ice can be translated into an increase in precipitation (and therefore accumulation) over the Greenland Ice Sheet, with Noel et al. (2014) explicitly linking this to changes in the surface mass balance of the Greenland Ice Sheet.

In the Antarctic, there has been comparatively little research on the impacts of recent sea ice variability on precipitation at an interannual or interdecadal scale. Most of the studies are model-based, looking either at future projections of sea ice loss (Krinner et al., 2007; Lenaerts et al., 2016; Watkins and Simmonds, 1995; Weatherly, 2004), or at past variability in sea ice at a timescale of thousands of years (Fyke et al., 2017). Studies by Wang et al. (2020) and Sodemann and Stohl (2009) also found links between Antarctic sea ice and precipitation through the use of water source tracing. The majority of these studies suggest that changes in sea ice around Antarctica are associated with changes in precipitation. Noone and Simmonds (2004) and Lenaerts et al. (2016) suggested that this association is due to the influence of sea ice on evaporation rates over the Southern Ocean, while Krinner et al. (2007) suggested that it is driven by the influence of sea ice on storm tracks and atmospheric dynamics around Antarctica. In contrast, Fyke et al. (2017) suggested that the association between precipitation and sea ice may instead be driven by both variables simultaneously being influenced by large-scale climate variability.

In this chapter, I aim to explore the relationship between East Antarctic SIC and precipitation variability in the more recent past by examining the observation-derived satellite sea ice record and atmospheric reanalysis data from the past four decades. I achieve this through correlation and composite analysis of seasonal HadISST sea ice concentration and ERA5 precipitation, evaporation, meridional moisture flux, and $500 \mathrm{hPa}$ geopotential height, over the period 1979-2018. Section 2 displays and describes the results of this analysis, including the correlation between sea ice and precipitation. Section 3 discusses possible drivers of this correlation, and situates these findings in the context of previous studies. 
68 I Sea ice modulates precipitation response to large-scale climate variability across East Antarctica

\subsection{Results}

SIC around the coast of East Antarctica is strongly correlated with precipitation, evaporation, northward moisture flux, and 500hPa geopotential height (H500), in both large-scale patterns around the continent, as well as on smaller local scales. These associations were examined at annual, seasonal, monthly, and daily timescales. The relationships were strongest at a monthly and seasonal scale with no lag over austral winter and early spring, encompassing the period of July-August-September (JAS). The results described below are for this timescale and period only, and have been separated into local-scale correlations (Section 2.1), large-scale correlations (Section 2.2), and composite analysis (Section 2.3).

\subsubsection{Localised correlations}

Figure 5.1 shows that JAS SIC averaged across sectors of 10 degrees, for the ocean area south of $50^{\circ} \mathrm{S}$, was strongly and inversely correlated with total precipitation within each given sector around East Antarctica. Inverse correlations were strongest over the sea ice zone in, and immediately adjacent to, each sector, between the coastline and $60^{\circ} \mathrm{S}$. The correlation was strongest and most spatially extensive for sea ice between $0-20^{\circ} \mathrm{E}$ (Figure $5.1 \mathrm{a}, \mathrm{b}), 60-90^{\circ} \mathrm{E}$ (Figure 5.1g-j) and $150-180^{\circ} \mathrm{E}$ (Figure 5.1p-r). The correlation extended onto the coast for the majority of sectors, but most extensively with SIC between $80-110^{\circ} \mathrm{E}$ (Figure 5.1i-1), in some places reaching as far south as $80^{\circ} \mathrm{S}$. In these sea ice sectors, SIC was more strongly correlated with precipitation in inland regions 20 degrees to the east of each sector over the East Antarctic Ice Sheet than within the sea ice sector itself.

SIC in each sector was also positively correlated with northward moisture flux and inversely correlated with evaporation, showing that high SIC was associated with reduced evaporation and enhanced northward transport of moisture over each given sea ice sector (Figures 5.2 and 5.3). The correlations with northward moisture flux within each sector had largely the same pattern as with precipitation. These were strongest in the sea ice sectors between $60-110^{\circ} \mathrm{E}$ and $150-180^{\circ} \mathrm{E}$, with a correlation coefficient reaching 0.6 (Figure 5.2g-1). In most sectors, the correlation was strongest over the ocean, however, SIC in the regions between 20-50 and 90-110 was most strongly correlated with northward moisture flux on the inland portion of the sector (Figures 5.22c-f and 5.2j-1, respectively).

Additionally, all SIC sectors had inverse correlations with $\mathrm{H} 500$ centred immediately to the east of each given sector and positive correlations with H500 to the west (Figure 5.4). These correlations were strongest at $70-80^{\circ} \mathrm{E}$ (Figure 5.4h,j) and $150-170^{\circ} \mathrm{E}$ (Figure 5.4p-r), 

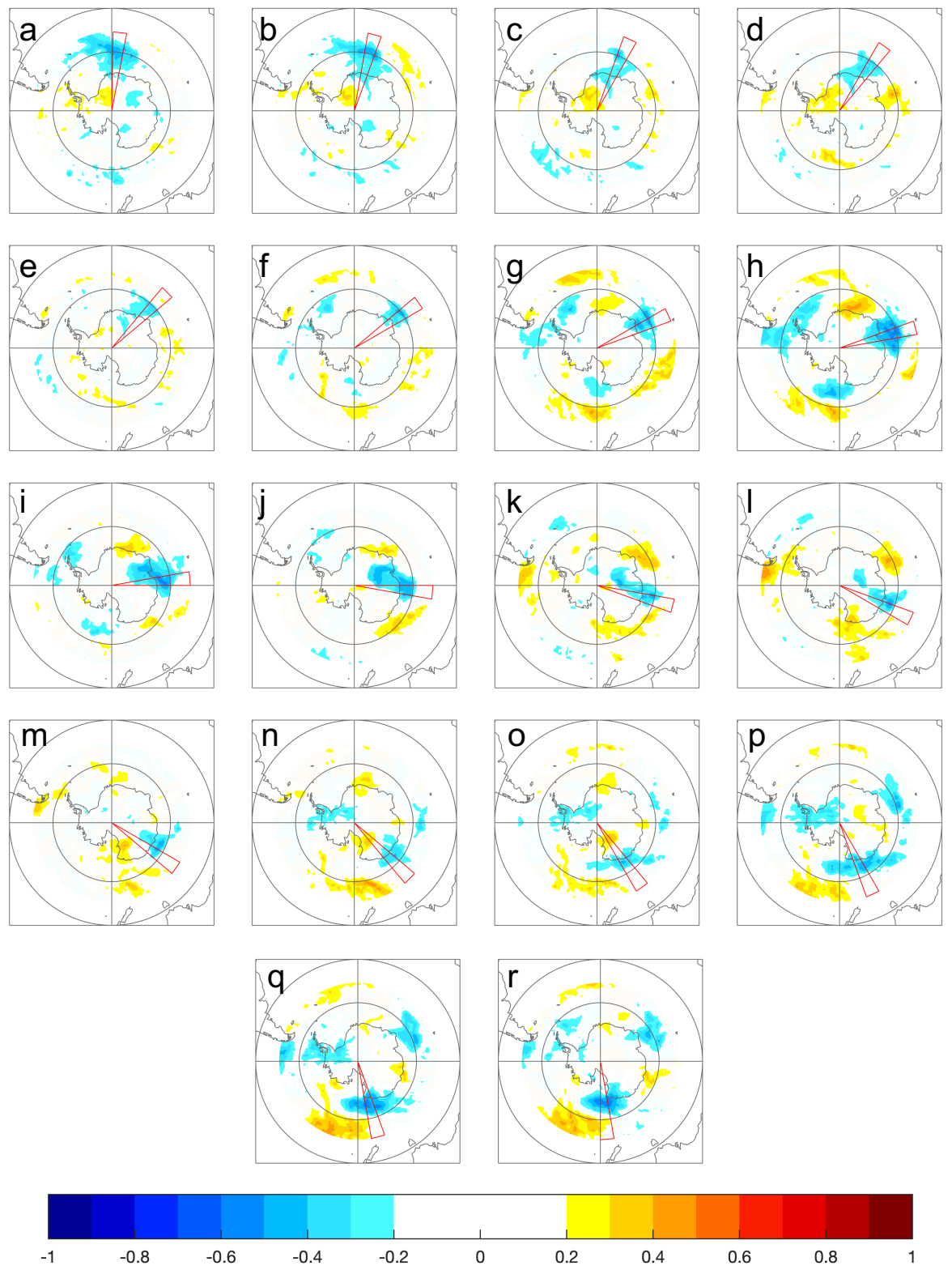

Fig. 5.1 Correlation between ERA5 July-August-September total precipitation and average HadISST sea ice concentration for the same season in latitudes south of $50^{\circ} \mathrm{S}$, and in $10^{\circ}$ sectors of longitude between $0-180^{\circ} \mathrm{E}$ (a-r) around the coast of East Antarctica over 1979-2018. Sea ice sector boundaries are outlined in red. All correlations shown are significant at the 5\% level.

where the coefficient of correlation reached -0.5 in the inverse cases, and 0.5 in the positive cases. This pattern corresponds to southerly airflow over the sea ice zone when SIC is high, and northerly airflow when SIC is low.

Correlations between SIC and localised evaporation were spatially different than those with precipitation and northward moisture flux. Each SIC sector was positively correlated 
70 I Sea ice modulates precipitation response to large-scale climate variability across East Antarctica
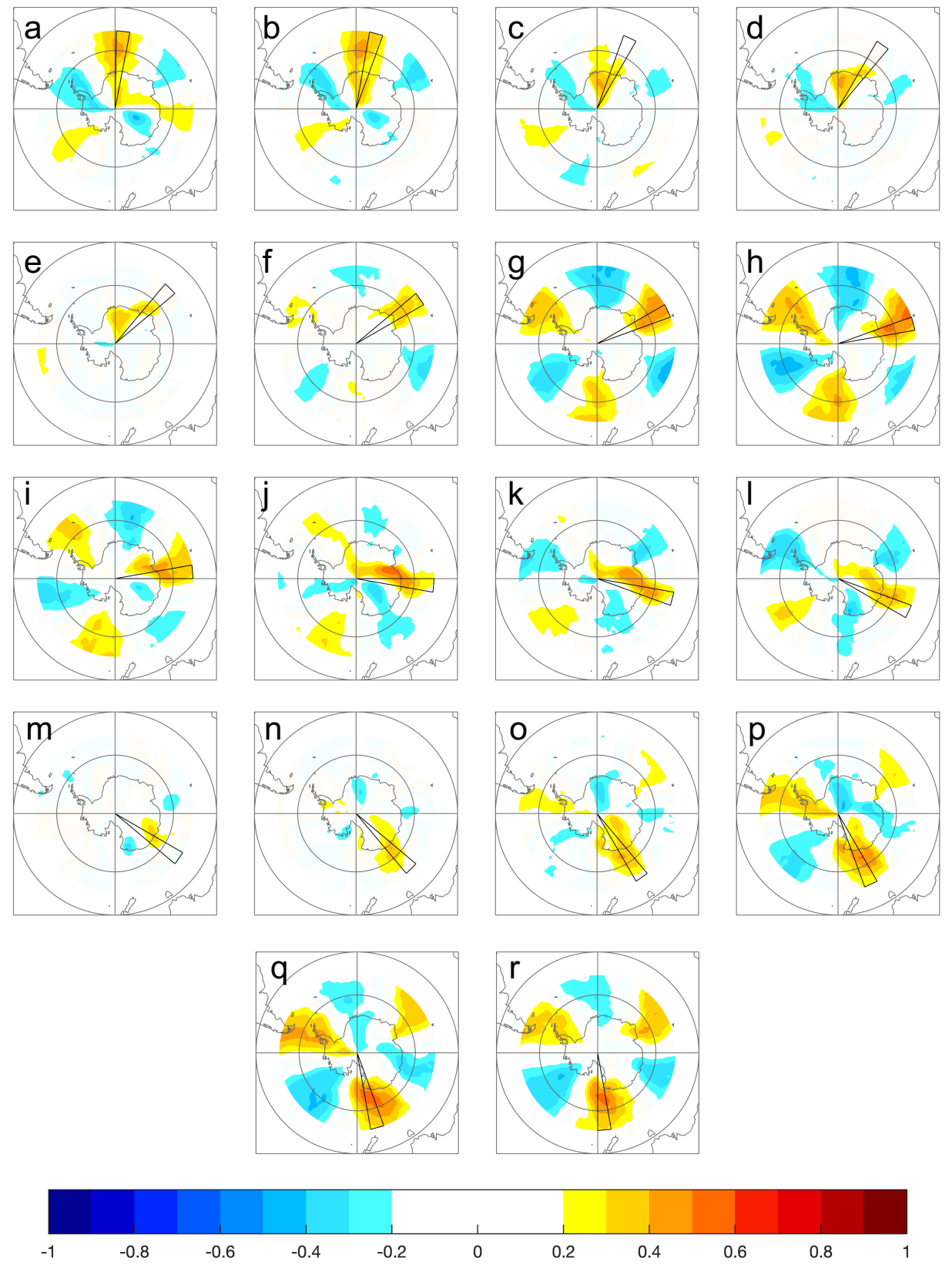

Fig. 5.2 Correlation between ERA5 July-August-September average northward water vapor flux and average HadISST sea ice concentration for the same season in latitudes south of $50^{\circ} \mathrm{S}$, and in $10^{\circ}$ sectors of longitude between 0-180 E (a-r) around the coast of East Antarctica over 1979-2018. Sea ice sector boundaries are outlined in black. All correlations shown are significant at the 5\% level.

with evaporation only in a narrow band around the approximate ice edge (Figure 5.3). This correlation was strongest and most spatially extensive between $0-50^{\circ} \mathrm{E}$, with a correlation coefficient reaching 0.8 (Figure 5.3a-f). Between $0-80^{\circ} \mathrm{E}$ (Figure 5.3a-i) and $160-180^{\circ} \mathrm{E}$ (Figure 5.3p-r), SIC was negatively correlated with evaporation (with correlation coefficient 

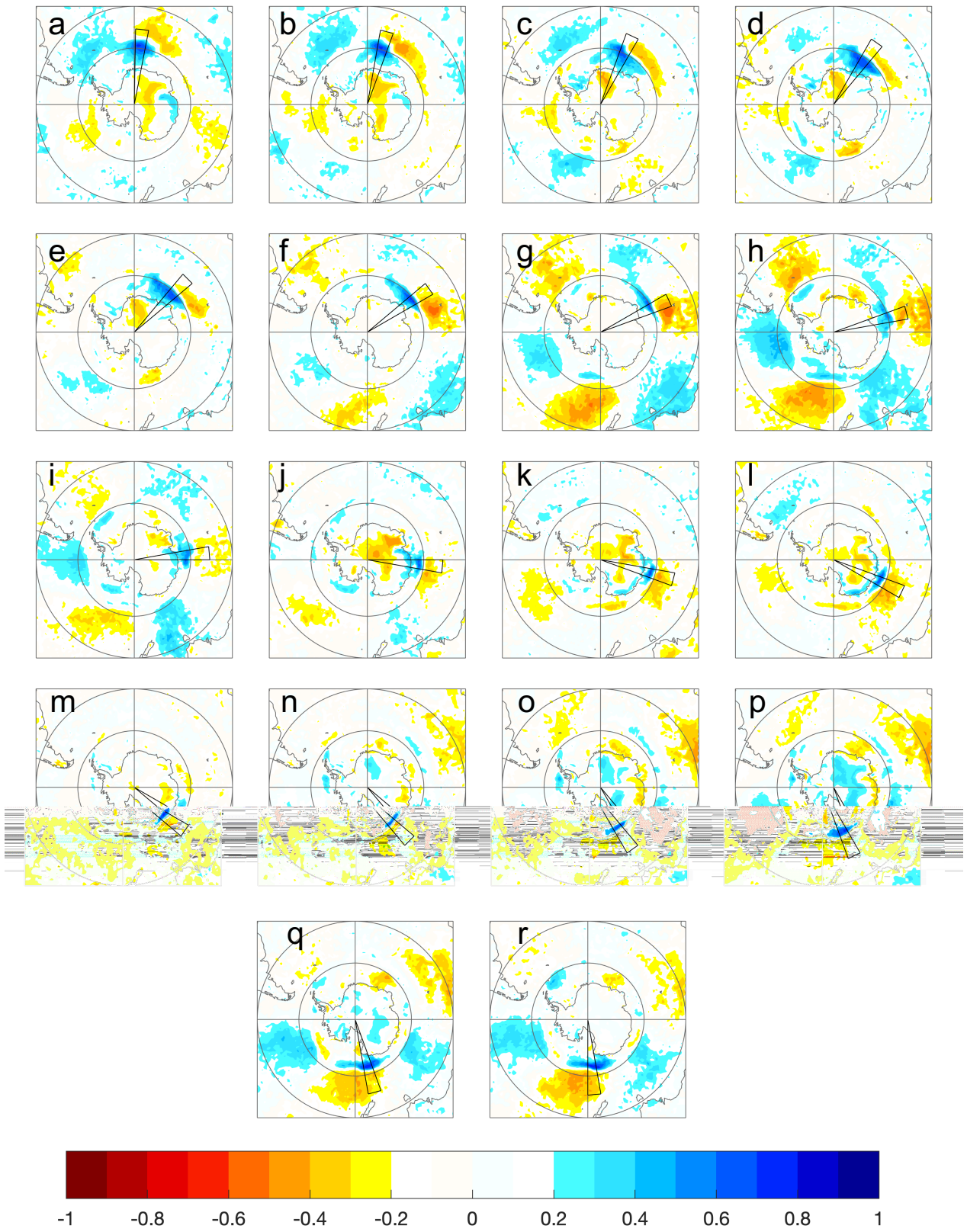

Fig. 5.3 Correlation between ERA5 July-August-September total evaporation and HadISST average sea ice concentration for the same season in latitudes south of $50^{\circ} \mathrm{S}$, and in $10^{\circ}$ sectors of longitude between $0-180^{\circ} \mathrm{E}$ (a-r) around the coast of East Antarctica over 1979-2018. Sea ice sector boundaries are outlined in black. All correlations shown are significant at the 5\% level. Note that negative values for the ERA5 evaporation data indicate evaporation, while positive values indicate condensation.

reaching -0.6) in a zone immediately to the northeast of the sector boundary and the zone of positive correlation. 
72 I Sea ice modulates precipitation response to large-scale climate variability across East Antarctica
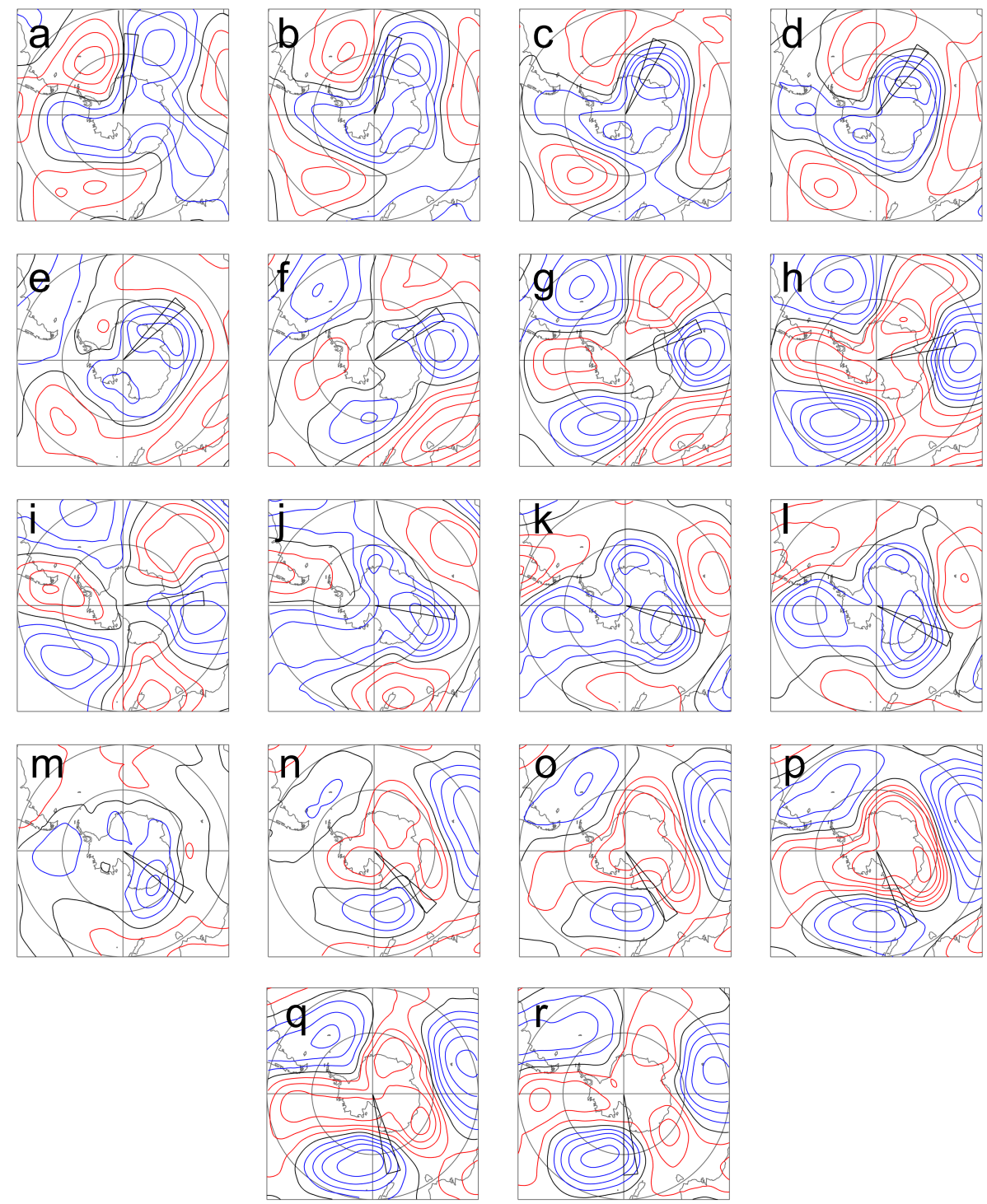

Fig. 5.4 Correlation between ERA5 July-August-September mean 500hPa geopotential height and average HadISST sea ice concentration for the same season in latitudes south of $50^{\circ} \mathrm{S}$, and in $10^{\circ}$ sectors of longitude between $0-180^{\circ} \mathrm{E}$ (a-r) around the coast of East Antarctica over 1979-2018. Red contour lines denote positive correlation, blue lines denote negative correlation. Contour intervals are 0.1 throughout. Sea ice sector boundaries are outlined in black.

\subsubsection{Larger scale correlation}

Around much of East Antarctica, SIC was also correlated with larger-scale patterns in each of the other variables across the continent and around the Southern Ocean, with resemblances to both the Southern Annular Mode and a zonal wave-3 pattern. 
SIC between $60-90^{\circ} \mathrm{E}$ and $150-180^{\circ} \mathrm{E}$ displayed a clear wave- 3 pattern of alternating zones of positive and negative correlation with precipitation, northward moisture flux, evaporation, and H500 around the continent between 40-60 ${ }^{\circ} \mathrm{S}$ (Figures 5.1-5.41-4, subfigures g-j and p-r for each). This pattern consisted of centres of correlation (negative for precipitation and evaporation, positive for northward moisture flux) directly south of Africa $\left(50^{\circ} \mathrm{E}\right)$ and South America $\left(100^{\circ} \mathrm{W}\right)$, and within the sea ice sector itself, each separated by a zone of correlation of the opposite sign. The pattern of correlation between SIC and H500 matched this same zonal wave-3 distribution but was longitudinally offset, so that the centres of correlation with each of the other climate variables were situated in the middle of two opposing centres of correlation with $\mathrm{H} 500$ (reaching $\mathrm{r}=0.5$ and $\mathrm{r}=-0.5$ ). This implies the SIC anomalies are most strongly correlated with meridional flow between the H500 centres, where positive SIC anomalies are beneath southerly flow and negative beneath northerly.

Between $90-120^{\circ} \mathrm{E}$, SIC was correlated with a pattern in $\mathrm{H} 500$ resembling a positive phase of the Southern Annular Mode (SAM; Figure 5.4j-1). This pattern consisted of an inverse correlation with $\mathrm{H} 500$ over the Antarctic continent (reaching $\mathrm{r}=-0.4$ ), and a positive correlation with H500 around the continent over the Southern Ocean. In these same sectors, SIC was inversely correlated with precipitation over the continental interior in, and to the west of, the sea ice zone between $40-100^{\circ} \mathrm{E}$ (reaching $\mathrm{r}=-0.6$, Figure $5.1 \mathrm{j}-1$ ), and with evaporation across the entire Antarctic plateau (reaching $\mathrm{r}=-0.5$, Figure 5.3j-1). Accompanying this was a positive correlation with northward moisture flux in roughly the same position as the correlation with precipitation (reaching $r=0.6$, Figure $5.2 \mathrm{j}-1$ ).

\subsubsection{Composite analysis}

To more closely examine causality in the relationship between sea ice, circulation, and Antarctic precipitation, composite analysis was undertaken and is displayed in Figure 5.5. Figure 5.5 (Column 1) shows that during periods where mean meridional moisture transport in a given sector is southward, there is a band extending north-south of positive anomalous precipitation across the entire oceanic portion of each sector. This is accompanied by two longitudinal bands of negative precipitation anomaly to the east and west of the positive anomaly, and covering a similarly sized area (between 20-30 degrees of longitude). When these periods coincide with anomalously high SIC within each sector, positive anomalous precipitation occurs only north of the approximate sea ice edge (Figure 5.5, Column 2). When periods of southward meridional moisture transport occur when SIC is anomalously low, the positive precipitation anomaly extends further southward to the coastline, and further inland (Figure 5.5, Column 3). 
74 I Sea ice modulates precipitation response to large-scale climate variability across East Antarctica

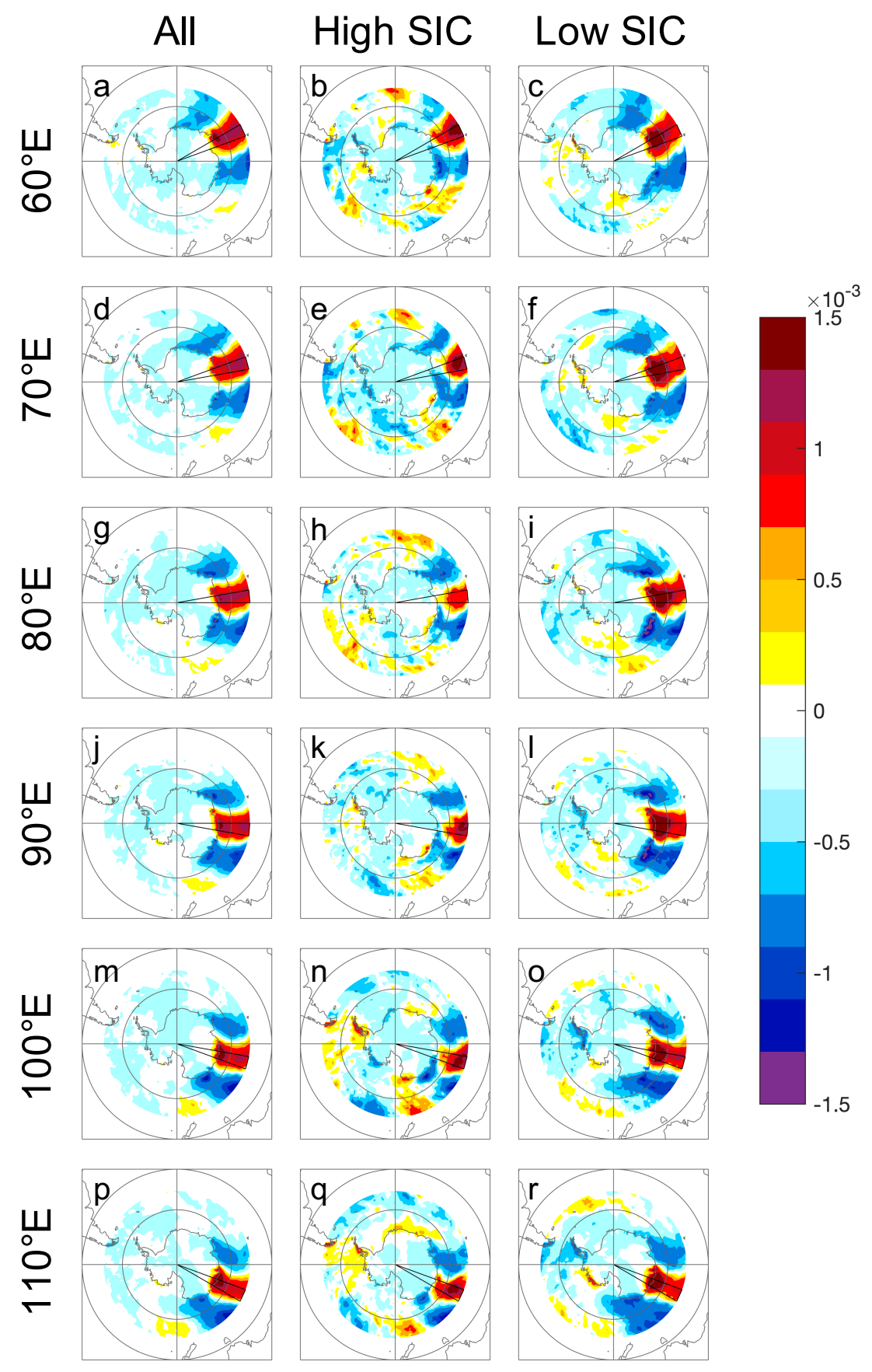

Fig. 5.5 ERA5 total JAS precipitation anomaly averaged for periods with mean southward moisture transport over the same 10-degree sea ice sectors described in Figures 5.1-5.4 (but only between $60-120^{\circ} \mathrm{E}$ ) shown in Column 1. Columns 2 and 3 show average total JAS precipitation anomaly over the same sectors, for periods with mean southward moisture transport and SIC in the same sectors is in the upper quartile (Column 2) or lower quartile (Column 3). Sector boundaries are outlined in black. Composites in Columns 1, 2, and 3 have 1200, 350, 470 members, respectively. 


\subsection{Discussion}

The analysis presented in Section 5.2 identifies a strong correlation between SIC and precipitation around the Southern Ocean and Antarctic continent. The results suggest that this link is driven by a combination of the influence of SIC on surface heat and moisture fluxes, and large-scale climate variability.

At a local scale, within each SIC sector around East Antarctica winter SIC was inversely correlated with local precipitation and evaporation and positively correlated with northward moisture flux. SIC was also significantly and positively correlated with geopotential height anomalies associated with meridional air flow over the sea ice zone. These findings support the idea that changes in SIC influence local precipitation via associated changes in surface heat and moisture fluxes. Figure 5.3 suggests that a reduction in SIC is associated with an increase in evaporation particularly around the average sea ice edge, and most strongly between $0-50^{\circ} \mathrm{E}$. This pattern of correlation at the sea ice edge matches the pattern described by Wang et al. (2020) and reflects the strong variability in SIC at the ice edge comparative to the rest of the sea ice zone. Changes to surface evaporation and warming over the edge of the sea ice zone contribute to an increased atmospheric moisture availability for precipitation, thus driving a negative correlation between SIC and precipitation.

The reasons for the particular strength of the SIC-evaporation correlation in the sea ice sectors between $0-50^{\circ} \mathrm{E}$ remain unclear. Wang et al. (2020) also noted a particularly strong evaporation response to sea ice changes in this region, so it is unlikely to be due to error in the analysis or data. The sea ice in this region is particularly extensive, and experiences significantly more variability than the rest of East Antarctica (Raphael and Hobbs, 2014). It is possible that this heightened variability provides greater opportunity for a response in evaporation, driving a stronger correlation between the two.

The extension of the correlation between SIC and precipitation across the rest of the sea ice zone and into coastal Antarctica likely stems from the relationship between SIC and meridional circulation anomalies. Anomalously low SIC is often accompanied and driven by enhanced northerly flow, and high SIC by southerly flow (Holland and Kwok, 2012; Renwick et al., 2012; Simpkins et al., 2012), as evidenced in Figure 5.4. Enhanced northerly flow would also act to transport the anomalous atmospheric moisture southward from the ice edge to coastal Antarctica, driving increases in precipitation across the sea ice zone. This effect would be especially strong in winter, when storm tracks are most active and tend to drive the highest amounts of precipitation (Tietavainen and Vihma, 2008), explaining why the SIC-precipitation relationships in this study are strongest in winter. The particularly 
76 I Sea ice modulates precipitation response to large-scale climate variability across East Antarctica

strong correlation between SIC and precipitation at the coastline is likely due to the steep terrain of the East Antarctic coast, which drives orographic precipitation as the southward moving warm moist air is forced to rapidly rise (Delaygue et al., 2000; Orr et al., 2008). These findings agree with those of previous studies on Arctic sea ice (e.g. Alexander et al., 2004; Barry and Serreze, 2000; Bintanja et al., 2011; Bintanja and Selten, 2014; Higgins and Cassano, 2009; Kopec et al., 2016), and suggestions by a small number of studies on Antarctic sea ice (Lenaerts et al., 2016; Noone and Simmonds, 2004; Wang et al., 2020; Weatherly, 2004) that a reduction in sea ice drives an increase in surface heat fluxes, due to the exposure of the comparatively warmer open ocean, and vice versa.

The correlation between SIC and precipitation could also be the result of precipitation variability driving changes in SIC. However, research shows that enhanced snowfall generally results in an increase in Antarctic SIC, by positively affecting sea ice growth and reducing surface melt through changes to surface albedo, insulation of sea ice, and by promoting surface flooding and refreezing (Fichefet and Maqueda, 1999; Stammerjohn et al., 2011; Turner et al., 2015). Because the correlation between SIC and precipitation in this study is negative, where increased precipitation is associated with decreased SIC, any influence of precipitation on sea ice is likely to be minimal in comparison to other mechanisms linking the two variables.

The idea that SIC may be thermodynamically driving changes in precipitation does not, however, account for the significant correlations between SIC and precipitation, evaporation, northward moisture flux, and geopotential height in more distant regions around Antarctica. Sodemann and Stohl (2009) and Wang et al. (2020) show that the moisture for Antarctic precipitation over the Southern Ocean and coastal regions of the continent tends to have a localised oceanic source. It is therefore unlikely that changes in SIC around East Antarctica could be thermodynamically affecting precipitation in parts of West Antarctica. This suggests that these links could be a product of large-scale circulation variability affecting both SIC and precipitation across Antarctica in tandem. There are many examples of patterns of climate variability such as the Southern Annular Mode (SAM; e.g. Hall and Visbeck, 2002; Lefebvre et al., 2004; Marshall et al., 2017) and El Niño Southern Oscillation (ENSO; e.g. Bromwich et al., 2000; Isaacs et al., 2021; Yuan, 2004) affecting both sea ice and precipitation around Antarctica, through their alteration to both the atmosphere and ocean.

In this study, the correlation between SIC at $60-90^{\circ} \mathrm{E}$ and $150-180^{\circ} \mathrm{E}$ with precipitation showed a clear zonal wave-3 pattern, with three alternating positive and negative centres of correlation in the Southern Ocean around Antarctica (Figure 5.1g-f,p-r). The wave-3 pattern was also visible in correlations between SIC and evaporation (Figure 5.3g-f,p-r), 
northward moisture flux (Figure 5.2g-f,p-r), and H500. These findings suggest that since the zonal wave-3 pattern in atmospheric circulation is associated with changes to meridional flow (as described in Raphael, 2007), it affects meridional moisture/heat transport, SIC, evaporation and precipitation. This supports previous findings that zonal wave-3 drives changes in sea ice (Raphael, 2007; Yuan and Li, 2008) and the suggestion by Fyke et al. (2017) of a zonal wave-3 signature in Antarctic precipitation. As a consequence, these findings suggest that the correlation between much of East Antarctic SIC and precipitation could be due to both variables covarying in response to zonal wave-3 variability in large-scale atmospheric circulation, as opposed to changes in SIC driving change in precipitation.

The correlation of SIC with precipitation in the continental interior may also be the product of a joint response to large-scale atmospheric variability in the form of the SAM. SIC between $90-120^{\circ} \mathrm{E}$ was strongly correlated with a SAM-like pattern in the H500 field, composed of a negative anomaly over the continent and a positive anomaly surrounding it (Figure 5.4j-1). This same area of sea ice was also the only area which had a strong correlation with precipitation and northward moisture flux over the continental interior (Figures 5.1j$1 \& 5.2 \mathrm{j}-1)$, along with an inverse correlation with evaporation over the entire Antarctic plateau (Figure 5.3j-1). The relationship between Antarctic SIC and the SAM has been well-documented (and is described in detail in Chapter 1 of this thesis), and often consists of an increase in sea ice in response to the enhanced katabatic winds associated with a negative phase of the SAM (Holland et al., 2017; Lefebvre et al., 2004; Stammerjohn et al., 2008). Several studies have also identified a link between the SAM and Antarctic precipitation, where the strengthened katabatic winds and increased zonal flow around Antarctica associated with a positive SAM phase reduce maritime moisture intrusions, thereby reducing continental precipitation (Marshall et al., 2017; Silvestri and Vera, 2009). As with the relationship with zonal wave-3, it is therefore a possibility that the correlation between SIC and precipitation in these sectors (between $90-120^{\circ} \mathrm{E}$ ) is driven not by SIC influencing precipitation, but by a shared correlation with the SAM.

The results shown in Figure 5.5 suggest that a combination of both mechanisms, largescale climate variability and sea ice forcing, is responsible for the correlation between SIC and precipitation, and more specifically that the response of Antarctic coastal precipitation to large-scale climate variability is modulated by SIC. Figure 5.5 shows that when the mean meridional moisture flux is southward, there is a strong positive precipitation anomaly. This precipitation anomaly shifts in strength and extent depending on the average SIC, strengthening and extending inland from the coast when SIC is low (Figure 5.5), and only extending as far south as the sea ice edge when SIC is high (Figure 5.5). This supports the assertion by Wang et al. (2020) that positive evaporation anomalies in the Southern 
78 I Sea ice modulates precipitation response to large-scale climate variability across East Antarctica

Ocean only drive an increase to precipitation over the continent if there is a strong southward meridional moisture flux over the region.

The findings described here assert that similarly, large-scale southward moisture transport only translates into coastal precipitation with the addition of anomalous atmospheric moisture from lower than usual SIC in the adjoining ocean. I suggest therefore that the correlation between SIC and Antarctic precipitation over the sea ice zone and further inland is due to both large-scale circulation variability and to the localised effect of sea ice changes on precipitation. This new conclusion supports aspects of studies such as Lenaerts et al. (2016) and Krinner et al. (2007) which suggest that SIC drives changes in precipitation, as well as the findings of Fyke et al. (2017) that this relationship is actually driven by a shared correlation with atmospheric variability.

\subsection{Conclusions}

This study constitutes the first direct analysis of the relationship between recent sea ice variability and precipitation in the Southern Hemisphere, and presents evidence that Southern Hemisphere SIC variability is associated with changes in Antarctic precipitation. In this chapter, I examined the relationship between recent East Antarctic SIC variability and precipitation, using the 40-year satellite sea ice record and ERA5 reanalysis data over the period from 1979-2018. Correlation analysis revealed a strong inverse association between seasonal SIC and precipitation in the austral winter and early spring around the majority of the East Antarctic, as well as strong correlations with evaporation, northward moisture flux, and $500 \mathrm{hPa}$ geopotential height. These associations occurred both locally and at a larger scale, with clear zonal wave-3 and SAM patterns visible in all correlations around certain sectors of East Antarctica. These patterns suggested that the relationship between SIC and precipitation may be influenced by a shared correlation with large-scale atmospheric variability. However, composite analysis showed that the response of precipitation to climate variability is dependent on SIC, leading to the conclusion that Antarctic precipitation is influenced by both SIC and climate variability.

These findings highlight the complex interplay between sea ice and climate in East Antarctica, and the important role that sea ice variability plays in driving changes to regional climate. As sea ice is projected to experience a strong decline in the future in response to anthropogenic climate change, these findings have implications for the future of precipitation over the Southern Ocean and the Antarctic continent. Given the role that precipitation plays in determining ice sheet surface mass balance, more research is needed to investigate the 
potential consequences of this relationship on the mass balance of the Antarctic Ice Sheet, as has been done for the Arctic. 



\section{Chapter 6}

\section{Synthesis and conclusions}

The overarching aim of this thesis was to investigate the relationships between climate variability and sea ice around East Antarctica, the spatial variability in these relationships, and the impacts that these may have on other aspects of the climate and cryosphere. This aim was motivated by a gap in the knowledge of sea-ice-climate relationships around East Antarctica in comparison to other sea ice regions (such as West Antarctica), despite growing awareness of the vulnerability of the East Antarctic region to climate change. I addressed this research aim through statistical analysis of the satellite-derived sea ice record, and atmospheric reanalysis data for the period between 1979-2018. The first two research chapters (Chapters $3 \& 4$ ) addressed the impact of climate variability on different parts of East Antarctica. The final research chapter (Chapter 5) explored the influence of sea ice on climate at a broader scale, by examining its relationship with precipitation around the entire East Antarctic. In this concluding chapter I summarise the key findings of my research, discuss their contribution to scientific knowledge, and outline the possible future avenues of research that they make possible.

\subsection{Summary}

\subsubsection{SAM and IOD influence sea ice variability around Western Pa- cific sector of East Antarctica}

The results presented in Chapter 3 confirm and extend previous findings (e.g. Nuncio and Yuan, 2015) of a teleconnection between sea ice around Wilkes Land and SST variability in the equatorial Indian Ocean. While previous studies have examined this teleconnection in 
austral spring only, the results presented in this thesis suggest that this link is present in austral summer and winter as well. During winter, spring, and summer, a significant correlation was observed between the DMI IOD index, and SIC around Wilkes Land (Figure 3.4). Further correlation analysis showed that SIC was also correlated with a wave train within the 500 $\mathrm{hPa}$ geopotential height field, linking Wilkes Land to the tropical Indian Ocean (Figure 3.5). Significant correlations were also observed between the IOD and southerly winds, northward heat transport and low air temperatures (Figure 3.6). These findings suggest that IOD-associated atmospheric variability triggers an atmospheric wave train which propagates polewards from the tropics to Wilkes Land, altering regional circulation and in turn affecting SIC through changes to local climate and sea ice transport.

There was also a significant correlation between sea ice in the broader Western Pacific sector and the SAM, which was for the most part positive (i.e. a positive SAM phase is associated with higher SIC and vice versa), though around George V Land this correlation was negative in winter and spring (Figure 3.7). Further correlation and composite analysis with ERA5 reanalysis revealed strong associations between the SAM and local-scale katabatic winds, T2M, NthHF, and sea ice motion (Figure 3.8). The results suggest that the inverse SAM-SIC association around George V Land in winter and spring may be due to the enhanced katabatic winds associated with a negative SAM phase, which in turn influence sea ice production and transport in wind-driven coastal polynyas. The shift to a weak positive correlation in this same region in summer and autumn may be the result of decreased importance of polynyas to SIC during summer and autumn when SIC in the WPS tends to be at its minimum. However, the summer correlations may also be less physically meaningful due to the small amount of sea ice that remains in the WPS through summer. These results highlight that the effects of SAM variability on sea ice around East Antarctica are strongly spatially variable, as a result of interactions with different local climates and landscapes.

Despite sea ice in the same region of the WPS being correlated with both the SAM and the IOD, no clear evidence of interactions between the two climate modes was found. Composite analysis, however, suggested that the response of SIC to each phase of one climate mode was altered depending on the phase of the other, with the strongest SIC response elucidated when the modes were out of phase with one another. 


\subsubsection{ENSO modulates summer and autumn SIC around Dronning Maud Land}

The results presented in Chapter 4 show, for the first time, a clear link between ENSO and SIC variability in East Antarctica, around Dronning Maud Land. There was an inverse linear correlation between the Niño 3.4 index and SIC between Dronning Maud Land and Enderby Land in summer and autumn (Figure 4.2). SIC in this region around Dronning Maud Land was also inversely correlated with local-scale climate variables, such as local T2M, SST, and northerly air flow (Figure 4.4). Dronning Maud Land SIC was also significantly correlated with SST in the equatorial Pacific Ocean during the same period, as well as with a wave train in the H500 field, extending from the South Pacific into Dronning Maud Land in a pattern that resembled the PSA-1 pattern (e.g. Karoly, 1989; Mo and Higgins, 1998; Mo and Paegle, 2001). Further analysis identified significant correlations between SIC and both meridional heat flux and sea ice motion around DML.

These findings suggest that ENSO-associated tropical SST anomalies excite the poleward propagation of an atmospheric Rossby wave train, which alters regional circulation around Antarctica into DML, in turn affecting local scale heat fluxes and advection. These changes can affect the formation, melt and transport of sea ice around DML, causing a covariance between SIC and ENSO. This mechanism is similar to that proposed by Renwick (2002), Yuan (2004), Liu et al. (2002) and Kwok and Comiso (2002), which have identified links between ENSO and SIC in West Antarctica. The findings in this thesis suggest that the impacts of ENSO extend further around the continent into East Antarctica. The results highlight the importance of climate variability and tropical teleconnections as drivers of interannual sea ice variability, and suggest that the influence of ENSO on SIC is more extensive than previously thought.

\subsubsection{SIC modulates precipitation response to climate variability}

Building on the findings in Chapters 3 and 4, that East Antarctic SIC is influenced by climate variability, Chapter 5 considered whether changes in SIC also influenced changes in climate by examining the relationship of SIC with precipitation around the entire East Antarctic coast. This constitutes the first direct analysis of the relationship between recent Antarctic SIC variability and precipitation using observed sea ice data. A significant correlation was observed between SIC variability around East Antarctica and precipitation variability across the continent and the Southern Ocean. 
The SIC-precipitation correlation was temporally and spatially variable, occurring with the greatest strength in austral winter and early spring, between July and September (Figure 5.1). SIC within any given sector was inversely correlated with localised precipitation, accompanied by strong correlations with northward moisture flux, evaporation, and 500 $\mathrm{hPa}$ geopotential height (Figures 5.2, 5.3, and 5.4 respectively). SIC in many sectors was also correlated with larger-scale atmospheric circulation, including clear ZW3 and SAM patterns in correlations with all climate variables considered here. The relative influence of each of these two modes varied around the coastline, often changing from a ZW3-dominant pattern to a SAM pattern over the space of only 20 degrees of longitude. While these results are to be expected from the zonally-asymmetric ZW3 pattern (e.g. Raphael, 2004; van Loon and Jenne, 1972), they are less so with the typically annular SAM pattern (e.g. Fyfe, 2003; Marshall, 2007; Thompson and Wallace, 2000). This could be explained, however, by findings of studies such as Fogt et al. (2012a), who showed that the SAM experiences some zonal asymmetry in austral winter and spring, related to variability in jet stream entrance and exit regions. This zonal asymmetry could then cause the SAM to drive SIC changes in some regions but not others. These findings reiterate the need for future studies to consider SIC-climate relationships at small spatial scales.

The results showed that SIC appeared to modulate the precipitation response to climate variability. Composite analysis showed different responses in precipitation for periods when the mean meridional moisture flux over a given sector was southward, and when SIC in that sector was either anomalously high or anomalously low. The positive precipitation anomalies that accompanied southward moisture flux extended further inland when SIC was anomalously low, and stopped at the average sea ice edge when SIC was anomalously high. Previous studies of SIC-precipitation relationships at much longer timescales, or in modelled projections, have suggested that the relationship is driven either by the direct influence of SIC on precipitation (Krinner et al., 2007; Lenaerts et al., 2016), or by large-scale climate variability driving changes in both variables, causing them to co-vary (Fyke et al., 2017). The findings in this chapter present evidence that the relationship is driven by a combination of these factors i.e. that SIC and precipitation co-vary in response to large-scale atmospheric forcing, but that the precipitation response to atmospheric forcing is also modulated by localised SIC. 


\subsection{Synthesis}

The influence of large-scale climate variability on East Antarctic sea ice can be broadly split into two categories: tropical teleconnections (ENSO and the IOD), and extra-tropical patterns of variability in circumpolar circulation (ZW3 and SAM). Tropical teleconnections affect sea ice around Dronning Maud Land (affected by ENSO) and the Western Pacific sector (affected by the IOD) as a result of atmospheric Rossby waves propagating poleward from SST anomalies in the tropics (Pacific Ocean for ENSO, Indian Ocean for IOD), and perturbing regional circulation around Antarctica. The IOD and ENSO only affect sea ice at locations where perturbation of regional flow by wave trains results in anomalous meridional flow (for example on either side of an atmospheric pressure anomaly) over the sea ice zone, which affects air temperatures, sea ice transport, and thus sea ice concentration. Dronning Maud Land, for example, is affected by an ENSO-associated wave train that propagates from the Pacific to Antarctica, driving a sequence of anomalous high and low pressure centres clockwise around West Antarctica and extending into Dronning Maud Land, before dissipating. The configuration of the high and low pressure centres produces anomalous meridional flow over DML, driving changes to SIC. Similarly, the Western Pacific sector is the location at which the southward-propagating wave train associated with the IOD reaches Antarctica, the configuration of which drives anomalous meridional flow over Wilkes Land, which in turn affects SIC.

ZW3 and the SAM, in contrast to the tropical teleconnections, are patterns of variability in the circumpolar circulation, and have a broader influence on SIC around the East Antarctic coastline. ZW3 introduces asymmetries to the zonal flow around Antarctica, increasing the meridional component of the circumpolar circulation. SIC is affected by ZW3 wherever this perturbation of the circumpolar circulation results in increased meridional flow over the sea ice zone, which occurs in less fixed locations than with the ENSO and IOD associated wave trains. The SAM is a measure of the strength of zonal flow around Antarctica, and of changes in the strength and position of the circumpolar westerlies. The SAM affects sea ice around much of the East Antarctic coastline, although its impact is still very spatially variable, often inducing completely different responses in regions of sea ice only 20 degrees of longitude apart. My results show that these differing responses are likely driven by interaction between large-scale SAM variability in circulation and local climate and cryospheric features in each location, such as polynyas and katabatic winds. In Oates Land for example, my results suggest that the SAM may influence SIC via its impact on coastal polynya size and sea ice production, which drive SIC variability by affecting sea ice formation and northward transport. 
SIC variability around East Antarctica also modulates the response of regional climate over the continent to large-scale modes of climate variability such as ZW3. It is shown that precipitation over the inland coastal regions of Antarctica in response to regional climate variability changed in response to SIC variability. Specifically, increased southward moisture flux was only associated with increased precipitation in the inland coastal regions of the continent when SIC was anomalously low, and therefore moisture evaporating from the open ocean had a shorter distance to travel before reaching the continent. This finding implies that any changes in sea ice could result in changes to the relationship between climate variability and precipitation in Antarctica.

\subsection{Contributions and Future Directions}

The findings in this thesis make a clear and significant contribution to scientific knowledge of sea-ice-climate relationships around East Antarctica. My results expand understanding of the role that ENSO, IOD, SAM and ZW3 play in the variability of sea ice concentration in the East Antarctic region. This includes identifying climate-sea-ice links in regions and seasons than have previously been discussed in conjunction with climate variability. In particular, the findings in this thesis highlight the large regional variation in the relationships between sea ice and climate around East Antarctica, and underscore the importance of considering future changes in sea ice at a regional and local, rather than continental, scale. This knowledge can be used to improve the parameterisation of sea ice models by more, and thus reduce associated uncertainty in broader climate and earth system models.

Future research could build on the results in this thesis by exploring the sea-ice-climate relationships in the Western Pacific sector and Dronning Maud land at a smaller scale, using higher resolution data from regional model outputs such as RACMO or the Antarctic Mesoscale Prediction System (AMPS), along with higher-resolution Sentinel satellite imagery.

This could include an exploration on the combined effect of different climate modes on sea ice, such as that between the IOD and the SAM on SIC in the Western Pacific sector (Chapter 3). Future work should examine whether SIC modulates the influence of climate variability on heat transport and air temperatures over the ice sheet, as it does with moisture variability and precipitation.

In particular, there is a pressing need for future research to address how the climate-sea ice relationships discussed in this thesis may be affected by projected climate change. Will 
these relationships still function in a similar way in the coming decades and centuries? Or will they change in response to changes in other components of the climate and cryosphere? These questions could be explored through a similar analysis approach to this thesis, but using GCM projections forced with a range of different emissions scenarios.

These questions are relevant when considered alongside the evidence presented in this thesis that sea ice may modulate the effect of climate variability on precipitation over the Antarctic continent. Estimated projections of SIC around Antarctica show a marked decrease in response to anthropogenic climate change. The findings of this study suggest that this sea ice decrease may result in greater coupling of climate variability with continental precipitation. This possibility has wide reaching implications, because of the impact that changes in precipitation have on the mass balance of the East Antarctic Ice Sheet (EAIS; e.g. Boening et al., 2012; Massom et al., 2004). Future work should assess the direct impacts of recent SIC variability and change on the surface mass balance of the EAIS. The EAIS holds the equivalent of $53 \mathrm{~m}$ of potential sea level rise, and there is growing awareness of its potential mass loss in response to climate change (e.g. Golledge et al., 2017; Shen et al., 2018). This future work could therefore provide important insight into whether future changes in Antarctic sea ice could have much broader consequences for global sea level. 



\section{References}

Alexander, M. A., Bhatt, U. S., Walsh, J. E., Timlin, M. S., Miller, J. S., and Scott, J. D. (2004). The atmospheric response to realistic Arctic sea ice anomalies in an AGCM during winter. Journal of Climate, 17:890-905.

Ambrizzi, T., Hoskins, B. J., and Hsu, H. H. (1995). Rossby-wave propagation and teleconnection patterns in the austral winter. Journal of the Atmospheric Sciences, 52:3661-3672.

Ambrizzi, T., Kayano, M. T., and Stephenson, D. B. (1998). A comparison of global tropospheric teleconnections using observed satellite and general circulation model total ozone column data for 1979-91. Climate Dynamics, 14:133-150.

Aoki, S. (2017). Breakup of land-fast sea ice in Lutzow-Holm Bay, East Antarctica, and its teleconnection to tropical Pacific sea surface temperatures. Geophysical Research Letters, 44:3219-3227.

Ashok, K., Guan, Z. Y., and Yamagata, T. (2003). Influence of the Indian Ocean Dipole on the Australian winter rainfall. Geophysical Research Letters, 30.

Baba, K. and Renwick, J. (2017). Aspects of intraseasonal variability of Antarctic sea ice in austral winter related to ENSO and SAM events. Journal of Glaciology, 63:838-846.

Bader, J., Flugge, M., Kvamsto, N. G., Mesquita, M. D. S., and Voigt, A. (2013). Atmospheric winter response to a projected future Antarctic sea-ice reduction: a dynamical analysis. Climate Dynamics, 40:2707-2718.

Barber, D. and Massom, R. (2007). Chapter 1 the role of sea ice in arctic and antarctic polynyas. In Smith, W. and Barber, D., editors, Polynyas: Windows to the World, volume 74 of Elsevier Oceanography Series, pages 1-54. Elsevier.

Barlow, M., Nigam, S., and Berbery, E. H. (2001). ENSO, Pacific decadal variability, and US summertime precipitation, drought, and stream flow. Journal of Climate, 14:2105-2128.

Barry, R. G. and Serreze, M. C. (2000). Atmospheric components of the Arctic Ocean freshwater balance and their interannual variability. Freshwater Budget of the Arctic Ocean, 70:45-56.

Behera, S. K. and Yamagata, T. (2003). Influence of the Indian Ocean Dipole on the Southern Oscillation. Journal of the Meteorological Society of Japan, 81:169-177. 
Bendtsen, J., Mortensen, J., Lennert, K., Ehn, J. K., Boone, W., Galindo, V., Hu, Y. B., Dmitrenko, I. A., Kirillov, S. A., Kjeldsen, K. K., Kristoffersen, Y., Barber, D. G., and Rysgaard, S. (2017). Sea ice breakup and marine melt of a retreating tidewater outlet glacier in northeast Greenland (81 degrees n). Scientific Reports, 7.

Bhatt, U. S., Alexander, M. A., Deser, C., Walsh, J. E., Miller, J. S., Timlin, M. S., Scott, J., and Tomas, R. A. (2008). The atmospheric response to realistic reduced summer Arctic sea ice anomalies. Arctic Sea Ice Decline: Observations, Projections, Mechanisms, and Implications, Geophys. Monogr, 180:91-110.

Bintanja, R., Graversen, R. G., and Hazeleger, W. (2011). Arctic winter warming amplified by the thermal inversion and consequent low infrared cooling to space. Nature Geoscience, 4:758-761.

Bintanja, R. and Selten, F. M. (2014). Future increases in Arctic precipitation linked to local evaporation and sea-ice retreat. Nature, 509:479-+.

Bintanja, R., van Oldenborgh, G. J., Drijfhout, S. S., Wouters, B., and Katsman, C. A. (2013). Important role for ocean warming and increased ice-shelf melt in Antarctic sea-ice expansion. Nature Geoscience, 6:376-379.

Black, E., Slingo, J., and Sperber, K. R. (2003). An observational study of the relationship between excessively strong short rains in coastal East Africa and Indian Ocean SST. Monthly Weather Review, 131:74-94.

Boening, C., Lebsock, M., Landerer, F., and Stephens, G. (2012). Snowfall-driven mass change on the East Antarctic Ice Sheet. Geophysical Research Letters, 39.

Bracegirdle, T. J. and Marshall, G. J. (2012). The reliability of Antarctic tropospheric pressure and temperature in the latest global reanalyses. Journal of Climate, 25:7138-7146.

Brandt, R. E., Warren, S. G., Worby, A. P., and Grenfell, T. C. (2005). Surface albedo of the Antarctic sea ice zone. Journal of Climate, 18:3606-3622.

Brayshaw, D. J., Woollings, T., and Vellinga, M. (2009). Tropical and extratropical responses of the North Atlantic atmospheric circulation to a sustained weakening of the MOC. Journal of Climate, 22:3146-3155.

Bromwich, D. H., Monaghan, A. J., and Guo, Z. C. (2004). Modeling the ENSO modulation of Antarctic climate in the late 1990s with the polar MM5. Journal of Climate, 17:109-132.

Bromwich, D. H., Nicolas, J. P., Monaghan, A. J., Lazzara, M. A., Keller, L. M., Weidner, G. A., and Wilson, A. B. (2013). Central West Antarctica among the most rapidly warming regions on earth. Nature Geoscience, 6:139-145.

Bromwich, D. H., Rogers, A. N., Kallberg, P., Cullather, R. I., White, J. W. C., and Kreutz, K. J. (2000). Ecmwf analyses and reanalyses depiction of ENSO signal in Antarctic precipitation. Journal of Climate, 13:1406-1420.

Cai, W. J., Sullivan, A., and Cowan, T. (2011a). Interactions of ENSO, the IOD, and the SAM in CMIP3 models. Journal of Climate, 24:1688-1704. 
Cai, W. J., van Rensch, P., Cowan, T., and Hendon, H. H. (2011b). Teleconnection pathways of ENSO and the IOD and the mechanisms for impacts on Australian rainfall. Journal of Climate, 24:3910-3923.

Caldeira, K. and Cvijanovic, I. (2014). Estimating the contribution of sea ice response to climate sensitivity in a climate model. Journal of Climate, 27:8597-8607.

Camargo, S. J. and Sobel, A. H. (2005). Western North Pacific tropical cyclone intensity and ENSO. Journal of Climate, 18:2996-3006.

Campagne, P., Crosta, X., Houssais, M. N., Swingedouw, D., Schmidt, S., Martin, A., Devred, E., Capo, S., Marieu, V., Closset, I., and Masse, G. (2015). Glacial ice and atmospheric forcing on the Mertz Glacier polynya over the past 250 years. Nature Communications, 6:6642.

Casey, K. A., Fudge, T. J., Neumann, T. A., Steig, E. J., Cavitte, M. G. P., and Blankenship, D. D. (2014). The $1500 \mathrm{~m}$ South Pole ice core: recovering a 40 ka environmental record. Annals of Glaciology, 55:137-146.

Clark, C. O., Webster, P. J., and Cole, J. E. (2003). Interdecadal variability of the relationship between the Indian Ocean zonal mode and East African coastal rainfall anomalies. Journal of Climate, 16:548-554.

Clem, K. R., Fogt, R. L., Turner, J., Lintner, B. R., Marshall, G. J., Miller, J. R., and Renwick, J. A. (2020). Record warming at the South Pole during the past three decades. Nature Climate Change, 10:762.

Clem, K. R., Renwick, J. A., and McGregor, J. (2017). Large-scale forcing of the Amundsen Sea Low and its influence on sea ice and west Antarctic temperature. Journal of Climate, 30:8405-8424.

Clem, K. R., Renwick, J. A., and McGregor, J. (2018). Autumn cooling of western East Antarctica linked to the tropical Pacific. Journal of Geophysical Research-Atmospheres, 123:89-107.

Clem, K. R., Renwick, J. A., McGregor, J., and Fogt, R. L. (2016). The relative influence of ENSO and SAM on Antarctic Peninsula climate. Journal of Geophysical ResearchAtmospheres, 121:9324-9341.

Coggins, J. H. J. and McDonald, A. J. (2015). The influence of the Amundsen Sea Low on the winds in the Ross Sea and surroundings: Insights from a synoptic climatology. Journal of Geophysical Research-Atmospheres, 120:2167-2189.

Comiso, J. C. (1986). Characteristics of arctic winter sea ice from satellite multispectral microwave observations. Journal of Geophysical Research: Oceans, 91(C1):975-994.

Comiso, J. C. and Nishio, F. (2008). Trends in the sea ice cover using enhanced and compatible AMSR-E, SSM/I, and SMMR data. Journal of Geophysical Research-Oceans, 113. 
Copernicus Climate Change Service (C3S) (2017). ERA5: Fifth generation of ECMWF atmospheric reanalyses of the global climate. Copernicus Climate Change Service Climate Data Store (CDS). accessed 07/06/19.

Cullather, R. I., Bromwich, D. H., and VanWoert, M. L. (1996). Interannual variations in Antarctic precipitation related to El Nino Southern Oscillation. Journal of Geophysical Research-Atmospheres, 101:19109-19118.

Curry, J. A., Schramm, J. L., and Ebert, E. E. (1995). Sea-ice albedo climate feedback mechanism. Journal of Climate, 8:240-247.

Dai, A. and Wigley, T. M. L. (2000). Global patterns of ENSO-induced precipitation. Geophysical Research Letters, 27:1283-1286.

Day, J. J., Bamber, J. L., and Valdes, P. J. (2013). The Greenland Ice Sheet's surface mass balance in a seasonally sea ice-free Arctic. Journal of Geophysical Research-Earth Surface, 118:1533-1544.

Delaygue, G., Masson, V., Jouzel, J., Koster, R. D., and Healy, R. J. (2000). The origin of Antarctic precipitation: a modelling approach. Tellus Series B-Chemical and Physical Meteorology, 52:19-36.

Deser, C., Walsh, J. E., and Timlin, M. S. (2000). Arctic sea ice variability in the context of recent atmospheric circulation trends. Journal of Climate, 13:617-633.

Dieckmann, G. S. and Hellmer, H. H. (2010). The importance of sea ice: an overview, volume 2. Wiley-Blackwell Oxford.

Ding, Q. H. and Steig, E. J. (2013). Temperature change on the Antarctic Peninsula linked to the tropical Pacific. Journal of Climate, 26:7570-7585.

Ding, Q. H., Steig, E. J., Battisti, D. S., and Kuttel, M. (2011). Winter warming in West Antarctica caused by central tropical Pacific warming. Nature Geoscience, 4:398-403.

Doddridge, E. W. and Marshall, J. (2017). Modulation of the seasonal cycle of Antarctic sea ice extent related to the Southern Annular Mode. Geophysical Research Letters, 44:9761-9768.

Domeisen, D. I. V., Garfinkel, C. I., and Butler, A. H. (2019). The teleconnection of El Nino Southern Oscillation to the stratosphere. Reviews of Geophysics, 57:5-47.

Eicken, H., Fischer, H., and Lemke, P. (1995). Effects of the snow cover on antarctic sea ice and potential modulation of its response to climate change. Annals of Glaciology, 21:369-376.

Ekaykin, A. A., Lipenkov, V. Y., Kuzmina, I. N., Petit, J. R., Masson-Delmotte, V., and Johnsen, S. J. (2004). The changes in isotope composition and accumulation of snow at vostok station, East Antarctica, over the past 200 years. Annals of Glaciology, Vol 39, 2004, 39:569-575.

England, M. R., Polvani, L. M., Sun, L. T., and Deser, C. (2020). Tropical climate responses to projected Arctic and Antarctic sea-ice loss. Nature Geoscience, 13:275-281. 
Feng, J. J., Zhang, Y. Z., Cheng, Q. M., Liang, X. S., and Jiang, T. C. (2019). Analysis of summer Antarctic sea ice anomalies associated with the spring Indian Ocean dipole. Global and Planetary Change, 181:102982.

Ferrari, R., Jansen, M. F., Adkins, J. F., Burke, A., Stewart, A. L., and Thompson, A. F. (2014). Antarctic sea ice control on ocean circulation in present and glacial climates. Proc Natl Acad Sci U S A, 111:8753-8758.

Ferreira, D., Marshall, J., Bitz, C. M., Solomon, S., and Plumb, A. (2015). Antarctic ocean and sea ice response to ozone depletion: A two-time-scale problem. Journal of Climate, 28:1206-1226.

Ferster, B. S., Subrahmanyam, B., and Macdonald, A. M. (2018). Confirmation of ENSOSouthern Ocean teleconnections using satellite-derived SST. Remote Sensing, 10(2):331.

Fichefet, T. and Maqueda, M. A. M. (1999). Modelling the influence of snow accumulation and snow-ice formation on the seasonal cycle of the Antarctic sea-ice cover. Climate Dynamics, 15:251-268.

Fogt, R. L. and Bromwich, D. H. (2006). Decadal variability of the ENSO teleconnection to the high-latitude South Pacific governed by coupling with the Southern Annular Mode. Journal of Climate, 19:979-997.

Fogt, R. L., Jones, J. M., and Renwick, J. (2012a). Seasonal zonal asymmetries in the Southern Annular Mode and their impact on regional temperature anomalies. Journal of Climate, 25(18):6253-6270.

Fogt, R. L. and Wovrosh, A. J. (2015). The relative influence of tropical sea surface temperatures and radiative forcing on the Amundsen Sea Low. Journal of Climate, 28:8540-8555.

Fogt, R. L., Wovrosh, A. J., Langen, R. A., and Simmonds, I. (2012b). The characteristic variability and connection to the underlying synoptic activity of the amundsen-bellingshausen seas low. Journal of Geophysical Research: Atmospheres, 117(D7).

Fretwell, P., Pritchard, H. D., Vaughan, D. G., Bamber, J. L., Barrand, N. E., Bell, R., Bianchi, C., Bingham, R. G., Blankenship, D. D., Casassa, G., Catania, G., Callens, D., Conway, H., Cook, A. J., Corr, H. F. J., Damaske, D., Damm, V., Ferraccioli, F., Forsberg, R., Fujita, S., Gim, Y., Gogineni, P., Griggs, J. A., Hindmarsh, R. C. A., Holmlund, P., Holt, J. W., Jacobel, R. W., Jenkins, A., Jokat, W., Jordan, T., King, E. C., Kohler, J., Krabill, W., Riger-Kusk, M., Langley, K. A., Leitchenkov, G., Leuschen, C., Luyendyk, B. P., Matsuoka, K., Mouginot, J., Nitsche, F. O., Nogi, Y., Nost, O. A., Popov, S. V., Rignot, E., Rippin, D. M., Rivera, A., Roberts, J., Ross, N., Siegert, M. J., Smith, A. M., Steinhage, D., Studinger, M., Sun, B., Tinto, B. K., Welch, B. C., Wilson, D., Young, D. A., Xiangbin, C., and Zirizzotti, A. (2013). Bedmap2: improved ice bed, surface and thickness datasets for Antarctica. The Cryosphere, 7:375-393.

Fujita, K. and Abe, O. (2006). Stable isotopes in daily precipitation at Dome Fuji, East Antarctica. Geophysical Research Letters, 33.

Fyfe, J. C. (2003). Separating extratropical zonal wind variability and mean change. Journal of Climate, 16:863-874. 
Fyke, J., Lenaerts, J. T. M., and Wang, H. L. (2017). Basin-scale heterogeneity in Antarctic precipitation and its impact on surface mass variability. Cryosphere, 11:2595-2609.

Genthon, C. and Cosme, E. (2003). Intermittent signature of ENSO in west-Antarctic precipitation. Geophysical Research Letters, 30(21).

Gillett, N. P., Kell, T. D., and Jones, P. D. (2006). Regional climate impacts of the Southern Annular Mode. Geophysical Research Letters, 33(23).

Gloersen, P. (1995). Modulation of hemispheric sea-ice cover by enso events. Nature, 373:503-506.

Golledge, N. R., Levy, R. H., McKay, R. M., and Naish, T. R. (2017). East Antarctic Ice Sheet most vulnerable to weddell sea warming. Geophysical Research Letters, 44:2343-2351.

Goosse, H., Lefebvre, W., de Montety, A., Crespin, E., and Orsi, A. H. (2009). Consistent past half-century trends in the atmosphere, the sea ice and the ocean at high southern latitudes. Climate Dynamics, 33:999-1016.

Gossart, A., Helsen, S., Lenaerts, J. T. M., Broucke, S. V., van Lipzig, N. P. M., and Souverijns, N. (2019). An evaluation of surface climatology in state-of-the-art reanalyses over the Antarctic Ice Sheet. Journal of Climate, 32:6899-6915.

Greene, C. A., Young, D. A., Gwyther, D. E., Galton-Fenzi, B. K., and Blankenship, D. D. (2018). Seasonal dynamics of Totten ice shelf controlled by sea ice buttressing. Cryosphere, 12:2869-2882.

Grieger, J., Leckebusch, G. C., Raible, C. C., Rudeva, I., and Simmonds, I. (2018). SubAntarctic cyclones identified by 14 tracking methods, and their role for moisture transports into the continent. Tellus Series a-Dynamic Meteorology and Oceanography, 70.

Grotzner, A., Sausen, R., and Claussen, M. (1996). The impact of sub-grid scale seaice inhomogeneities on the performance of the atmospheric general circulation model ECHAM3. Climate Dynamics, 12:477-496.

Gui, D., Lei, R., Pang, X., Hutchings, J. K., Zuo, G., and Zhai, M. (2020). Validation of remote-sensing products of sea-ice motion: a case study in the western arctic ocean. Journal of Glaciology, 66(259):807-821.

Hall, A. and Visbeck, M. (2002). Synchronous variability in the Southern Hemisphere atmosphere, sea ice, and ocean resulting from the annular mode. Journal of Climate, 15:3043-3057.

Han, W. Q. and Webster, P. J. (2002). Forcing mechanisms of sea level interannual variability in the Bay of Bengal. Journal of Physical Oceanography, 32:216-239.

Hanna, E. and Bamber, J. (2001). Derivation and optimization of a new antarctic sea-ice record. International Journal of Remote Sensing, 22(1):113-139.

Harangozo, S. A. (2004). The impact of winter ice retreat on Antarctic winter sea-ice extent and links to the atmospheric meridional circulation. International Journal of Climatology, 24:1023-1044. 
Harig, C. and Simons, F. J. (2015). Accelerated west Antarctic ice mass loss continues to outpace East Antarctic gains. Earth and Planetary Science Letters, 415:134-141.

Higgins, M. E. and Cassano, J. J. (2009). Impacts of reduced sea ice on winter Arctic atmospheric circulation, precipitation, and temperature. Journal of Geophysical ResearchAtmospheres, 114.

Hirasawa, N., Nakamura, H., and Yamanouchi, T. (2000). Abrupt changes in meteorological conditions observed at an inland Antarctic station in association with wintertime blocking. Geophysical Research Letters, 27:1911-1914.

Hobbs, W. R., Massom, R., Stammerjohn, S., Reid, P., Williams, G., and Meier, W. (2016). A review of recent changes in Southern Ocean sea ice, their drivers and forcings. Global and Planetary Change, 143:228-250.

Hobbs, W. R. and Raphael, M. N. (2010). The Pacific zonal asymmetry and its influence on Southern Hemisphere sea ice variability. Antarctic Science, 22:559-571.

Holland, M. M., Landrum, L., Kostov, Y., and Marshall, J. (2017). Sensitivity of Antarctic sea ice to the Southern Annular Mode in coupled climate models. Climate Dynamics, 49:1813-1831.

Holland, P. R. and Kwok, R. (2012). Wind-driven trends in Antarctic sea-ice drift. Nature Geoscience, 5:872-875.

Hosking, J. S., Orr, A., Marshall, G. J., Turner, J., and Phillips, T. (2013a). The influence of the amundsen-bellingshausen seas low on the climate of west antarctica and its representation in coupled climate model simulations. Journal of Climate, 26(17):6633-6648.

Hosking, J. S., Orr, A., Marshall, G. J., Turner, J., and Phillips, T. (2013b). The influence of the Amundsen-bellingshausen seas low on the climate of West Antarctica and its representation in coupled climate model simulations. Journal of Climate, 26:6633-6648.

IPCC (2019). Intergovernmental Panel on Climate Change (IPCC) special report on the ocean and cryosphere in a changing climate.

Isaacs, F. E., Renwick, J. A., Mackintosh, A. N., and Dadic, R. (2021). ENSO modulates summer and autumn sea ice variability around Dronning Maud Land, Antarctica. Journal of Geophysical Research: Atmospheres, 126:e2020JD033140.

Jacobs, S. S. (2004). Bottom water production and its links with the thermohaline circulation. Antarctic Science, 16:427-437.

Jones, D. A. and Simmonds, I. (1993). A climatology of southern hemisphere extratropical cyclones. Climate Dynamics, 9(3):131-145.

Jones, J. M., Gille, S. T., Goosse, H., Abram, N. J., Canziani, P. O., Charman, D. J., Clem, K. R., Crosta, X., de Lavergne, C., Eisenman, I., England, M. H., Fogt, R. L., Frankcombe, L. M., Marshall, G. J., Masson-Delmotte, V., Morrison, A. K., Orsi, A. J., Raphael, M. N., Renwick, J. A., Schneider, D. P., Simpkins, G. R., Steig, E. J., Stenni, B., Swingedouw, D., and Vance, T. R. (2016). Assessing recent trends in high-latitude Southern Hemisphere surface climate. Nature Climate Change, 6:917-926. 
Jones, P. D. and Lister, D. H. (2015). Antarctic near-surface air temperatures compared with ERA-interim values since 1979. International Journal of Climatology, 35:1354-1366.

Kalnay, E., Kanamitsu, M., Kistler, R., Collins, W., Deaven, D., Gandin, L., Iredell, M., Saha, S., White, G., Woollen, J., et al. (1996). The ncep/ncar 40-year reanalysis project. Bulletin of the American meteorological Society, 77(3):437-472.

Karoly, D. J. (1989). Southern Hemisphere circulation features associated with El NiñoSouthern Oscillation events. Journal of Climate, 2:1239-1252.

Khazendar, A., Schodlok, M. P., Fenty, I., Ligtenberg, S. R., Rignot, E., and van den Broeke, M. R. (2013). Observed thinning of Totten Glacier is linked to coastal polynya variability. Nature Communications, 4:2857.

Kidson, J. W. (1988). Indices of the Southern Hemisphere zonal wind. Journal of Climate, $1: 183-194$.

Kidson, J. W. and Renwick, J. A. (2002). The Southern Hemisphere evolution of ENSO during 1981-99. Journal of Climate, 15:847-863.

Kidston, J., Taschetto, A. S., Thompson, D. W. J., and England, M. H. (2011). The influence of Southern Hemisphere sea-ice extent on the latitude of the mid-latitude jet stream. Geophysical Research Letters, 38.

Kimura, N. (2004). Sea ice motion in response to surface wind and ocean current in the Southern Ocean. Journal of the Meteorological Society of Japan. Ser. II, 82(4):1223-1231.

Kimura, N. and Wakatsuchi, M. (2011). Large-scale processes governing the seasonal variability of the Antarctic sea ice. Tellus Series a-Dynamic Meteorology and Oceanography, 63:828-840.

Kopec, B. G., Feng, X., Michel, F. A., and Posmentier, E. S. (2016). Influence of sea ice on Arctic precipitation. Proc Natl Acad Sci U S A, 113:46-51.

Kostov, Y., Marshall, J., Hausmann, U., Armour, K. C., Ferreira, D., and Holland, M. M. (2017). Fast and slow responses of southern ocean sea surface temperature to sam in coupled climate models. Climate Dynamics, 48(5-6):1595-1609.

Krinner, G., Magand, O., Simmonds, I., Genthon, C., and Dufresne, J. L. (2007). Simulated Antarctic precipitation and surface mass balance at the end of the twentieth and twenty-first centuries. Climate Dynamics, 28:215-230.

Kumar, A., Perlwitz, J., Eischeid, J., Quan, X. W., Xu, T. Y., Zhang, T., Hoerling, M., Jha, B., and Wang, W. Q. (2010). Contribution of sea ice loss to Arctic amplification. Geophysical Research Letters, 37:n/a-n/a.

Kwok, R. and Comiso, J. C. (2002). Spatial patterns of variability in Antarctic surface temperature: Connections to the Southern Hemisphere annular mode and the Southern Oscillation. Geophysical Research Letters, 29:50-1-50-4.

Kwok, R., Comiso, J. C., Lee, T., and Holland, P. R. (2016). Linked trends in the South Pacific sea ice edge and Southern Oscillation index. Geophysical Research Letters, 43:10295-10302. 
Lau, N. C. and Nath, M. J. (2004). Coupled gcm simulation of atmosphere-ocean variability associated with zonally asymmetric SST changes in the tropical Indian Ocean. Journal of Climate, 17:245-265.

Lefebvre, W. and Goosse, H. (2005). Influence of the Southern Annular Mode on the sea ice-ocean system: the role of the thermal and mechanical forcing. Ocean Science, $1: 145-157$.

Lefebvre, W. and Goosse, H. (2008). An analysis of the atmospheric processes driving the large-scale winter sea ice variability in the Southern Ocean. Journal of Geophysical Research-Oceans, 113:C02004.

Lefebvre, W., Goosse, H., Timmermann, R., and Fichefet, T. (2004). Influence of the Southern Annular Mode on the sea ice-ocean system. Journal of Geophysical Research-Oceans, 109.

Lenaerts, J. T. M., Vizcaino, M., Fyke, J., van Kampenhout, L., and van den Broeke, M. R. (2016). Present-day and future Antarctic Ice Sheet climate and surface mass balance in the Community Earth System Model. Climate Dynamics, 47:1367-1381.

L'Heureux, M. L. and Thompson, D. W. J. (2006). Observed relationships between the El Nino-Southern Oscillation and the extratropical zonal-mean circulation. Journal of Climate, 19(2):276-287.

Li, T., Wang, B., Chang, C. P., and Zhang, Y. S. (2003). A theory for the Indian Ocean dipole-zonal mode. Journal of the Atmospheric Sciences, 60:2119-2135.

Lin, J. and Qian, T. (2019). A new picture of the global impacts of El Nino-Southern Oscillation. Scientific Reports, 9:17543.

Liu, J., Curry, J. A., Wang, H., Song, M., and Horton, R. M. (2012). Impact of declining Arctic sea ice on winter snowfall. Proc Natl Acad Sci U S A, 109:4074-4079.

Liu, J. P., Chen, Z. Q., Francis, J., Song, M. R., Mote, T., and Hu, Y. Y. (2016). Has Arctic sea ice loss contributed to increased surface melting of the Greenland Ice Sheet? Journal of Climate, 29:3373-3386.

Liu, J. P., Curry, J. A., and Martinson, D. G. (2004). Interpretation of recent Antarctic sea ice variability. Geophysical Research Letters, 31.

Liu, J. P., Martinson, D. G., Yuan, X. J., and Rind, D. (2002). Evaluating Antarctic sea ice variability and its teleconnections in global climate models. International Journal of Climatology, 22:885-900.

Ludescher, J., Yuan, N. M., and Bunde, A. (2019). Detecting the statistical significance of the trends in the Antarctic sea ice extent: an indication for a turning point. Climate Dynamics, 53:237-244.

Lytle, V. and Ackley, S. (2001). Snow-ice growth: a fresh-water flux inhibiting deep convection in the weddell sea, antarctica. Annals of Glaciology, 33:45-50. 
Mahlstein, I., Gent, P. R., and Solomon, S. (2013). Historical Antarctic mean sea ice area, sea ice trends, and winds in CMIP5 simulations. Journal of Geophysical ResearchAtmospheres, 118:5105-5110.

Maqueda, M. A. M., Willmott, A. J., and Biggs, N. R. T. (2004). Polynya dynamics: A review of observations and modeling. Reviews of Geophysics, 42.

Marshall, G. J. (2003). Trends in the Southern Annular Mode from observations and reanalyses. Journal of Climate, 16:4134-4143.

Marshall, G. J. (2007). Half-century seasonal relationships between the Southern Annular Mode and Antarctic temperatures. International Journal of Climatology, 27:373-383.

Marshall, G. J. (2009). On the annual and semi-annual cycles of precipitation across Antarctica. International Journal of Climatology, 29:2298-2308.

Marshall, G. J., Orr, A., and Turner, J. (2013). A predominant reversal in the relationship between the SAM and East Antarctic temperatures during the twenty-first century. Journal of Climate, 26:5196-5204.

Marshall, G. J. and Thompson, D. W. J. (2016). The signatures of large-scale patterns of atmospheric variability in Antarctic surface temperatures. Journal of Geophysical Research-Atmospheres, 121:3276-3289.

Marshall, G. J., Thompson, D. W. J., and van den Broeke, M. R. (2017). The signature of Southern Hemisphere atmospheric circulation patterns in Antarctic precipitation. Geophysical Research Letters, 44:11580-11589.

Marzocchi, A. and Jansen, M. F. (2017). Connecting Antarctic sea ice to deep-ocean circulation in modern and glacial climate simulations. Geophysical Research Letters, 44:6286-6295.

Massom, R., Reid, P., Stammerjohn, S., Raymond, B., Fraser, A., and Ushio, S. (2013). Change and variability in East Antarctic sea ice seasonality, 1979/80-2009/10. Plos One, 8.

Massom, R. A., Eicken, H., Hass, C., Jeffries, M. O., Drinkwater, M. R., Sturm, M., Worby, A. P., Wu, X., Lytle, V. I., Ushio, S., et al. (2001). Snow on antarctic sea ice. Reviews of Geophysics, 39(3):413-445.

Massom, R. A., Pook, M. J., Comiso, J. C., Adams, N., Turner, J., Lachlan-Cope, T., and Gibson, T. T. (2004). Precipitation over the interior East Antarctic Ice Sheet related to midlatitude blocking-high activity. Journal of Climate, 17:1914-1928.

Maykut, G. A. (1986). The surface heat and mass balance. In The geophysics of sea ice, pages 395-463. Springer.

McIntosh, P. C. and Hendon, H. H. (2018). Understanding Rossby wave trains forced by the Indian Ocean Dipole. Climate Dynamics, 50:2783-2798.

McMillan, M., Shepherd, A., Sundal, A., Briggs, K., Muir, A., Ridout, A., Hogg, A., and Wingham, D. (2014). Increased ice losses from Antarctica detected by cryosat-2. Geophysical Research Letters, 41:3899-3905. 
Medley, B. and Thomas, E. R. (2019). Increased snowfall over the Antarctic Ice Sheet mitigated twentieth-century sea-level rise. Nature Climate Change, 9:34-+.

Meehl, G. A., Arblaster, J. M., Bitz, C. M., Chung, C. T. Y., and Teng, H. Y. (2016). Antarctic sea-ice expansion between 2000 and 2014 driven by tropical Pacific decadal climate variability. Nature Geoscience, 9:590-+.

Meehl, G. A., Arblaster, J. M., Chung, C. T. Y., Holland, M. M., DuVivier, A., Thompson, L., Yang, D., and Bitz, C. M. (2019). Sustained ocean changes contributed to sudden Antarctic sea ice retreat in late 2016. Nature Communications, 10:14.

Meier, W. N., Hovelsrud, G. K., van Oort, B. E. H., Key, J. R., Kovacs, K. M., Michel, C., Haas, C., Granskog, M. A., Gerland, S., Perovich, D. K., Makshtas, A., and Reist, J. D. (2014). Arctic sea ice in transformation: A review of recent observed changes and impacts on biology and human activity. Reviews of Geophysics, 52:185-217.

Mesquita, M. D. S., Hodges, K. I., Atkinson, D. E., and Bader, J. (2011). Sea-ice anomalies in the Sea of Okhotsk and the relationship with storm tracks in the Northern Hemisphere during winter. Tellus Series a-Dynamic Meteorology and Oceanography, 63:312-323.

Meyers, G., McIntosh, P., Pigot, L., and Pook, M. (2007). The years of El Nino, La Nina, and interactions with the tropical indian ocean. Journal of Climate, 20:2872-2880.

Michel, L. N., Danis, B., Dubois, P., Eleaume, M., Fournier, J., Gallut, C., Jane, P., and Lepoint, G. (2019). Increased sea ice cover alters food web structure in East Antarctica. Scientific Reports, 9:8062.

Miles, B. W. J., Stokes, C. R., and Jamieson, S. S. R. (2016). Pan-ice-sheet glacier terminus change in East Antarctica reveals sensitivity of Wilkes Land to sea-ice changes. Science Advances, 2.

Miles, B. W. J., Stokes, C. R., and Jamieson, S. S. R. (2017). Simultaneous disintegration of outlet glaciers in Porpoise Bay (Wilkes Land), East Antarctica, driven by sea ice break-up. Cryosphere, 11:427-442.

Miles, B. W. J., Stokes, C. R., Vieli, A., and Cox, N. J. (2013). Rapid, climate-driven changes in outlet glaciers on the Pacific coast of East Antarctica. Nature, 500:563-+.

Mo, K. C. and Higgins, R. W. (1998). The Pacific-South American modes and tropical convection during the Southern Hemisphere winter. Monthly Weather Review, 126:15811596.

Mo, K. C. and Paegle, J. N. (2001). The Pacific-South American modes and their downstream effects. International Journal of Climatology, 21:1211-1229.

Mo, K. C. and White, G. H. (1985). Teleconnections in the Southern Hemisphere. Monthly Weather Review, 113(1):22-37.

Nadeau, L. P., Ferrari, R., and Jansen, M. F. (2019). Antarctic sea ice control on the depth of North Atlantic deep water. Journal of Climate, 32:2537-2551. 
National Academies of Sciences, Engineering and Medicine and others (2017). Antarctic Sea Ice Variability in the Southern Ocean-Climate System: Proceedings of a Workshop. Washington, DC: The National Academies Press.

Newman, L., Heil, P., Trebilco, R., Katsumata, K., Constable, A., Van Wijk, E., Assmann, K., Beja, J., Bricher, P., Coleman, R., et al. (2019). Delivering sustained, coordinated, and integrated observations of the southern ocean for global impact. Frontiers in Marine Science, 6:433.

Nicolas, J. P. and Bromwich, D. H. (2014). New reconstruction of Antarctic near-surface temperatures: Multidecadal trends and reliability of global reanalyses. Journal of Climate, 27:8070-8093.

Noel, B., Fettweis, X., van de Berg, W. J., van den Broeke, M. R., and Erpicum, M. (2014). Sensitivity of Greenland Ice Sheet surface mass balance to perturbations in sea surface temperature and sea ice cover: a study with the regional climate model MAR. Cryosphere, 8:1871-1883.

Noone, D. and Simmonds, I. (2002). Annular variations in moisture transport mechanisms and the abundance of delta o-18 in Antarctic snow. Journal of Geophysical ResearchAtmospheres, 107.

Noone, D. and Simmonds, I. (2004). Sea ice control of water isotope transport to Antarctica and implications for ice core interpretation. Journal of Geophysical Research-Atmospheres, 109.

Noone, D., Turner, J., and Mulvaney, R. (1999). Atmospheric signals and characteristics of accumulation in Dronning Maud Land, Antarctica. Journal of Geophysical ResearchAtmospheres, 104:19191-19211.

Notz, D. and Stroeve, J. (2018). The trajectory towards a seasonally ice-free Arctic Ocean. Current Climate Change Reports, 4:407-416.

Nuncio, M. and Yuan, X. J. (2015). The influence of the Indian Ocean Dipole on Antarctic sea ice. Journal of Climate, 28:2682-2690.

Okumura, Y. M. and Deser, C. (2010). Asymmetry in the duration of El Nino and La Nina. Journal of Climate, 23:5826-5843.

Orme, L. C., Charman, D. J., Reinhardt, L., Jones, R. T., Mitchell, F. J. G., Stefanini, B. S., Barkwith, A., Ellis, M. A., and Grosvenor, M. (2017). Past changes in the North Atlantic storm track driven by insolation and sea-ice forcing. Geology, 45:335-338.

Orr, A., Marshall, G. J., Hunt, J. C. R., Sommeria, J., Wang, C. G., van Lipzig, N. P. M., Cresswell, D., and King, J. C. (2008). Characteristics of summer airflow over the Antarctic Peninsula in response to recent strengthening of westerly circumpolar winds. Journal of the Atmospheric Sciences, 65:1396-1413.

Parkinson, C. L. (2019). A 40-y record reveals gradual Antarctic sea ice increases followed by decreases at rates far exceeding the rates seen in the Arctic. Proceedings of the National Academy of Sciences, 116:14414-14423. 
Parkinson, C. L. and Cavalieri, D. J. (2012). Antarctic sea ice variability and trends, 19792010. Cryosphere, 6:871-880.

Pezza, A. B., Durrant, T., Simmonds, I., and Smith, I. (2008). Southern Hemisphere synoptic behavior in extreme phases of SAM, ENSO, sea ice extent, and Southern Australia rainfall. Journal of Climate, 21:5566-5584.

Pezza, A. B., Rashid, H. A., and Simmonds, I. (2012). Climate links and recent extremes in Antarctic sea ice, high-latitude cyclones, Southern Annular Mode and ENSO. Climate Dynamics, 38:57-73.

Polvani, L. M. and Smith, K. L. (2013). Can natural variability explain observed Antarctic sea ice trends? new modeling evidence from CMIP5. Geophysical Research Letters, 40:3195-3199.

Pope, J. O., Holland, P. R., Orr, A., Marshall, G. J., and Phillips, T. (2017). The impacts of El Nino on the observed sea ice budget of West Antarctica. Geophysical Research Letters, 44:6200-6208.

Powell, D. C., Markus, T., and Stössel, A. (2005). Effects of snow depth forcing on southern ocean sea ice simulations. Journal of Geophysical Research: Oceans, 110(C6).

Power, S., Casey, T., Folland, C., Colman, A., and Mehta, V. (1999). Inter-decadal modulation of the impact of ENSO on Australia. Climate Dynamics, 15:319-324.

Pozo-Vazquez, D., Esteban-Parra, M. J., Rodrigo, F. S., and Castro-Diez, Y. (2001). The association between ENSO and winter atmospheric circulation and temperature in the North Atlantic region. Journal of Climate, 14(16):3408-3420.

Price, J. F., Weller, R. A., and Schudlich, R. R. (1987). Wind-driven ocean currents and ekman transport. Science, 238(4833):1534-1538.

Pritchard, H. D., Arthern, R. J., Vaughan, D. G., and Edwards, L. A. (2009). Extensive dynamic thinning on the margins of the Greenland and Antarctic Ice Sheets. Nature, 461:971-975.

Purich, A. and England, M. H. (2019). Tropical teleconnections to Antarctic sea ice during austral spring 2016 in coupled pacemaker experiments. Geophysical Research Letters, 46:6848-6858.

Purich, A., England, M. H., Cai, W., Chikamoto, Y., Timmermann, A., Fyfe, J. C., Frankcombe, L., Meehl, G. A., and Arblaster, J. M. (2016). Tropical Pacific SST drivers of recent Antarctic sea ice trends. Journal of Climate, 29:8931-8948.

Rahaman, W., Chatterjee, S., Ejaz, T., and Thamban, M. (2019). Increased influence of ENSO on Antarctic temperature since the industrial era. Scientific Reports, 9:6006.

Rai, S., Khare, N., and Pandey, A. C. (2008). Antarctica sea ice variability and southeast indian ocean SST: Possible-relationship. Indian Journal of Marine Sciences, 37:35-39.

Rao, S. A., Behera, S. K., Masumoto, Y., and Yamagata, T. (2002). Interannual subsurface variability in the tropical Indian Ocean with a special emphasis on the Indian Ocean Dipole. Deep-Sea Research Part Ii-Topical Studies in Oceanography, 49:1549-1572. 
Raphael, M. N. (2004). A zonal wave 3 index for the Southern Hemisphere. Geophysical Research Letters, 31.

Raphael, M. N. (2007). The influence of atmospheric zonal wave three on Antarctic sea ice variability. Journal of Geophysical Research-Atmospheres, 112.

Raphael, M. N. and Hobbs, W. (2014). The influence of the large-scale atmospheric circulation on Antarctic sea ice during ice advance and retreat seasons. Geophysical Research Letters, 41:5037-5045.

Raphael, M. N., Hobbs, W., and Wainer, I. (2011). The effect of Antarctic sea ice on the Southern Hemisphere atmosphere during the southern summer. Climate Dynamics, 36:1403-1417.

Raphael, M. N., Holland, M. M., Landrum, L., and Hobbs, W. R. (2019). Links between the Amundsen Sea Low and sea ice in the Ross Sea: seasonal and interannual relationships. Climate Dynamics, 52(3):2333-2349.

Raphael, M. N., Marshall, G. J., Turner, J., Fogt, R. L., Schneider, D., Dixon, D. A., Hosking, J. S., Jones, J., and Hobbs, W. R. (2016). The Amundsen Sea low: Variability, change, and impact on Antarctic climate. Bulletin of the American Meteorological Society, 97:111-121.

Rayner, N. A., Parker, D. E., Horton, E. B., Folland, C. K., Alexander, L. V., Rowell, D. P., Kent, E. C., and Kaplan, A. (2003). Global analyses of sea surface temperature, sea ice, and night marine air temperature since the late nineteenth century. Journal of Geophysical Research-Atmospheres, 108.

Reeh, N., Thomsen, H. H., Higgins, A. K., and Weidick, A. (2001). Sea ice and the stability of north and northeast Greenland floating glaciers. Annals of Glaciology, Vol 33, 33:474-480.

Reiss, C. S., Cossio, A., Santora, J. A., Dietrich, K. S., Murray, A., Mitchell, B. G., Walsh, J., Weiss, E. L., Gimpel, C., Jones, C. D., and Watters, G. M. (2017). Overwinter habitat selection by Antarctic krill under varying sea-ice conditions: implications for top predators and fishery management. Marine Ecology Progress Series, 568:1-16.

Renwick, J. A. (2002). Southern Hemisphere circulation and relations with sea ice and sea surface temperature. Journal of Climate, 15:3058-3068.

Renwick, J. A. (2005). Persistent positive anomalies in the Southern Hemisphere circulation. Monthly Weather Review, 133:977-988.

Renwick, J. A., Kohout, A., and Dean, S. (2012). Atmospheric forcing of Antarctic sea ice on intraseasonal time scales. Journal of Climate, 25:5962-5975.

Rignot, E., Mouginot, J., Scheuchl, B., van den Broeke, M., van Wessem, M. J., and Morlighem, M. (2019). Four decades of Antarctic Ice Sheet mass balance from 1979-2017. Proc Natl Acad Sci U S A, 116:1095-1103.

Rind, D., Healy, R., Parkinson, C., and Martinson, D. (1995). The role of sea-ice in 2x co2 climate model sensitivity .1. the total influence of sea-ice thickness and extent. Journal of Climate, 8:449-463. 
Rinke, A., Dethloff, K., Dorn, W., Handorf, D., and Moore, J. C. (2013). Simulated Arctic atmospheric feedbacks associated with late summer sea ice anomalies. Journal of Geophysical Research-Atmospheres, 118:7698-7714.

Rintoul, S. R., Silvano, A., Pena-Molino, B., van Wijk, E., Rosenberg, M., Greenbaum, J. S., and Blankenship, D. D. (2016). Ocean heat drives rapid basal melt of the Totten ice shelf. Science Advances, 2:e1601610.

Robinson, S. A., King, D. H., Bramley-Alves, J., Waterman, M. J., Ashcroft, M. B., Wasley, J., Turnbull, J. D., Miller, R. E., Ryan-Colton, E., Benny, T., Mullany, K., Clarke, L., Barry, L. A., and Hua, Q. (2018). Rapid change in East Antarctic terrestrial vegetation in response to regional drying. Nature Climate Change, 8:879-+.

Rogers, J. C. and Loon, H. V. (1982). Spatial variability of sea level pressure and $500 \mathrm{mb}$ height anomalies over the Southern Hemisphere. Monthly Weather Review, 110:13751392.

Romero-Centeno, R., Zavala-Hidalgo, J., Gallegos, A., and O'Brien, J. J. (2003). Isthmus of tehuantepec wind climatology and ENSO signal. Journal of Climate, 16(15):2628-2639.

Ropelewski, C. F. and Halpert, M. S. (1986). North American precipitation and temperature patterns associated with the El Niño/Southern Oscillation (ENSO). Monthly Weather Review, 114:2352-2362.

Saji, N. H., Goswami, B. N., Vinayachandran, P. N., and Yamagata, T. (1999). A dipole mode in the tropical Indian Ocean. Nature, 401:360-363.

Saji, N. H. and Yamagata, T. (2003). Possible impacts of Indian Ocean Dipole mode events on global climate. Climate Research, 25:151-169.

Sasgen, I., Konrad, H., Ivins, E. R., den Broeke, M. R. V., Bamber, J. L., Martinec, Z., and Klemann, V. (2013). Antarctic ice-mass balance 2003 to 2012: regional reanalysis of grace satellite gravimetry measurements with improved estimate of glacial-isostatic adjustment based on gps uplift rates. Cryosphere, 7:1499-1512.

Schlosser, E., Powers, J. G., Duda, M. G., Manning, K. W., Reijmer, C. H., and van den Broeke, M. R. (2010). An extreme precipitation event in Dronning Maud Land, Antarctica: a case study with the Antarctic mesoscale prediction system. Polar Research, 29:330-344.

Schlosser, E., Reijmer, C., Oerter, H., and Graf, W. (2004). The influence of precipitation origin on the delta18o-t relationship at Neumayer station, Ekstrmisen, Antarctica. Annals of Glaciology, 39:41-48.

Schneider, D. P., Okumura, Y., and Deser, C. (2012). Observed Antarctic interannual climate variability and tropical linkages. Journal of Climate, 25:4048-4066.

Screen, J. A. (2013). Influence of Arctic sea ice on european summer precipitation. Environmental Research Letters, 8(4):044015.

Screen, J. A. and Simmonds, I. (2010). The central role of diminishing sea ice in recent Arctic temperature amplification. Nature, 464:1334-1337. 
Sen Gupta, A. and England, M. H. (2006). Coupled ocean-atmosphere-ice response to variations in the Southern Annular Mode. Journal of Climate, 19(18):4457-4486.

Serreze, M. C., Barrett, A. P., Stroeve, J. C., Kindig, D. N., and Holland, M. M. (2009). The emergence of surface-based Arctic amplification. Cryosphere, 3:11-19.

Shen, Q., Wang, H., Shum, C. K., Jiang, L., Hsu, H. T., and Dong, J. (2018). Recent high-resolution Antarctic ice velocity maps reveal increased mass loss in Wilkes Land, East Antarctica. Scientific Reports, 8:4477.

Shepherd, A., Ivins, E., Rignot, E., Smith, B., van den Broeke, M., Velicogna, I., Whitehouse, P., Briggs, K., Joughin, I., Krinner, G., Nowicki, S., Payne, T., Scambos, T., Schlegel, N., Geruo, A., Agosta, C., Ahlstrom, A., Babonis, G., Barletta, V., Blazquez, A., Bonin, J., Csatho, B., Cullather, R., Felikson, D., Fettweis, X., Forsberg, R., Gallee, H., Gardner, A., Gilbert, L., Groh, A., Gunter, B., Hanna, E., Harig, C., Helm, V., Horvath, A., Horwath, M., Khan, S., Kjeldsen, K. K., Konrad, H., Langen, P., Lecavalier, B., Loomis, B., Luthcke, S., McMillan, M., Melini, D., Mernild, S., Mohajerani, Y., Moore, P., Mouginot, J., Moyano, G., Muir, A., Nagler, T., Nield, G., Nilsson, J., Noel, B., Otosaka, I., Pattle, M. E., Peltier, W. R., Pie, N., Rietbroek, R., Rott, H., Sandberg-Sorensen, L., Sasgen, I., Save, H., Scheuchl, B., Schrama, E., Schroder, L., Seo, K. W., Simonsen, S., Slater, T., Spada, G., Sutterley, T., Talpe, M., Tarasov, L., van de Berg, W. J., van der Wal, W., van Wessem, M., Vishwakarma, B. D., Wiese, D., Wouters, B., and Team, I. (2018). Mass balance of the Antarctic Ice Sheet from 1992 to 2017. Nature, 558:219-+.

Silvestri, G. and Vera, C. (2009). Nonstationary impacts of the Southern Annular Mode on Southern Hemisphere climate. Journal of Climate, 22:6142-6148.

Simmonds, I. and Jacka, T. H. (1995). Relationships between the interannual variability of Antarctic sea-ice and the Southern Oscillation. Journal of Climate, 8:637-647.

Simpkins, G. R., Ciasto, L. M., Thompson, D. W. J., and England, M. H. (2012). Seasonal relationships between large-scale climate variability and Antarctic sea ice concentration. Journal of Climate, 25:5451-5469.

Singarayer, J. S., Bamber, J. L., and Valdes, P. J. (2006). Twenty-first-century climate impacts from a declining Arctic sea ice cover. Journal of Climate, 19:1109-1125.

Smith, C. A. and Sardeshmukh, P. D. (2000). The effect of ENSO on the intraseasonal variance of surface temperatures in winter. International Journal of Climatology, 20:15431557.

Smith, D. (1996). Extraction of winter total sea-ice concentration in the greenland and barents seas from ssm/i data. Remote Sensing, 17(13):2625-2646.

Sodemann, H. and Stohl, A. (2009). Asymmetries in the moisture origin of Antarctic precipitation. Geophysical Research Letters, 36.

Stammerjohn, S., Maksym, T., Heil, P., Massom, R. A., Vancoppenolle, M., and Leonard, K. C. (2011). The influence of winds, sea-surface temperature and precipitation anomalies on Antarctic regional sea-ice conditions during IPY 2007. Deep-Sea Research Part Ii-Topical Studies in Oceanography, 58:999-1018. 
Stammerjohn, S. E., Martinson, D. G., Smith, R. C., Yuan, X., and Rind, D. (2008). Trends in Antarctic annual sea ice retreat and advance and their relation to El Nino-Southern Oscillation and Southern Annular Mode variability. Journal of Geophysical ResearchOceans, 113.

Steele, M., Zhang, J., Rothrock, D., and Stern, H. (1997). The force balance of sea ice in a numerical model of the Arctic Ocean. Journal of Geophysical Research: Oceans, 102(C9):21061-21079.

Steig, E. J., Schneider, D. P., Rutherford, S. D., Mann, M. E., Comiso, J. C., and Shindell, D. T. (2009). Warming of the Antarctic ice-sheet surface since the 1957 International Geophysical Year (vol 457, pg 459, 2009). Nature, 460:766.

Stenni, B., Scarchilli, C., Masson-Delmotte, V., Schlosser, E., Ciardini, V., Dreossi, G., Grigioni, P., Bonazza, M., Cagnati, A., Karlicek, D., Risi, C., Udisti, R., and Valt, M. (2016). Three-year monitoring of stable isotopes of precipitation at concordia station, East Antarctica. Cryosphere, 10:2415-2428.

Stroeve, J. C., Jenouvrier, S., Campbell, G. G., Barbraud, C., and Delord, K. (2016). Mapping and assessing variability in the Antarctic marginal ice zone, pack ice and coastal polynyas in two sea ice algorithms with implications on breeding success of snow petrels. Cryosphere, 10:1823-1843.

Stuecker, M. F., Bitz, C. M., and Armour, K. C. (2017). Conditions leading to the unprecedented low Antarctic sea ice extent during the 2016 austral spring season. Geophysical Research Letters, 44:9008-9019.

Sturm, M. and Massom, R. A. (2009). Snow and sea ice. Sea ice, 2:153-204.

Sumata, H., Lavergne, T., Girard-Ardhuin, F., Kimura, N., Tschudi, M. A., Kauker, F., Karcher, M., and Gerdes, R. (2014). An intercomparison of a rctic ice drift products to deduce uncertainty estimates. Journal of Geophysical Research: Oceans, 119(8):48874921.

Suzuki, K., Yamanouchi, T., and Motoyama, H. (2008). Moisture transport to Syowa and Dome Fuji stations in Antarctica. Journal of Geophysical Research-Atmospheres, 113.

Tamura, T., Ohshima, K. I., and Nihashi, S. (2008). Mapping of sea ice production for Antarctic coastal polynyas. Geophysical Research Letters, 35:n/a-n/a.

Thompson, D. W. J. and Solomon, S. (2002). Interpretation of recent Southern Hemisphere climate change. Science, 296:895-899.

Thompson, D. W. J. and Wallace, J. M. (2000). Annular modes in the extratropical circulation. part i: Month-to-month variability. Journal of Climate, 13:1000-1016.

Tietavainen, H. and Vihma, T. (2008). Atmospheric moisture budget over Antarctica and the Southern Ocean based on the ERA-40 reanalysis. International Journal of Climatology, 28:1977-1995. 
Titchner, H. A. and Rayner, N. A. (2014). The Met Office Hadley Centre sea ice and sea surface temperature data set, version 2: 1. sea ice concentrations. Journal of Geophysical Research-Atmospheres, 119:2864-2889.

Trathan, P. N., Wienecke, B., Barbraud, C., Jenouvrier, S., Kooyman, G., Bohec, C. L., Ainley, D. G., Ancel, A., Zitterbart, D. P., Chown, S. L., LaRue, M., Cristofari, R., Younger, J., Clucas, G., Bost, C. A., Brown, J. A., Gillett, H. J., and Fretwell, P. T. (2020). The emperor penguin - vulnerable to projected rates of warming and sea ice loss. Biological Conservation, 241.

Trenberth, K. E. (1980). Planetary-waves at 500-mb in the Southern-Hemisphere. Monthly Weather Review, 108:1378-1389.

Trenberth, K. E. (1997). The definition of el nino. Bulletin of the American Meteorological Society, 78(12):2771-2778.

Tschudi, M., Meier, W., Stewart, J., Fowler, C., and Maslanik, J. (2019). Polar pathfinder daily $25 \mathrm{~km}$ ease-grid sea ice motion vectors, version 4. Boulder, CO: NASA National Snow and Ice Data Center Distributed Active Archive Center, 10.

Turner, J. (2004). The El Nino-Southern Oscillation and Antarctica. International Journal of Climatology, 24:1-31.

Turner, J., Bracegirdle, T. J., Phillips, T., Marshall, G. J., and Hosking, J. S. (2013a). An initial assessment of Antarctic sea ice extent in the CMIP5 models. Journal of Climate, 26:1473-1484.

Turner, J., Comiso, J. C., Marshall, G. J., Lachlan-Cope, T. A., Bracegirdle, T., Maksym, T., Meredith, M. P., Wang, Z., and Orr, A. (2009). Non-annular atmospheric circulation change induced by stratospheric ozone depletion and its role in the recent increase of Antarctic sea ice extent. Geophysical Research Letters, 36:L08502.

Turner, J., Hosking, J. S., Bracegirdle, T. J., Marshall, G. J., and Phillips, T. (2015). Recent changes in Antarctic sea ice. Philosophical Transactions of the Royal Society aMathematical Physical and Engineering Sciences, 373.

Turner, J., Hosking, J. S., Bracegirdle, T. J., Phillips, T., and Marshall, G. J. (2017a). Variability and trends in the Southern Hemisphere high latitude, quasi-stationary planetary waves. International Journal of Climatology, 37:2325-2336.

Turner, J., Hosking, J. S., Marshall, G. J., Phillips, T., and Bracegirdle, T. J. (2016). Antarctic sea ice increase consistent with intrinsic variability of the Amundsen Sea Low. Climate Dynamics, 46:2391-2402.

Turner, J., Lachlancope, T. A., Thomas, J. P., and Colwell, S. R. (1995). The synoptic origins of precipitation over the Antarctic Peninsula. Antarctic Science, 7:327-337.

Turner, J., Phillips, T., Hosking, J. S., Marshall, G. J., and Orr, A. (2013b). The amundsen sea low. International Journal of Climatology, 33(7):1818-1829.

Turner, J., Phillips, T., Hosking, J. S., Marshall, G. J., and Orr, A. (2013c). The Amundsen Sea low. International Journal of Climatology, 33:1818-1829. 
Turner, J., Phillips, T., Marshall, G. J., Hosking, J. S., Pope, J. O., Bracegirdle, T. J., and Deb, P. (2017b). Unprecedented springtime retreat of Antarctic sea ice in 2016. Geophysical Research Letters, 44:6868-6875.

Turner, J., Phillips, T., Thamban, M., Rahaman, W., Marshall, G. J., Wille, J. D., Favier, V., Winton, V. H. L., Thomas, E., and Wang, Z. (2019). The dominant role of extreme precipitation events in Antarctic snowfall variability. Geophysical Research Letters, 46:3502-3511.

Van Den Broeke, M. R. and Van Lipzig, N. P. (2004). Changes in Antarctic temperature, wind and precipitation in response to the Antarctic oscillation. Annals of Glaciology, 39:119-126.

van Loon, H. and Jenne, R. L. (1972). The zonal harmonic standing waves in the Southern Hemisphere. Journal of Geophysical Research, 77(6):992-1003.

Walden, V. P., Warren, S. G., and Tuttle, E. (2003). Atmospheric ice crystals over the Antarctic plateau in winter. Journal of Applied Meteorology, 42:1391-1405.

Walsh, J. E. (1983). The role of sea ice in climatic variability: Theories and evidence. Atmosphere-Ocean, 21:229-242.

Wang, B. and Chan, J. C. L. (2002). How strong ENSO events affect tropical storm activity over the western North Pacific. Journal of Climate, 15:1643-1658.

Wang, C., Deser, C., Yu, J.-Y., DiNezio, P., and Clement, A. (2017). El niño and southern oscillation (enso): a review. Coral reefs of the eastern tropical Pacific, pages 85-106.

Wang, G. M., Hendon, H. H., Arblaster, J. M., Lim, E. P., Abhik, S., and van Rensch, P. (2019). Compounding tropical and stratospheric forcing of the record low Antarctic sea-ice in 2016. Nature Communications, 10.

Wang, H. L., Fyke, J. G., Lenaerts, J. T. M., Nusbaumer, J. M., Singh, H., Noone, D., Rasch, P. J., and Zhang, R. D. (2020). Influence of sea-ice anomalies on Antarctic precipitation using source attribution in the community earth system model. Cryosphere, 14:429-444.

Watkins, A. B. and Simmonds, I. (1995). Sensitivity of numerical prognoses to Antarctic sea-ice distribution. Journal of Geophysical Research-Oceans, 100:22681-22696.

Watterson, I. (2000). Southern midlatitude zonal wind vacillation and its interaction with the ocean in gcm simulations. Journal of Climate, 13(3):562-578.

Weatherly, J. W. (2004). Sensitivity of Antarctic precipitation to sea ice concentrations in a general circulation model. Journal of Climate, 17:3214-3223.

Welhouse, L. J., Lazzara, M. A., Keller, L. M., Tripoli, G. J., and Hitchman, M. H. (2016). Composite analysis of the effects of ENSO events on Antarctica. Journal of Climate, 29:1797-1808.

Wilks, D. S. (2011). Statistical Methods in the Atmospheric Sciences, volume 100. Academic Press, 3 edition. 
Worby, A., Jeffries, M., Weeks, W., Morris, K., and Jana, R. (1996). The thickness distribution of sea ice and snow cover during late winter in the bellingshausen and amundsen seas, antarctica. Journal of Geophysical Research: Oceans, 101(C12):28441-28455.

Yeh, S. W., Cai, W. J., Min, S. K., McPhaden, M. J., Dommenget, D., Dewitte, B., Collins, M., Ashok, K., An, S. I., Yim, B. Y., and Kug, J. S. (2018). ENSO atmospheric teleconnections and their response to greenhouse gas forcing. Reviews of Geophysics, 56:185-206.

Yin, J. H. (2005). A consistent poleward shift of the storm tracks in simulations of 21st century climate. Geophysical Research Letters, 32.

Yuan, X. (2004). ENSO-related impacts on Antarctic sea ice: a synthesis of phenomenon and mechanisms. Antarctic Science, 16:415.

Yuan, X. J. and Li, C. H. (2008). Climate modes in southern high latitudes and their impacts on Antarctic sea ice. Journal of Geophysical Research-Oceans, 113.

Yuan, X. J. and Martinson, D. G. (2000). Antarctic sea ice extent variability and its global connectivity. Journal of Climate, 13:1697-1717.

Yuan, X. J. and Martinson, D. G. (2001). The Antarctic dipole and its predictability. Geophysical Research Letters, 28:3609-3612.

Yuan, X. J., Martinson, D. G., and Liu, W. T. (1999). Effect of air-sea-ice interaction on winter 1996 Southern Ocean subpolar storm distribution. Journal of Geophysical Research-Atmospheres, 104:1991-2007.

Zhang, J. L. (2007). Increasing Antarctic sea ice under warming atmospheric and oceanic conditions. Journal of Climate, 20:2515-2529.

Zhou, T. J. and Yu, R. C. (2004). Sea-surface temperature induced variability of the Southern Annular Mode in an atmospheric general circulation model. Geophysical Research Letters, 31.

Zwally, H. J., Comiso, J. C., and Gordon, A. L. (1985). Antarctic offshore leads and polynyas and oceanographic effects. Oceanology of the Antarctic continental shelf, 43:203-226. 